NBER WORKING PAPER SERIES

\title{
THE GENERAL EQUILIBRIUM IMPACTS OF UNEMPLOYMENT INSURANCE: EVIDENCE FROM A LARGE ONLINE JOB BOARD
}

\author{
Ioana Marinescu \\ Working Paper 22447 \\ http://www.nber.org/papers/w22447 \\ NATIONAL BUREAU OF ECONOMIC RESEARCH \\ 1050 Massachusetts Avenue \\ Cambridge, MA 02138 \\ July 2016
}

I would like to thank Sanggi Kim and Sarah Sajewski for excellent research assistance. The views expressed herein are those of the author and do not necessarily reflect the views of the National Bureau of Economic Research.

NBER working papers are circulated for discussion and comment purposes. They have not been peer-reviewed or been subject to the review by the NBER Board of Directors that accompanies official NBER publications.

(C) 2016 by Ioana Marinescu. All rights reserved. Short sections of text, not to exceed two paragraphs, may be quoted without explicit permission provided that full credit, including (C) notice, is given to the source. 
The General Equilibrium Impacts of Unemployment Insurance: Evidence from a Large Online Job Board

Ioana Marinescu

NBER Working Paper No. 22447

July 2016

JEL No. J63,J64,J65

\section{ABSTRACT}

During the Great Recession, U.S. unemployment benefits were extended by up to 73 weeks. Theory predicts that extensions increase unemployment by discouraging job search, a partial equilibrium effect. Using data from the large job board CareerBuilder.com, I find that a $10 \%$ increase in benefit duration decreased state-level job applications by $1 \%$, but had no robust effect on job vacancies. Job seekers thus faced reduced competition for jobs, a general equilibrium effect. Calibration implies that the general equilibrium effect reduces the impact of unemployment insurance on unemployment by $40 \%$ : increasing benefit duration by $10 \%$ increases unemployment by only $0.6 \%$ in equilibrium.

Ioana Marinescu

Harris School of Public Policy

University of Chicago

1155 East 60th Street

Chicago, IL 60637

and NBER

ioanamarinescu@uchicago.edu 


\section{Introduction}

During the Great Recession, the duration of unemployment benefits in the US was extended from 26 to up to 99 weeks. A vast amount of empirical evidence based on prior extensions in unemployment benefits unambiguously shows that extensions increase the unemployment duration of benefit recipients (e.g. Katz and Meyer 1990; Meyer 2002; Schmieder, Wachter, and Bender 2012). Empirical evidence from the Great Recession in the US confirms the prevailing wisdom by showing that extensions had a positive effect on the unemployment duration of likely benefit recipients (Rothstein 2011; Farber and Valletta 2013). Since extensions contribute to increasing unemployment in a situation where unemployment is already high, there is a legitimate concern that unemployment benefits extensions may have been a bad policy choice.

However, the partial equilibrium effect of benefit extensions on benefit recipients does not capture the full impact of the extensions on aggregate unemployment during the Great Recession. Indeed, unemployment benefit extensions could also have general equilibrium effects through search externalities. Theoretically, as unemployment benefit recipients reduce their job search effort in response to the extensions, competition for jobs decreases and it becomes easier for unemployed job seekers who are not affected by the extensions to find a job. Levine (1993) and Lalive, Landais, and Zweimüller (2013) document empirically the presence of such search externalities for US extensions prior to the Great Recession, and for Austrian extensions respectively. Even for benefit recipients themselves, $\mathrm{UI}$ benefit extensions can increase the job finding rate per application. Thus, a UI induced decrease in applications leads to a less than proportional decrease in job finding for UI recipients. Due to this search externality, the impact of the extensions on aggregate unemployment could be smaller than the partial equilibrium impact of increasing potential benefit duration for a small number of benefit recipients.

Extensions could also have general equilibrium ${ }^{2}$ effects through firm behavior, generating a labor demand externality. If benefit extensions reduce the number of applicants for each job, it may become harder for firms to fill job vacancies, and the value of vacancies may decrease. Extensions can also decrease the value of vacancies by increasing the reservation wage of benefit recipients, so that employers face more demanding applicants. If extensions decrease the value of a vacancy, firms may post fewer job vacancies. A decrease in the number of vacancies makes it harder for all job seekers to

\footnotetext{
${ }^{2}$ General equilibrium is used here as in labor economics (e.g. Landais, Michaillat, and Saez, 2014) to mean that the extensions generate externalities in the labor market. It does not mean to imply that we will analyze the impact of the extensions on markets other than the labor market.
} 
find a job. Through this labor demand externality, extensions contribute to further increasing aggregate unemployment. Hagedorn et al. (2013) show evidence that extensions during the Great Recession decreased the number of vacancies, suggesting that the impact of the extensions on aggregate unemployment during the Great Recession is larger than the impact of these extensions on benefit recipients.

However, whether the negative impact of extensions on the number of vacancies (labor demand externality) dominated the positive impact of extensions on job finding (search externality) during the Great Recession is unknown. In particular, while Hagedorn et al. (2013) provide evidence on the labor demand externality, we have no evidence on the search externalities generated by extensions during the Great Recession. Therefore, whether the macro impact of extensions on aggregate unemployment is larger or smaller than the micro effect on benefit recipients remains an open question.

To answer this question, this paper uses new data on state-level job applications and job vacancies from CareerBuilder.com, arguably the largest American online job board ${ }^{3}$. If extensions during the Great Recession resulted in a decrease in aggregate job search effort, we should observe a decrease in the total number of job applications in the aftermath of an extension. All other things equal, such a decrease in job applications increases the hiring rate per application sent, a search externality, and therefore contributes to reducing unemployment. I can also ascertain whether extensions decreased the number of job vacancies posted, a labor demand externality, and therefore contributed to increasing unemployment. Thus, a key innovation of this paper is to estimate the impact of extensions on both job applications and job vacancies during the Great Recession.

If extensions reduce the total number of job applications more than they reduce the total number of job vacancies, then extensions increase the vacancy to applications ratio (a measure of search-intensity adjusted labor market tightness), and therefore increase the job finding probability per application sent. In this case, economic theory predicts that the macro impact of extensions on aggregate unemployment is smaller than the micro impact on the unemployment of benefit recipients (Landais, Michaillat, and Saez, 2014), so that the general equilibrium effect dampens the partial equilibrium effect. Conversely, if benefit extensions decrease labor market tightness, then the macro impact of extensions on aggregate unemployment is larger than the micro impact on benefit recipients.

\footnotetext{
${ }^{3}$ Monster.com is similar in size, and whether Monster or CareerBuilder is largest depends on the exact size measure used.
} 
To identify the impact of unemployment insurance on applications and vacancies, I use state-level variation in potential unemployment benefits duration (PBD) induced by the federal Emergency Unemployment Compensation (EUC) and state-run extended benefits (EB). My first identification strategy is a timing of events approach, and shows that the number of vacancies in the state stays flat as far as seven months before and after a state's largest benefit extension. By contrast, state-level job applications significantly decline in the first month of a benefit extension, and continue to decline for several months thereafter. Using this strategy, a one-week increase in potential benefit duration (PBD) leads to a $0.4 \%$ decline in applications at the state level. Equivalently, a $10 \%$ increase in PBD decreases state-level applications by $1 \%$ (an elasticity of -0.1 ).

A second identification strategy uses the fact that benefit extensions (EUC and EB) depend on state-level unemployment rates reaching specific thresholds. I exploit this source of variation by using a global parametric fuzzy regression discontinuity approach that relies on nonlinearities in PBD as a function of the state unemployment rate. I find that PBD decreases the total number of applications at the state level, but has no robust impact on the number of vacancies. Furthermore, only the federal EUC program has a negative impact on PBD, while the state-level EB has no significant effect. Overall, this second identification strategy confirms that PBD extensions decrease the total number of applications at the state level, but have no robust impact on the number of vacancies.

One may be concerned that the impact of PBD extensions on job applications and vacancies is biased by the lack of representativity of my data or by unobserved changes in the composition of job vacancies. However, I show that the negative impact of PBD on applications is robust to controlling for changes in the composition of job vacancies by industry and education requirement. I also show that the absence of an impact of PBD on vacancies is maintained when using all online vacancies from Help Wanted Online rather than just CareerBuilder vacancies. Finally, I find that PBD does not affect posted wages or how choosy job seekers are. The lack of an impact of extensions on posted wages and job seeker choosiness is consistent with the fact that extensions do not affect the number of vacancies: since extensions do not have an impact on how choosy job seekers are nor posted wages, they do not contribute to decreasing the value of vacancies.

In contrast to my results, Hagedorn et al. (2013) found a negative impact of unemployment insurance extensions on vacancies during the Great Recession. Hagedorn, Manovskii, and Mitman (2016) suggest that the difference between our results is due to a difference in data source. However, I still find no effect of the extensions on the number of vacancies when using the Help Wanted Online data with my 
identification strategy. Their identification strategy relies on comparing counties along state borders. Borrowing their identification strategy and using county level data, I find no effect of the extensions on vacancies. Furthermore, I show that the border county design cannot recover the causal impact of unemployment insurance on applications and vacancies due to large across-county spillover effects. More generally, these results suggest that one should be wary of using border county designs to assess the impact of labor market policies that have geographic spillover effects.

Overall, this paper's main empirical results are informative about the general equilibrium impacts of unemployment insurance: they indicate that unemployment insurance extensions during the Great Recession did not lead to a labor demand externality (no impact on the number of vacancies or posted wages), but did generate a job search externality (a negative impact on the number of applications). On net, extensions had a positive and significant impact on labor market tightness, implying that the macro effect of unemployment insurance on unemployment is smaller than the micro effect. This result has important implications for policy design. Indeed, to the extent that labor market tightness is inefficiently low during recessions and inefficiently high during booms, the fact that unemployment insurance increases labor market tightness implies that optimal unemployment insurance generosity should be high in recessions and low in booms, i.e. countercyclical (Landais, Michaillat, and Saez 2014).

To quantify the macro impact of unemployment insurance, I calibrate the theoretical model by Landais, Michaillat, and Saez 2014 in which this macro impact is the sum of the micro impact and the general equilibrium effect. I find that the macro impact is smaller than the micro impact: the general equilibrium effect reduces the micro impact by $40 \%$. In equilibrium, a $10 \%$ increase in unemployment benefit duration increases aggregate unemployment by only $0.6 \%$.

The remainder of the paper is organized as follows. Section 2 discusses how unemployment benefit extensions were decided, describes the data and presents the theoretical framework. Section 3 discusses the identification strategy and the results for the timing of events approach, and the parametric fuzzy regression discontinuity designs. Section 4 presents robustness tests and discusses the results. In particular, section 4 presents the calibration results for the impact of PBD extensions on aggregate unemployment. Section 5 presents interpretations and discussion of findings. Finally, Section 6 concludes. 


\section{Policy background, data, and theoretical framework}

\subsection{Policy background}

By default, PBD in the United States is 26 weeks. During times of high unemployment, the extended benefits (EB) program provides additional weeks of benefits if one of two conditions is satisfied:

- the state's 13-week average insured unemployment rate (IUR) in the most recent 13 weeks is at least 5.0 percent and at least 120 percent of the average of its 13-week IURs in the last 2 years for the same 13-week calendar period; or

- at state option, the current 13-week average IUR is at least 6.0 percent, and regardless of the experience in previous years. The IUR option is in place for the months when a state chose this option $^{4}$.

States have the option of electing an alternative trigger authorized by the Unemployment Compensation Amendments of 1992 (Public Law 102-318). The TUR option is in place for the months when a state chose this option. This trigger is based on a 3-month average total unemployment rate (TUR) using seasonally adjusted data:

- If this TUR average exceeds 6.5 percent and is at least 110 percent of the same measure in either of the prior 2 years, a state can offer 13 weeks of EB.

- If the average TUR exceeds 8 percent and meets the same 110-percent test, 20 weeks of EB can be offered.

Normally, extended benefits are financed $50 \%$ by states and $50 \%$ by the federal government. Under the American Recovery and Reinvestment Act of 2009 (ARRA) passed on Feb. 17, 2009, benefits are financed entirely by the federal government. As a result, many states chose the TUR option ${ }^{5}$. Federal funding of EB was still in place at the end of this paper's sampling frame (July 2011).

The Tax Relief, Unemployment Insurance Reauthorization, and Job Creation Act of (P.L. 111-312, December 2010) temporarily changed the look-back timeframe to three years, as unemployment

\footnotetext{
${ }^{4} 78 \%$ of states choose this option, and this share is stable over the sample frame of this paper.

${ }^{5}$ In this paper's sample frame, and before ARRA, only $21 \%$ of state-week observations had the TUR option on, while after ARRA 63\% of state-week observations had the TUR option on. As of January 2011, Arkansas, lowa, Louisiana, Maryland, Mississippi, Montana, Oklahoma, Utah, and Wyoming could qualify for extended benefits (EB) under TUR but chose not to use that option. Legislators in these states were afraid of adopting extended benefits under TUR because they were afraid of having to raise taxes when the federal funding expires. Furthermore, many legislators were afraid that more benefits would increase unemployment.
} 
indicators in most states had been consistently high for the past two years and would have resulted in many states being unable to meet the conditions. This three-year look-back exception was still in place at the end of the sampling frame (July 2011).

The federal Emergency Unemployment Compensation Act (EUC) 2008 further extended benefits. EUC-08 is an emergency federal benefits program that is payable to individuals who have exhausted all rights to regular compensation with respect to a benefit year that ended on or after May 1, 2007. Typically, a jobseeker collects EUC benefits before EB benefits. EUC evolved in the following way:

- The EUC08 program (June 30, 2008), provides up to 13 weeks of 100 percent federally-financed compensation in all states. Public Law (P.L.) 110-449 expanded the EUC08 program on November 21, 2008 to provide up to 20 weeks of benefits. This constitutes tier 1 or EUC1.

- Tier 2 of EUC (EUC2) was created by Public Law (P.L.) 110-449. It provides 13 weeks of benefits in states where TUR (defined as for EB) is above $6 \%$ or IUR (defined as for EB) is above $4 \%$.

- Public Law No. 111-92, enacted on November 6, 2009, expanded the EUC08 program:

o It increased the maximum EUC2 entitlement from 13 weeks to 14 weeks of benefits in all states, and established that this Tier was no longer triggered by a state reaching a specified rate of unemployment;

o It created EUC3 providing up to 13 additional weeks of benefits in states with IUR above 4 percent or TUR above 6 percent;

o It created EUC4 providing up to 6 additional weeks of benefits in states with IUR above 6 percent or TUR above 8.5 percent.

The impact of the EUC and EB extensions on the job search effort of benefit recipients may be different for three reasons. First, because EB benefits only become available after workers have exhausted their regular and EUC benefits, the impact of EB on job search is likely to be smaller due to discounting. Second, EB has more stringent job search requirements than EUC (see Federal-State Extended Unemployment Compensation Act of 1970), so EB may have a lower impact on job search effort. Third, the estimated impact of EB and EUC could differ because EB partially depends on states' choice while EUC does not. Therefore, some of the variation in weeks of EB may be endogenous: for example, states with high unemployment prospects may choose to provide more EB by adopting the TUR option. Since estimated impact of EUC and EB on aggregate job search effort may be different, I will be investigating the contrasting effects of EUC and EB. 
For both EUC and EB, TUR conditions are much more likely to be satisfied than the IUR conditions. For example, EUC2 and EUC3 require that TUR be above $6 \%$ or IUR above $4 \%$. In the data sample, when TUR is above $6 \%$, IUR is above $4 \%$ in $97 \%$ of the cases. On the other hand, when IUR is below $4 \%$, TUR is nonetheless above $6 \%$ in $54 \%$ of the cases. If TUR is below $6 \%$, IUR is above $4 \%$ in only $1.8 \%$ of cases, so IUR is unlikely to trigger increases in PBD.

Since the conditions governing the maximum weeks of UI benefits are fairly complex, Figure 1 summarizes the regulation in a simplified form. The figure ignores some of the finer points of the regulation discussed above and simply shows how PBD depends on TUR during different time frames and in states that had the TUR option for EB (i.e. the majority of states). This overview of the policies suggests that one can use sharp changes in benefit duration at $6.5 \%$ and $8 \%$ TUR (for EB) and $6 \%$ and 8.5\% TUR (for EUC) to identify the impact of benefit duration on applications and vacancies.

\subsection{Data}

The data on applications and job vacancies comes from proprietary data provided to me by CareerBuilder.com. Job vacancies are defined as the total number of online job advertisements posted by firms in a given state during a given month. CareerBuilder charges firms several hundred dollars to post a job ad on the website for one position for one month. A firm that wishes to advertise multiple positions needs to pay for each position separately, though quantity discounts are available. By contrast, the service is free for job seekers.

One can compare job vacancies in CareerBuilder.com with data on job vacancies in the representative JOLTS (Job Openings and Labor Turnover Survey). The number of vacancies on CareerBuilder.com represents 35\% of the total number of vacancies in the US in January 2011 as counted in JOLTS. Compared to the distribution of vacancies across industries in JOLTS, some industries are overrepresented in CareerBuilder data, in particular information technology, finance and insurance, and real estate, rental and leasing. The most underrepresented industries are state and local government, accommodation and food services, other services, and construction. When comparing the distribution of jobs across US regions in JOLTS vs CareerBuilder, I find that CareerBuilder has the same geographic 
distribution of jobs as JOLTS. As for the time series properties of the CareerBuilder vacancy data, vacancies in CB follow very closely the trends in the JOLTS data ${ }^{6}$ (correlation of $0.57, \mathrm{P}$-value<0.01).

In Marinescu and Rathelot (2014), we use a representative sample of vacancies and job seekers from CareerBuilder.com in 2012. The distribution of vacancies across occupations is essentially identical (correlation of 0.95 ) to the distribution of vacancies across all jobs on the Internet as captured by the Help Wanted Online data. Furthermore, the distributions of unemployed job seekers on CareerBuilder.com across states and occupations are similar to those of the nationally representative Current Population Survey (correlations of more than 0.7). Overall, the vacancies and job seekers on CareerBuilder.com are broadly representative of the US economy as a whole, and they form a substantial fraction of the market.

In the CareerBuilder data, for each state, information is available on the distribution of vacancies by industry, the level of education required ${ }^{7}$, and the posted wage. The posted wage is reported in seven bins $^{8}$, and, when a wage range is offered, these bins are based on the upper bound of the offered wage. Among vacancies that post a wage, the median is $\$ 50,000$ : indeed, $52 \%$ of vacancies with posted wages post a wage of $\$ 50,000$ or more. This median wage is somewhat higher than the $\$ 45,230$ US average wage in 2011 (BLS Occupational Employment Statistics), but again the CareerBuilder compensation is based on the upper bound of the offered wage.

The CareerBuilder data spans September 2007 to July 2011. An individual application is defined as a person clicking on the "Apply Now" button in a job ad". The variable "Applications" is the number of individual applications received by all jobs in a given state and month.

The recorded applications are from any job seeker, including unemployment benefit recipients, nonemployed job seekers who do not receive unemployment benefits, and employed workers. According to

\footnotetext{
${ }^{6}$ Labor market tightness as measured by $\log ($ jobs in JOLTS)- $\log$ (unemployed in CPS) is also highly correlated with search intensity adjusted labor market tightness measured as log(jobs on CareerBuilder)-log(applications on CareerBuilder). The correlation is 0.57 , P-value $<0.01$.

${ }^{7}$ When there is no education requirement, it just means that the field was not filled by the employer. The employer can still specify an education requirement within the text of the ad.

${ }^{8}$ The wage bins are: $\$ 1-\$ 30000, \$ 30001-\$ 50000, \$ 50001-\$ 75000, \$ 75001-\$ 100000, \$ 100001-\$ 200000, \$ 200001-$ $\$ 500000$, higher than $\$ 500000$.

${ }^{9}$ Tracking cookies, resumes, and other variables are ways that CareerBuilder limits the ability for any job seeker to apply to the same job more than once.
} 
CarrerBuilder's applicant survey, just under half of the applicants are employed ${ }^{10}$. Therefore, given that applications by non-UI recipients constitute a substantial share of total applications, if we only had data on the applications of UI recipients, we would not be able to adequately quantify the impact of PBD on labor market tightness. Because we have the number of vacancies as well as the number of applications to these vacancies coming from all types of job seekers, this data is uniquely suited to study the impact of PBD on labor market tightness.

To reproduce the border-county design used by Hagedorn et al. (2013) to identify the impact of PBD on vacancies, I exploit an additional sample that aggregates vacancies and applications at the county level rather than at the state level. To identify border counties, I use the publicly available border counties pair data from Dube, Lester, and Reich (2010).

To determine how many weeks of extended benefits are effectively available for each state and week, I use data from the Department of Labor EB and EUC trigger notices. These notices report the Potential benefit duration (PBD) in weeks, which is an upper bound on the duration of $\mathrm{UI}$ for two reasons. First, regulations entail lower maximum durations for some workers, in particular those who have only worked for a short period of time prior to becoming unemployed ${ }^{11}$. Second, many job seekers find a job early and do not receive the maximum possible duration of benefits. Trigger notices also contain the TUR, IUR, and look-back criteria. This allows me to determine when the conditions for each extension are realized. Since this data has weekly frequency while the CareerBuilder data has monthly frequency, I take the monthly average of the PBD, IUR and TUR to merge it with the monthly data on applications and vacancies.

Data from the Bureau of Labor Statistics was used to supplement the above information on jobs and jobseekers. First, I use data on the total number of unemployed people and the labor force (Labor Force Statistics from the Current Population Survey). Second, I use data on vacancies and hires from the Job Openings and Labor Turnover Survey (JOLTS).

Table 1 shows summary statistics for key variables. Particularly noteworthy are the large numbers of applications per state. The number of CareerBuilder applications is about twice as high as the number of unemployed individuals in the state; on average, each vacancy receives about 30 applications per

\footnotetext{
${ }^{10}$ This statistic is interesting but cannot be taken at face value since it is based on the selected sample of those applicants who were willing to answer the survey.

${ }^{11}$ Benefit durations are capped through the maximum total amount that people can collect based on their prior earnings (Meyer 2002).
} 
month. Figure 2 shows the evolution of the unemployment rate, job vacancies (from Job Openings and Labor Turnover Survey) and PBD at the national level. This graph shows that PBD and unemployment are positively correlated, consistent with the fact that PBD is increased when unemployment exceeds some thresholds.

\subsection{Theoretical framework}

An increase in PBD increases the unemployment duration of UI recipients (e.g. Katz and Meyer 1990; J. F. Schmieder, Wachter, and Bender 2012; Rothstein 2011; Farber and Valletta 2013), chiefly because of a decrease in job search effort rather than an increase in the reservation wage (Card, Chetty, and Weber 2007; Lalive 2007; van Ours and Vodopivec 2008; Krueger and Mueller 2011; J. Schmieder, von Wachter, and Bender 2012) $)^{12}$. Therefore, we expect the number of job applications sent by UI recipients to decrease when PBD increases and, hence, we expect the unemployment duration of UI recipients to increase. This phenomenon is the micro or partial equilibrium effect.

But what is the impact of a decrease in applications coming from UI recipients on the aggregate unemployment rate? To estimate the macro effect of unemployment insurance, we need to take into account general equilibrium effects through job search and labor demand externalities. If the number of vacancies stays the same, then the decrease in applications by UI recipients decreases competition for jobs. This decrease in the competition for jobs increases the chances of finding a job for non-UI recipients (Levine 1993; Lalive, Landais, and Zweimüller 2013). Furthermore, this decrease in the competition for jobs will also increase the rate at which UI recipients find jobs for each application made. Therefore, this job search externality dampens the impact of UI on aggregate unemployment.

However, since a lower number of applications per vacancy reduces an employer's choices for potential hires, it may discourage further vacancy creation. Moreover, if PBD increases the reservation wage, this may discourage vacancy creation as employers may not be able to meet the wage demands of applicants. If fewer vacancies are created, all job seekers find it more difficult to get a job. This labor demand externality amplifies the impact of UI on aggregate unemployment. Therefore, if the search externality dominates, the macro impact of $\mathrm{UI}$ on aggregate unemployment is smaller than the micro effect, while the opposite is true if the labor demand externality dominates.

\footnotetext{
${ }^{12}$ The impact of unemployment insurance on re-employment wages or reservation wages is estimated to be close to zero by this literature. Lalive, Landais, and Zweimüller (2013) and Nekoei and Weber (2013) are the exceptions to the rule and find a small positive impact of unemployment insurance extensions on re-employment wages.
} 
Landais, Michaillat, and Saez (2014) formalize this reasoning and show that, when unemployment insurance increases labor market tightness, the macro effect is smaller than the micro effect, and viceversa when unemployment insurance decreases labor market tightness. Furthermore, they demonstrate that optimal unemployment insurance should be countercyclical if the elasticity of labor market tightness with respect to unemployment benefits is positive, and pro-cyclical otherwise.

Here, the generosity of unemployment benefits is measured by potential benefit duration (PBD). If PBD increases labor market tightness, then the impact of PBD on aggregate unemployment is lower than the impact of PBD on the unemployment of $\mathrm{UI}$ recipients, and the opposite is true if PBD decreases labor market tightness. I will estimate the impact of PBD on log vacancies, log applications, and log tightness (log vacancies-log applications). If the impact of PBD on tightness is positive, then the macro impact of PBD is lower than its micro impact, and optimal unemployment benefit duration is counter-cyclical.

\section{Main results}

\subsection{Timing of events approach}

The timing of events approach uses the timing of PBD increases at the state level to identify the impact of PBD on applications and vacancies. If PBD has a negative impact on job search as measured by applications, we expect the number of applications to significantly drop in the first month after a PBD increase. More generally, if PBD has an impact on the outcome of interest, then this outcome should vary over time in the same way as PBD at the state level. The key identification assumption is that there is no omitted variable that evolves according to the same monthly timing as PBD and determines the outcome of interest.

\subsubsection{Methodology for timing of events approach}

For each state, I identify the largest increase in $\mathrm{PBD}^{13}$ that is not due to a change in the benefit schedule ${ }^{14}$ (see Figure 1) nor to a temporary lapse in EUC ${ }^{15}$. Emphasis is placed on the largest increase in

\footnotetext{
${ }^{13}$ The date of the largest increase in PBD and the amount of the increase for each state can be found in Appendix 1 , Table 8.

${ }^{14}$ This is because changes in schedule yield the largest increases in PBD for most states, but they all happen at the same time, which makes it impossible to separate the impact of PBD from a pure time effect.

${ }^{15}$ During the sample period, there were two lapses in extended benefits because legislators struggled to reach an agreement. These two lapses were in April to July 2010 and in November-December 2010. Ultimately, any benefits lost from these lapses were reinstated once the legislative agreement was reached. There was little reaction of job applications to these EUC lapses (Appendix 1, Figure 5); presumably, jobseekers were expecting these EUC lapses to be temporary.
} 
$\mathrm{PBD}^{16}$ for two reasons. First, when there are at least two increases in PBD in a state, some months of observation are both after the first increase and before the second increase, which makes it difficult to uniquely assign these observations to a "before" or "after" period. Second, given that it is more transparent to focus on just one increase in PBD, choosing the largest one should maximize power.

For each state, I only keep observations around the largest increase in PBD that do not involve any further change in PBD. As a result of this restriction, benefit duration is constant during the months prior to the largest PBD increase and also constant during the months after the largest PBD increase $\mathrm{e}^{17}$. I then use the following specification to estimate the impact of the largest increase in benefit duration on various outcomes:

$$
y_{s t}=\sum_{i=-8}^{7} \beta_{i} D_{i s t}+q_{t}+\delta_{t}+\gamma_{s}+\epsilon_{s t}
$$

where $y_{s t}$ is the outcome of interest in state $s$ and month $t . D_{i s t}$ is a dummy equal to 1 in month $i$ relative to the largest increase in PBD in a given state, where $i=0$ is the first month when the higher PBD is available during all weeks of the month. The dummy for month $i=-2$ is the omitted category ${ }^{18}$. $q_{t}$ is a quarter fixed effect to capture seasonality. $\delta_{t}$ is a year fixed effect and $\gamma_{s}$ is a state fixed effect. I cluster standard errors at the state level. To obtain the impact of one week of PBD on the outcome of interest, one can replace the $D_{\text {ist }}$ dummies by PBD. Given the sample selection, PBD is constant before the largest increase in PBD, then goes up to a new value and stays constant. Therefore, replacing the $D_{\text {ist }}$ dummies by PBD in this specification is similar to adding one "after the largest increase in PBD" dummy while allowing for a dose response effect.

\footnotetext{
${ }^{16}$ In Appendix 1, Table 10, I also report regression results for alternative definitions of the event (a PBD increase of 10 weeks or more and a PBD increase of less than 10 weeks); the results are similar to those obtained for the largest increase in PBD.

${ }^{17}$ This restriction also implies that, in practice, we have an unbalanced panel of states (see Appendix 1, Figure 6). I also used a balanced panel sample of 18 states that have a constant PBD three months before and after the largest increase in PBD. Using this sample, there is a significant decline in applications after the largest increase in PBD, while there is no significant change in the number of vacancies (Appendix 1, Figure 7). Thus, the balanced panel results are consistent with the results from the unbalanced panel (Figure 3).

${ }^{18}$ Because the data on applications is at the monthly level while PBD is defined weekly, the largest increase in benefit duration defined as above will typically occur over three months, with the first month having the lower potential benefit duration (PBD), the second month having a mix of lower and higher PBD, and the third month having the higher PBD. Therefore, I use the largest increase in benefit duration relative to two months prior (e.g. May to July). Any month that contained a mix of weeks with high and low benefit levels was excluded.
} 
The key assumption needed to identify the causal effect of PBD on the outcome of interest is that there are no omitted variables that follow the same time course as PBD around the maximum increase in PBD and affect the outcome of interest. This assumption is made more likely by the fact that these PBD increases occur at different times in different states and are mostly driven by states crossing thresholds in the state unemployment rate (TUR or IUR) that qualify them for additional weeks of benefits ${ }^{19}$.

As an additional robustness test, I add to the sample a control group for each state. For each state, I added all the states that had a constant PBD around the time of that state's largest PBD increase ${ }^{20}$. I define an experiment $e$ as the set of observations that includes a state $\mathrm{X}$ around its largest increase in $\mathrm{PBD}$, as well as all the control states for that particular state $\mathrm{X}$. One single natural experiment $e$ allows for a classic difference-in-differences specification. Here I am stacking all these difference-in-differences regressions for all the states. The stacked difference-in-differences specification is then defined as follows:

$$
y_{\text {est }}=\beta b_{\text {est }}+\text { after }_{e t}+q_{t}+\delta_{t}+\gamma_{e s}+\epsilon_{e s t}
$$

$y_{\text {est }}$ is the outcome of interest in experiment $e$, state $s$ and month $t . b_{\text {est }}$ is the Potential Benefit Duration in weeks, $q_{t}$ is a quarter fixed effect to capture seasonality, $\delta_{t}$ is a year fixed effect. after $r_{e t}$ is a dummy for the date being after the largest increase in PBD in experiment $e . \gamma_{e s}$ is an experiment by state fixed effect. Each state will appear at least once, during the time when it experiences its largest increase in PBD. Furthermore, each state appears whenever it can serve as a control for another state experiencing its largest increase in PBD: thus, there can be multiple observations for each state and month. Therefore, $\epsilon_{\text {est }}$ is the error term, and standard errors are clustered by state. I include the PBD $b_{\text {est }}$ rather than the interaction between a treatment dummy and an after dummy (as would be standard for a difference-in-differences specification) to allow for a dose response reaction, i.e. to quantify the impact of a one week increase in PBD on the outcomes of interest.

This difference-in-differences specification can control for variation over time in the outcomes of interest that is unrelated to PBD and is common between treatment and control states. The key assumption needed to identify the causal effect of PBD on the outcome of interest is that control states

\footnotetext{
${ }^{19}$ In a minority of states (20\%), the largest increase is due to the state adopting the TUR option.

${ }^{20}$ On average, each state has 21 control states.
} 
are a valid counterfactual for treated states (common trends assumption ${ }^{21}$ ). If an unobserved variable exists that follows the same time course as PBD around the maximum increase in PBD and affects the outcome of interest, then this variable should also affect the control states. Therefore, the difference-indifferences specification serves as a robustness test on the simple timing of events approach.

\subsubsection{Results from the timing of events approach}

I start by showing graphically how applications evolved around the largest increase in PBD (Figure 3, Panel A). While there was no significant trend in the number of applications prior to the largest increase in benefit duration, there was a significant drop in applications during the first month (month 0) after the increase in benefit duration. Given that the average increase in benefit duration was 15 weeks ${ }^{22}$, the estimated effect implies that a 1 week increase in PBD leads to a $0.4 \%$ decline in applications.

Applications continues to decline after the first period post benefit increase and the impact in the third month (month 2) is significantly higher than the impact in the first month, implying that a 1 week increase in PBD leads to a $1 \%$ decline in applications three months after the increase. This decline in applications after the PBD increase is robust to taking into account sample selection: if we restrict the sample to states that are in the sample in months 0,1 and 2 (23 states), the impact in month 2 is still significantly larger than the impact in month 0 . This decline in applications may be explained by the fact that more and more $\mathrm{UI}$ recipients become aware of the benefit extensions over time. Indeed, most states only notify $\mathrm{UI}$ recipients of their eligibility for extended benefits once they exhaust their regular benefits. To summarize, I find that a PBD increase coincides with a significant decline in job applications in the very first month of the PBD increase and this decline deepens in following months.

I next examine the impact of PBD on vacancies. There is no significant trend ${ }^{23}$ in job vacancies around the largest increase in PBD (Figure 3, Panel B). This implies that, as far as seven months after the largest increase in PBD, employers do not respond to a higher PBD by posting fewer vacancies. Since applications decrease after the largest increase in PBD and vacancies stay constant, labor market tightness (log vacancies-log applications) increases after the largest increase in PBD (Appendix 1, Figure 9).

\footnotetext{
${ }^{21}$ In practice, applications in the control states follow the same time path prior to the largest PBD increase as applications in the treated states, and the same holds for vacancies (Appendix 1, Figure 8). Therefore, the control group seems to satisfy the common trends assumption.

${ }_{22}^{23}$ The level of PBD around the largest increase in PBD is plotted in Appendix 1,Figure 6.

${ }^{23}$ Even though a few pre-event point estimates are significant, this is probably due to sampling variability as these estimates are based on fewer than 20 states (see Appendix 1, Figure 6).
} 
To summarize these graphical results in a regression format, I use the simple difference specification, which corresponds to Figure 3, and shows the average effect of one week of PBD on the outcomes of interest rather than estimating the impact month by month. Consistent with the results from Figure 3, the simple difference specification shows a significant and negative impact of PBD on applications (Table 2, col. 1) but no significant impact on vacancies (Table 2, col. 3).

To test the robustness of the timing of events approach to unobserved variables that follow the same timing as PBD and affect the outcomes of interest, I use a difference-in-differences specification. The impact of PBD on applications remains negative and statistically significant (Table 2, column 2). Overall, the specifications in columns 1-2 paint a consistent picture and indicate that a one week increase in PBD led to a $0.4 \%$ decline in job applications ${ }^{24}$.

As for the impact of PBD on vacancies, the difference-in-differences specification still yields an insignificant effect (Table 2, column 4). This result addresses an important concern with the simple difference specification. Indeed, if there is a positive trend in vacancies, as is the case during most of the period when PBD increases (see Figure 2), this positive trend may be masking the negative impact of PBD on vacancies. To the extent that such a trend is masking the negative effect of PBD on vacancies, the estimated impact of PBD on vacancies should become more negative when we add a control group of other states that share in this trend. Thus, the fact that the difference-in-differences specification also yields an insignificant impact of PBD on vacancies confirms that PBD has little if any impact on vacancies.

Finally, the impact of PBD on labor market tightness is positive and significant both in the simple difference and the difference-in-differences specification ${ }^{25}$ (Table 2, col. 5-6).

Using the timing of events approach, I have shown that an increase in PBD has a large, significant and negative impact on state-level job applications, consistent with PBD generating a search externality. However, PBD does not have a robust effect on vacancies: therefore, PBD does not generate a labor demand externality. Overall, PBD increases labor market tightness. Given the theory outlined above,

\footnotetext{
${ }^{24}$ The reader may wonder why the impact on job applications is only about $0.4 \%$ given that the impact of PBD on applications increases with time since the largest PBD increase (Figure 3, Panel A). This is because the figure is based on an unbalanced panel. In fact, the median state is only observed for 2 months after the PBD increase, so the regression mostly captures the short-run effect.

${ }^{25}$ The impact of PBD on applications and vacancies is robust to adding month fixed effects instead of year and quarter fixed effects in the difference-in-differences specification. However, because the point estimate of the impact of PBD on applications slightly decreases when month fixed effects are included, the impact of PBD on tightness falls short of statistical significance (see Appendix 1 Table 9).
} 
this implies that the general equilibrium effects of unemployment insurance dampen its partial equilibrium effect.

\subsection{Using a parametric fuzzy regression discontinuity}

The first part of the analysis used a timing of events approach to identify the causal impact of PBD on applications and vacancies. However, in such a design, observations around the PBD increase are associated with different unemployment rates for different states. Furthermore, the timing of events approach focuses on the largest increase in PBD for each state. If heterogeneity is present in the effects of various PBD increases, then the timing of events approach does not adequately quantify the average effect of $\mathrm{UI}$ extensions during the Great Recession. Using a regression discontinuity design is an alternative approach that can overcome some of these limitations.

To exploit the fact that PBD depends on states crossing TUR and IUR thresholds, I use a global parametric fuzzy regression discontinuity. In Appendix 2, I also report results for a local fuzzy regression discontinuity design around 6\% TUR. While the local fuzzy regression discontinuity is conceptually appealing, it leaves only 44 observations and therefore very limited statistical power. For the global parametric fuzzy regression discontinuity, I use a broader sample of all the 1,804 observations lying in the zone where there are any discontinuities in PBD as a function of TUR (and IUR). Compared to the local fuzzy regression discontinuity design, this approach has higher power but also more potential bias due to the inclusion of observations that lie further away from TUR discontinuities.

\subsubsection{Methodology}

To visualize the nonlinear relationship between TUR and PBD graphically, one can plot a smoothed version of PBD and applications residuals or vacancies residuals as a function of TUR. The residuals are from regressing log applications or log vacancies on state fixed effects. I then apply a kernel-weighted local polynomial smoothing to the residuals ${ }^{26}$. Additionally, TUR is restricted to between $4 \%$ and $10 \%$, so as to include some data prior to any TUR threshold being reached. This restriction discards data that is far away from the TUR thresholds that are the primary source of identification.

To complement the graphical analysis, I run a global parametric fuzzy regression discontinuity design that uses a broader sample. The regression discontinuity is fuzzy because crossing a threshold in TUR or IUR increases the probability of an increase in PBD by less than one due to delays in making benefits available, conditions on the rate of increase of unemployment, and states' policy choices (see policy

\footnotetext{
${ }^{26}$ The plot uses the Stata command Ipolyci.
} 
background above). The design is global and parametric because I include a range of observations around multiple discontinuities in PBD as a function of the assignment variables TUR and IUR, and control for global polynomials in TUR and IUR.

This approach results in the following instrumental variable specification, restricting to state-month observations with TUR between 4 and 10\%:

$$
y_{s t}=\beta b_{s t}+\alpha^{\prime} X_{s t}+q_{t}+\delta_{t}+\gamma_{s}+\epsilon_{s t}
$$

where $y_{s t}$ is log applications, log vacancies or log tightness (log vacancies-log applications) in state $s$ and month $t, b_{s t}$ is the average PBD over the month, $X_{s t}$ is a vector of controls which includes a quadratic in TUR and IUR, $q_{t}$ is a quarter fixed effect, $\delta_{t}$ is a year fixed effect, $\gamma_{s}$ is a state fixed effect, and $\epsilon_{s t}$ is the error term. Standard errors are clustered at the state level. $b_{s t}$ is instrumented with the PBD that should be available given rules. The instrument assumes there are no temporary EUC lapses and that all states have elected the TUR option for EB. Indeed, since states can elect the TUR option and thus provide more generous EB extensions (see 2.1 Policy background above), such EB benefits are potentially endogenous. To summarize, the instrument for PBD is PBD according to statutory rules, not taking into account temporary EUC expirations, and assuming that all states take up the TUR option.

In a version of the regression above, I split $b_{s t}$ into an EUC and an EB component to analyze whether these two programs have the same impact on the outcomes of interest. In this case, EB PBD is instrumented with EB PBD according to rules and assuming that all states have elected the TUR option, and EUC PBD is instrumented with the EUC PBD according to rules and ignoring temporary EUC lapses.

\subsubsection{Results}

I start with a graphical analysis of the data from December 2008 onwards to give an intuitive grasp of the dependency of vacancies residuals, applications residuals, and PBD on TUR (Figure 4). PBD indeed increases steeply around 6 to $6.5 \%$ TUR $^{27}$, which are the thresholds for EUC and EB respectively. PBD again increases around 8 to $8.5 \%$ TUR, which are the thresholds for EB and EUC respectively (note that the EUC threshold at $8.5 \%$ TUR only exists after November 2009). Application residuals tend to decrease over the same range of $\mathrm{TUR}^{28}$ values where PBD increases and to increase with the unemployment rate

\footnotetext{
${ }^{27}$ PBD increases already before TUR reaches $6 \%$ in some cases. The main reason is that the IUR condition for EUC (IUR $>=4 \%$ ) is satisfied for some states with TUR below $6 \%$.

${ }^{28}$ Applications also decrease when IUR thresholds are crossed. However, this is only clearly visible for the small subset of observations when no TUR thresholds are crossed (compare Panel A and Panel B in Appendix 1, Figure 11).
} 
(TUR) when PBD remains constant (Figure 4, Panel A). The fact that application residuals tend to increase with the TUR in the absence of a PBD increase should be expected given that a higher TUR means more unemployed jobseekers, who should be collectively sending more applications ${ }^{29}$. This graphical analysis supports the view that PBD has a strong negative effect on applications.

In contrast, vacancies residuals tend to increase with TUR but not in a way that is strongly correlated with PBD (Figure 4, Panel B). The positive co-movement of vacancies and TUR may seem surprising because one would expect worse economic conditions to be associated with both higher unemployment and fewer vacancies. However, when one looks back at Figure 2, the positive association between vacancies and TUR makes sense given the high frequency data used there. Indeed Figure 4 is based on data from December 2008 on, and early in 2009, the number of vacancies started increasing again from its trough while at the same time the unemployment rate was still increasing. Overall, the graphical analysis suggests that PBD has little impact on job vacancies.

Prior to the introduction of EUC, PBD depended on TUR only for states that had the TUR option for EB. Therefore, we should see that PBD goes up and application residuals go down around TUR thresholds in states with a TUR option for EB, but not so in states without such a TUR option. This is indeed the case (Appendix 1, Figure 10), which suggests that there is no mechanical relationship between application residuals and TUR. A clear negative relationship between applications and TUR only appears when PBD does depend on TUR.

I now use regression analysis to complement the graphical results, and check more systematically whether there is indeed a statistically significant negative impact of PBD on applications. I regress log applications on PBD and a number of controls, using the whole available time period (September 2007 to July 2011), and restricting to TUR between 4 and $10 \%$.

When I repeat a specification similar to the local fuzzy RD specification (see Appendix 2), I find a significant and negative impact of PBD on log applications (Table 3, col. 1). When adding date fixed effects instead of year and quarter fixed effects, the impact of PBD on applications remains negative but falls short of statistical significance (col .2). In column 3, I separate EUC and EB, and find that only EUC extensions have a negative impact on applications. The small effect of EB is consistent with expectations based on the policy. Indeed, additional weeks of benefits due to EB only kick in after EUC extension

\footnotetext{
${ }^{29}$ If we plot the residuals of applications per CPS unemployed, there is no increase in this outcome in between increases in PBD (Appendix 1, Figure 12). This confirms that the increase in the number of applications in between increases in PBD is largely driven by the increase in the number of unemployed job seekers.
} 
weeks have been used up, and so discounting implies a smaller effect of EB. Furthermore, EB has somewhat stronger job search requirements than EUC, which could dampen its effect on job applications. When adding month fixed effects (col. 4), the impact of EUC stays negative and significant while the impact of EB becomes positive if still statistically insignificant. The estimates in col. 4 can account for why the impact of total PBD on applications became smaller and insignificant when we added date fixed effects in col. 2: indeed, the total impact of PBD on applications is a mixture of a large negative impact of EUC and a small positive impact of EB. Overall, I find that a one-week increase in EUC is associated with a $0.72 \%$ decline in job applications (col. 4), while the state-level EB program has no significant effect on job applications during the Great Recession.

Having examined the impact of PBD on applications, I now analyze the impact of PBD on vacancies using the same specifications. While the impact of PBD on vacancies is negative and significant without date fixed effects (Table 4, col. 1), adding date fixed effects renders the impact of PBD positive and insignificant $^{30}$ (col. 2). When distinguishing between EUC and EB, we see that EB never has a significant impact on vacancies, and the point estimate is positive (col. 3 and 4). As for EUC, it appears to have a negative and significant effect on vacancies (col. 3), but this negative effect is not robust to adding month fixed effects (col. 4). Therefore, the apparent negative impact of PBD on vacancies is likely explained by changes in EUC that occur when a new federal law increases EUC for all states. EUC appears to have a negative impact on vacancies when we do not control for monthly changes in macroeconomic conditions. After accounting for common macro factors that vary from month to month, there is no significant impact of PBD on vacancies, consistent with the timing of events result.

Finally, we can examine the impact of PBD on log tightness, the difference between log vacancies and log applications. Just as in the case of the timing of events approach, the estimate of the impact of PBD on tightness for a given specification is almost exactly the difference between the estimated impact of PBD on vacancies and the estimated impact of PBD on applications (Appendix 1, Table 11). Thus, while EB has no effect on tightness, EUC PBD has a positive and significant impact on tightness (Table 4, col. 5): a one-week increase in EUC increases tightness by $0.8 \%$.

How do the estimates of the impact of PBD on applications compare with the estimates arising from different methodologies used above? In the timing of events approach, a one-week increase in PBD yields a $0.4 \%$ decline in applications (Table 2 , col. 2). This estimate implies that the median state saw a

\footnotetext{
${ }^{30}$ The lower bound of the $90 \%$ confidence interval is -0.001 and the upper bound is 0.004 .
} 
29\% decline in applications due to PBD extensions during the Great Recession (+73 weeks). When using the global parametric regression discontinuity design, I find that it is important to distinguish between EUC and EB. If we take the point estimates for EUC and EB in Table 3, col. 4, the impact of PBD in the median state is the sum of the impact of the increase in EUC (53 weeks) and the impact of the increase in EB (20 weeks), that is: $-0.0072 * 53+0.0032 * 20=-32 \%$ decline in applications. Therefore, across specifications, I find that unemployment extensions decreased applications by about $30 \%$ in the median state during the Great Recession.

The estimated effect of PBD on applications may seem large. However, one must remember that this estimate arises from more than tripling the duration of unemployment benefits. To get a sense of the magnitudes, it is useful to compare the elasticity of applications with respect to PBD to prior estimates of the elasticity of job search effort with respect to unemployment insurance. The elasticity of applications with respect to $\mathrm{PBD}$ is given by $\beta \triangle P B D /(\triangle P B D / P B D)$, where the numerator $\beta \triangle P B D$ is the percent impact $(\beta)$ of the PBD increase $(\triangle P B D)$ on applications, and the denominator $\triangle P B D / P B D$ is the percent increase in PBD. Given that, in the median state, PBD went from 26 to 99 weeks, the elasticity of labor market tightness with respect to unemployment insurance is given by $\beta \triangle P B D$ / $(\triangle P B D / P B D)=26 \beta$. If a one week increase in PBD yields a $0.4 \%$ decline in applications (timing of events estimate), the elasticity of applications with respect to PBD is $-0.004 * 26=-0.104$. This elasticity is small given that the elasticity of minutes spent in job search with respect to unemployment benefit amounts ${ }^{31}$ was estimated to be between -1.6 and -2.2 (Krueger and Mueller 2010). Of course, my sample includes both unemployed and employed job seekers, which reduces the estimated elasticity. Still, the elasticity of job applications with respect to PBD is orders of magnitude smaller than the elasticity of job search minutes with respect to unemployment benefit amounts. Thus, the large estimated impact of PBD on job applications arises from a small elasticity of applications with respect to PBD combined with a very large increase in PBD.

In conclusion, my empirical analysis shows that the increase in PBD during the Great Recession led to a substantial decline in total applications, and thus generated a search externality. Because changes in PBD had no robust effect on the number of vacancies, I conclude that extensions did not generate a labor demand externality. Overall, unemployment insurance extensions during the Great Recession increased labor market tightness. A positive impact of unemployment insurance on labor market

\footnotetext{
${ }^{31}$ Using the timing of events methodology, the impact of PBD on log total UI benefit payments is -0.01 . So the implied elasticity of applications with respect to $\mathrm{UI}$ benefits is $-0.004 / 0.01=-0.4$. This is a still a small elasticity compared to the estimates by Krueger and Mueller 2010.
} 
tightness implies that the general equilibrium effect of unemployment insurance contributes to reducing its impact on aggregate unemployment: thus, the macro impact of unemployment insurance on aggregate unemployment is smaller than its micro (partial equilibrium) impact on benefit recipients.

\section{Robustness tests and further results}

\subsection{Robustness tests}

The specification from the global parametric regression discontinuity design in column 4 in Table 3, with full controls including month fixed effects will serve as the baseline specification for these robustness tests.

The first robustness test I perform is to vary the degree of the polynomials in the assignment variables TUR and IUR that are used as controls. Using third or fourth degree polynomials rather than second degree polynomials does not affect the estimated impact of PBD on applications, vacancies or labor market tightness (Appendix 1, Table 12).

The impact of PBD on applications and tightness may be biased by changes in the composition of posted jobs. To address this issue, I add controls for the share of jobs in each education category and each 2digit NAICS industry (Table 5, col. 1 and 4). The impact of EUC PBD on applications is still significant and negative, and not statistically significantly different from the baseline estimates. Similarly, the impact of EUC PBD on tightness stays significant and positive. I conclude that the results are robust to changes in the composition of jobs by industry and education requirement.

To control for any systematic decline in applications over time that is unrelated to PBD increases, I add state-specific trends to the specification (Table 5, col. 2 and 5). This lowers the impact of EUC on applications (col. 2), but the point estimate is not statistically significantly different from the baseline. Similarly, the positive impact of EUC PBD on tightness is robust to state-specific trends (col. 5).

My interpretation of the main results is that the decrease in aggregate job search effort as measured by applications comes from UI recipients decreasing their job search effort in response to an increase in PBD. To support this interpretation, I test whether the impact of PBD on applications is greater in states 
that have a higher share of $U I$ recipients among their unemployed ${ }^{32}$. I find that the impact of EUC PBD on applications is significantly larger when the share of UI recipients in the state is higher (Table 5, col. 3). A similar result is observed for tightness in col. 6: the point estimate indicates that the impact of EUC PBD on tightness is greater when the share of $\mathrm{UI}$ recipients in the state is higher, though the interaction term is not statistically significant. Reassuringly, the main impact of EUC PBD on applications, which corresponds to a 0 share of $\mathrm{UI}$ recipients among the unemployed, is not statistically significant. I conclude that the impact of PBD on applications is larger in states with a higher share of $\mathrm{UI}$ recipients among the unemployed, which is consistent with a negative impact of PBD on the applications of UI recipients.

An alternative way to test whether the negative impact of PBD on job applications is due to the behavior of $\mathrm{UI}$ recipients is to separately estimate the impact of PBD on a sample of vacancies whose applicants are less likely to respond to increases in PBD. For example, it seems plausible that applications to high paying jobs will not be affected by increases in PBD. Indeed, highly educated workers have significantly shorter unemployment durations (Riddell and Song 2011) and are therefore unlikely to be using the PBD extensions. Furthermore, there is a cap in the dollar amount of benefits that can be collected, and therefore the replacement rate is lower for top earners, making it less advantageous to stay unemployed for long periods of time. I estimate the impact of PBD separately for vacancies with different levels of the posted wage, and find that the negative impact of EUC PBD on applications is driven by lower-earning job applicants (Appendix 1, Figure 13), who are more sensitive to increases in the generosity of unemployment insurance.

I have also performed these robustness tests using the number of vacancies as an outcome. Neither EUC nor EB have a significant impact on vacancies in these alternative specifications (Appendix 1,Table 13). In particular, the specification with state-specific trends (Appendix 1, Table 13, col. 3) helps address the above-mentioned concern that a positive trend in vacancies is masking the negative impact of PBD on vacancies. If this concern is valid, then adding state-specific trends should make the impact of PBD on vacancies more negative. However, with state trends, the impact of EUC becomes more positive (compare Appendix 1, Table 13 col. 1 and col. 3), not more negative. Overall, the absence of an impact of PBD on vacancies is robust.

\footnotetext{
${ }^{32}$ Specifically, I compute the average share of UI recipients in each state from December 2008 through the end of my sample. I use this time frame because the identifying variation in EUC as a function of TUR only exists when EUC levels change with TUR, which is after December 2008.
} 
Finally, for vacancies, I can also repeat the analysis with Help Wanted Online data, which counts all online vacancies and is available in my data extract since 2009. Overall, the correlation between the CareerBuilder vacancy count used for the main analysis and the Help Wanted Online vacancy count is extremely high at $\mathbf{0 . 9 5}$. Therefore, it is not surprising that using this alternative vacancy data, we still find no significant impact of EUC or EB PBD on all online job vacancies (Appendix 1, Table 13, col. 5). This result supports the external validity of my estimate of the impact of the extensions on vacancies.

\subsection{The impact of PBD on job seeker selectivity and posted wages}

In this subsection, I examine the impact of PBD on job seeker selectivity and posted wages using the same baseline specification as in Table 3, col. 3 .

If PBD increases reservation wages or other demands by UI recipients, this decreases the number of jobs suitable for application. To measure the number of jobs that job seekers consider, I use data on the number of times that a job vacancy snippet was viewed as part of a listing that comes out after a job search query. The number of applications per view is a measure of how selective jobseekers are: if reservation wages or other demands go up with PBD, the number of applications per view should go down. Empirically, I find that PBD does not have a significant impact on applications per view (Table 6, col. 1). This suggests that PBD does not affect job seeker selectivity.

My finding that PBD does not affect applications per job view is consistent with the lack of evidence for an impact of PBD on the reservation wage found in previous literature (e.g. Card, Chetty, and Weber 2007; Lalive 2007; van Ours and Vodopivec 2008; Krueger and Mueller 2011). At the same time, this result adds to the literature. Indeed, even if the reservation wage does not react to an increase in PBD, jobseekers could become more selective about other job characteristics besides the wage. My results are inconsistent with the idea that PBD increases jobseeker selectivity on non-wage job characteristics. Instead, an increase in PBD chiefly affects job search effort with no significant impact on jobseeker selectivity on either wage or non wage job attributes.

While the evidence on applications per view is inconsistent with PBD increasing reservation wages, firms may believe that PBD increases reservation wages. If that is the case, posted wages may increase as an equilibrium response. I find no effect of the PBD on the log average real posted wage ${ }^{33}$ among vacancies with a posted wage, and the point estimate is even negative (Table 6, col. 2 ). I then examine the impact

\footnotetext{
${ }^{33}$ To calculate the average posted wage, I take the mid-point of each bin, and for the highest bin (over $\left.\$ 500,000\right)$ I assume that the posted wage is $\$ 600,000$; I then use the CPI to convert nominal wages to real wages.
} 
of PBD on the distribution of nominal posted wages: I find no impact of PBD on the share of jobs with a posted wage above $\$ 50,000$, the share of jobs with a posted wage below $\$ 30,000$ and the share of jobs with a posted wage above $\$ 100,000$ (Table 6, cols. 3-5). Finally, given that not all jobs post a wage, there is a concern that PBD may affect the share of jobs that post a wage, and that the absence of an impact of PBD on posted wages may be driven by selection. However, I also find no impact of EUC PBD on the share of jobs with a posted wage ${ }^{34}$ (Table 6, col. 6). Overall, I conclude that PBD has no impact on the level or the distribution of posted wages. The absence of an impact of PBD on posted wages is consistent with the absence of an impact of PBD on reservation wages and on job seeker selectivity.

In this sub-section, I have shown that PBD does not have an impact on job seeker selectivity nor on posted wages. These results are consistent with the absence of an effect of PBD on the number of vacancies and thus strengthen the conclusion that PBD did not generate a labor demand externality.

\subsection{County pair difference specification}

Hagedorn et al. (2013) identify the impact of extensions by comparing unemployment and vacancies in adjacent counties belonging to different states while accounting for permanent differences between county pairs.

I use this identification strategy on the CareerBuilder county pairs dataset described above. For the sake of transparency, I use a simple specification for the county pair design:

$$
\Delta_{c} y_{c s t}=\beta_{1} \Delta_{\mathrm{c}} E U C_{c s t}+\beta_{2} \Delta_{\mathrm{c}} E B_{c s t}+\delta_{t}+\gamma_{p}+\epsilon_{c s t}
$$

where $y_{c s t}$ is the outcome $y$ in county $c$ in state $s$ at date $t . E U C_{c s t}$ is the number of weeks of EUC available, $E B_{c s t}$ is the number of weeks of EB available and $\epsilon_{c s t}$ is the error term. $\Delta_{\mathrm{c}}$ stands for the difference across counties in a pair at a given date $t$. $\delta_{t}$ is a date fixed effect (monthly) and $\gamma_{p}$ is a county pair fixed effect. Observations are weighed by the total population in the two counties of the county pair, and standard errors are clustered by border segment (i.e. all counties along a given state border). With this specification, one can test, for example, whether a higher PBD in a county (relative to the paired county's PBD) in a given month is associated with a smaller number of applications (relative to the paired county's applications), and after accounting for fixed differences in the number of

\footnotetext{
${ }^{34}$ There is some evidence for EB PBD diminishing the share of posted wages, but EB PBD does not have an impact on the number of applications (Table 3, col. 3-4), the number of vacancies (Table 4, col. 3-4), or the level of posted wages, so this result is not particularly enlightening.
} 
applications between the two counties in the pair. This specification can recover the causal effect of PBD on outcomes if, for each county, the paired county constitutes a valid counterfactual.

Using the border county pair specification above, I find no significant impact of PBD (EUC and EB) on applications, jobs or tightness (Table 7, col. 1-3). In Appendix 2, I also present specifications a la Hagedorn et al. (2013) and a la Dube, Lester, and Reich (2010). Across all of these specifications, I find no significant impact of PBD on vacancies, applications or tightness.

Why do we find insignificant effects across the board in the county pair design when other specifications have shown a significant effect of PBD on applications and labor market tightness? Cross-county spillover effects may bias the results. Indeed, more than half of applications (54\%) on CareerBuilder.com are across county (Marinescu and Rathelot, 2014). If there are spillover effects, then outcomes in a county should be affected by PBD in the paired county. Furthermore, the spillover effect, if any, should be larger if the county is the smaller (in terms of population) of the two counties in the pair than if the county is the larger of the two counties.

To test for spillover effects, I retain only the smaller county in the pair (the "reference county") and run the same specification as above, but in levels rather than differences; furthermore, I add controls for EUC and EB in the larger paired county, and I weigh observations by the population in the reference county. This is thus a simple panel specification for the smaller counties. Remarkably, there is no significant impact of EUC in the reference county on applications: instead, only EUC in the larger paired county has a negative and significant effect (Table 7, col. 4). For vacancies, there is no significant effect of PBD across the board (col. 5). For tightness, we see a positive and highly significant effect of EUC in the bigger paired county (col. 6). These results are evidence for strong spillover effects for the application and tightness outcomes flowing from the bigger to the smaller county in a pair ${ }^{35}$.

Taken together, these results support the view that there are important spillover effects across counties. Because of these spillover effects, taking differences between paired counties systematically biases the impact of PBD towards zero. In a nutshell, the county pair design cannot capture the causal impact of UI on applications and vacancies.

\footnotetext{
${ }^{35}$ The results from the large counties show that it is EUC in the county itself that negatively affects applications and positively affects tightness, with no significant effect from EUC in the paired (smaller) county.
} 


\section{Discussion and calibration}

\subsection{External validity}

One may wonder whether applications on CareerBuilder.com are a good measure of search effort. Unemployment benefit recipients during the Great Recession spent between 24 and 38\% of their job search time sending applications and answering job ads (Krueger and Mueller, 2011). Additionally, 27\% of job search time is spent browsing job ads. Nowadays, the overwhelming majority of vacancies are posted on the Internet (Barnichon 2010). Furthermore, Internet job search is associated with higher job finding rates than offline job search (Kuhn and Mansour 2011). Therefore, it is plausible to think that more than two thirds of job search time is spent on the Internet and that this is an effective method for job finding.

While I have shown that the increase in PBD led to a substantial decrease in applications, one may wonder whether this decline was due to a decrease in applications on the CareerBuilder website only. If so, it is possible that jobseekers applied through other channels and so the overall applications in the state may not have decreased as much as it seems. This scenario is very unlikely, because such changes in jobseekers' use of the CareerBuilder website are unlikely to coincide exactly with the timing of UI extensions. Still, I provide some additional evidence on this issue. First, one can show that the number of applications on CareerBuilder is significantly and positively related to hires in national monthly data from JOLTS (not shown). If applications on CareerBuilder were substituted by applications through other channels, this relationship would likely not be significant. Additionally, when graphing hires and applications between 2007 and 2011, one does not see that applications fall behind hires in relative terms as time goes by, as would be the case if applications in CareerBuilder had represented a lower and lower share of total applications (not shown).

Second, there is independent evidence showing that jobseekers are unlikely to have moved away from Internet job search during the Great Recession. Indeed, while there is no representative survey about online job search in the US during the Great Recession, a study using quarterly labor force survey data from the United Kingdom (Green et al. 2011) shows that there was an increased use of Internet for job search purposes among jobseekers during 2008-2009. In April to June 2009, over 4 in 5 British jobseekers used the Internet to look for jobs, and this proportion was even higher among the recipients of unemployment benefits (Green et al. 2011). Therefore, there is no reason to assume that jobseekers 
moved away from online job search during the recession. I conclude that my results are unlikely to be explained by jobseekers moving away from CareerBuilder.com to apply elsewhere.

\subsection{Why does PBD have no effect on vacancies?}

If the decrease in applications induced by PBD increases made it substantially harder for employers to recruit, it may be surprising that PBD did not affect vacancies. However, in practice, it is likely that PBD increases did not substantially increase the difficulty of recruitment. Indeed, there are on average 31 applications per job. Even if the number of applications decreases by $29 \%$, which is what I estimate to be the full effect of the PBD extensions, employers are still left with 22 applications per job. As is typical in the search and matching literature, assume that applications follow a Poisson process and vacancies are filled whenever they receive at least one applicant. Under these assumptions, with an average of 22 applications per job, the probability that a vacancy remains unfilled is equal to the probability of receiving 0 applications, i.e. $\exp (-22)$, which is extremely close to 0 . Furthermore, my conversations with CareerBuilder employees suggest that employers during the Great Recession were rather facing a glut of applications and wished for fewer applications. Thus, the decrease in applications may have reduced the cost of screening for firms. It is therefore unlikely that it became substantially harder to fill vacancies during the Great Recession. Consistent with this interpretation, the job filling rate during the Great Recession increased by about 30\% (Davis, Faberman, and Haltiwanger 2012). Overall, it is unlikely that extensions in the duration of unemployment insurance benefits affected the value of vacancies because, during the Great Recession, firms were receiving enough applications to quickly fill their vacancies.

\subsection{Long-run effects vs. short run effects}

My analysis captures the short-to-medium term effects of PBD on applications and vacancies. Indeed, the regression-based timing of events approach captures impacts of the largest increase in PBD in the next couple of months out because the average state is observed for two months post-PBD increase. When I use a fuzzy regression discontinuity designs, the estimated impacts are also only short to medium term. Indeed, we are comparing state-month observations with essentially the same TUR but different levels of PBD: because the unemployment rate is slow-moving and I have a short panel, observations with similar TUR will also tend to be close together in time.

My empirical analysis pertains to the short and medium run and assumes that firms and job seekers do not change their behavior in anticipation of the policy. For job seekers, it is evident from Figure 3 that 
they do not start lowering the number of applications prior to the policy change, and if anything their response is delayed. Firms could lower their number of vacancies if they expect the number of applicants to drop. Given that a vacancy takes about a month to fill, any such anticipatory effect would have to happen in the couple of months before the policy change, but we see no evidence for this in Figure 3. Therefore, despite the argument made by Hagedorn, Manovskii, and Mitman (2016) that I ignore firms' anticipations, the identification strategy used here is valid because there is no evidence for behavioral changes prior to the implementation of the policy.

While there are no anticipation effects, it is still possible in theory that PBD decreases labor market tightness in the longer run. The timing of events approach (Figure 3, Panel B) shows that the number of vacancies stays constant as far as seven months after the largest increase in PBD $^{36}$. Furthermore, the impact of a PBD increase on applications tends to get significantly more negative over time (Figure 3, Panel A). Therefore, at time horizons of the order of a year, the impact of PBD on labor market tightness is likely to remain positive ${ }^{37}$.

\subsection{Implied impact of PBD on aggregate unemployment}

Landais, Michaillat, and Saez (2014) demonstrate that, in a dynamic framework, the macro elasticity of aggregate unemployment with respect to unemployment benefits is the sum of the micro elasticity, which captures the partial equilibrium effect, and a general equilibrium effect, which is crucially dependent on labor market tightness:

$$
\epsilon^{M}=\epsilon^{m}-l \cdot\left(1+\epsilon^{d}\right) \cdot(1-\eta) \cdot \frac{b}{\theta} \cdot \frac{d \theta}{d b}
$$

where:

\footnotetext{
${ }^{36}$ As an alternative approach to understanding the timing of the impact of PBD on vacancies, I used up to three lags and leads of PBD in the specification relying on nonlinearities in PBD as a function of TUR. I find no significant effect of lags or leads of PBD (EUC and EB) on vacancies (Appendix 1, Table 15, col. 2-7). For applications, the impact of lagged EUC PBD stays negative, significant and fairly constant up to lag 3, while the lead of EUC PBD becomes insignificant at leads 2 and 3 . The first-difference specifications and the lag and lead analysis confirm that EUC PBD has a negative effect on applications but no significant effect on vacancies.

${ }^{37}$ It is possible that the impact of PBD on aggregate unemployment becomes negative in the longer run. This is in fact what happens in the theoretical model by Mitman and Rabinovich (2011), who find that optimal PBD should first increase and then decrease during a recession. Therefore, there seems to be agreement over the fact that an increase in PBD early on in a recession has little impact on unemployment. However, how exactly the impact of PBD on aggregate unemployment evolves over the course of a recession remains an open area for empirical investigation.
} 
- $\epsilon^{m}$ is the micro elasticity. It is the elasticity of unemployment probability of a worker whose individual benefits change.

- $\quad l$ is employment at the representative firm.

- $\epsilon^{d}$ is the discouraged worker elasticity.

- $\theta$ is labor market tightness measured as aggregate vacancies divided by aggregate search effort.

- $1-\eta>0$ is the elasticity of the job finding rate by unit of search effort.

- $\quad b$ are unemployment benefits.

The term $\frac{b}{\theta} \cdot \frac{d \theta}{d b}$ in the formula above is the elasticity of labor market tightness with respect to unemployment benefits ${ }^{38}$. I use the same calibration as Landais, Michaillat, and Saez (2014) for namely $\eta$ and $\epsilon^{d}$, namely $\eta=0.7$ and $\epsilon^{d}=0$.

If we take $l$ (employed workers in the representative firm) to be one minus the unemployment rate, then, given that the average unemployment rate is $7.38 \%$ in the sample, we have: $(1-\eta) l=$ $(1-0.7) *(1-0.0738)=0.2779$. What is the elasticity of labor market tightness with respect to PBD? If we use the global parametric regression discontinuity design estimates (Table 4, col. 5), the impact PBD in the median state is the impact of 53 weeks increase in EUC and 20 weeks increase in EB $^{39}$, i.e. $0.008 * 53-0.0019 * 20=39 \%$. In the median state, PBD went from 26 to 99 weeks, an increase of $281 \%$. Thus, the elasticity of labor market tightness with respect to PBD is: $39 / 281=0.14$. The macro elasticity of aggregate unemployment with respect to PBD is then:

$$
\epsilon^{M}=\epsilon^{m}-0.2779 * 0.14=\epsilon^{m}-0.04
$$

For the micro elasticity of unemployment with respect to PBD, the most relevant estimates are from Rothstein (2011) and Farber and Valletta (2013), since they use the same extensions. Rothstein (2011) estimates that a one-week increase in benefits increases unemployment duration by $0.37 \%$ (Table 3 ,

\footnotetext{
${ }^{38}$ Landais, Michaillat, and Saez (2014) write the macro elasticity as a function of the elasticity of labor market tightness with respect to the difference in consumption between employed and unemployed individuals. If we assume that the unemployed consume their unemployment benefit, this is the opposite of $\frac{b}{\theta} \cdot \frac{d \theta}{d b}$, which is why a minus sign appears after the micro elasticity instead of the plus sign in the original formula.

${ }^{39}$ Using the insignificant point estimate for the impact of PBD on tightness obtained when not distinguishing between EUC and EB (col. 2 in Appendix 1, Table 11) yields almost exactly the same estimate for the elasticity of labor market tightness with respect to PBD.
} 
column 3-5), which translates into an elasticity ${ }^{40}$ of $\epsilon^{m}=0.1$. This elasticity is the same as the one found by Farber and Valletta (2013). Importantly, this estimate of $\epsilon^{m}=0.1$ is essentially the same as the estimate from the US extended benefits program studied by Card and Levine (2000), and the same as the estimates from the regression discontinuity design for Germany in Schmieder, Wachter, and Bender (2012a), which range between 0.12 and 0.13 .

Using a micro elasticity estimate $\epsilon^{m}=0.1$, the macro elasticity of aggregate unemployment with respect to $\mathrm{PBD}^{41}$ is $\epsilon^{M}=0.1-0.04=0.06$. Therefore, general equilibrium effects reduce the impact of unemployment insurance by $40 \%$.

The wedge between the macro and the micro elasticity is close the one found in the calibration by Lalive, Landais, and Zweimüller (2013) using Austrian data. They use a research design that cannot fully account for the impact of extensions on job vacancies. Given the results from this paper, there is no robust effect of extensions on vacancies, so the formula they use to calculate the elasticity wedge is likely to be fairly accurate despite not taking into account the impact of the extensions on job vacancies. The fact that the estimates of the wedge between the macro and the micro elasticities for Austria and the United States are so close suggests that this wedge may not vary very much across developed countries. However, much more research is needed to confirm this point.

Given the most plausible calibration, the medium run macro impact of PBD on aggregate unemployment is small. The idea that a decrease in search effort could have little effect on aggregate unemployment may seem counterintuitive. Yet a previous paper studying a job search assistance experiment came to the same conclusion (Crépon et al. 2013). Because job search assistance increased the job finding rate of recipients but decreased the job finding rate of non-recipients, the impact on the aggregate job finding rate was zero. Conversely, PBD reduces job search effort by UI recipients but probably increases the job finding rate of non recipients, so it makes sense that PBD had a small effect on aggregate unemployment during the Great Recession.

A caveat to the interpretation that PBD has a small impact on aggregate unemployment is that the decrease in applications may not reduce labor market tightness as much as it seems. Indeed, the

\footnotetext{
${ }^{40}$ If we use Rothstein's calculation of the impact of the extensions on the unemployment exit hazard in 2010Q4, we find a decrease in the hazard of $11 \%$. Population adjusted, PBD was 87 weeks in 2010Q4. This gives an elasticity of 0.04 rather than 0.1 . With this lower estimate, the macro impact of PBD would be even lower.

${ }^{41}$ If we take the impact of PBD on tightness from the timing of events difference-in-differences specification (Table 2 , col. 6), the macro elasticity is $0.1-0.2779 * 26 * 0.0024=0.08$, and the wedge between the macro and the micro elasticity is $20 \%$.
} 
theoretical framework used here implicitly assumes that every applicant has the same probability of getting hired, so a decrease in the number of applications leads to a proportional increase in the probability of getting hired. However, if PBD reduces applications by candidates that are less hirable from the point of view of the firm, the impact of PBD on effective labor market tightness would be smaller than the impact of PBD on applications.

How plausible is the idea that PBD reduces applications by less hirable candidates? On the one hand, long-term unemployed job seekers are less likely to get a call back from employers than short-term unemployed and employed job seekers (Kroft, Lange, and Notowidigdo 2013). Therefore, to the extent that the increase in PBD mostly decreased the applications of the long-term unemployed, it may have somewhat increased the average quality of the applicant pool from the point of view of the firm, and therefore the decrease in applications may overestimate the increase in labor market tightness. On the other hand, the evidence that PBD does not affect job seeker selectivity is not consistent with PBD increasing the quality of applications. Therefore, it is not clear that PBD reduces applications by less hirable candidates, and therefore it is hard to conclude that my calibration underestimates the macro elasticity of unemployment with respect to PBD.

Given my estimates and calibration results, the macro effect of unemployment insurance extensions during the Great Recession in the US is small, and smaller than the micro effect. By contrast, and based on their own estimates and calibration results, Hagedorn et al. (2013) conclude that the macro effects of these unemployment insurance extensions are large, and larger than the micro effects. Hagedorn et al. (2013)'s identification strategy relies on comparing counties along state borders. However, as shown above, because of large spillover effects across counties, this identification strategy cannot pin down the impact of PBD on labor market tightness.

Even if there were a negative impact of PBD on vacancies, Hagedorn et al. (2013) are still overestimating the macro effect of unemployment insurance because they only take into account the labor demand externality and neglect the search externality. The labor demand externality contributes to increasing aggregate unemployment above and beyond the micro effect of the extensions on benefit recipients, while the search externality has the opposite effect. Therefore, it is not surprising that (Hagedorn et al. 2013) find that the macro effect of the extensions is larger than the micro effect. To determine the macro impact of the extensions on unemployment it is necessary to take into account the offsetting impacts of the labor demand externality and the search externality. 
Overall, I conclude, first, that the macro impact of PBD on aggregate unemployment is smaller than the micro impact of PBD on the unemployment of $\mathrm{UI}$ recipients in the medium run. This first conclusion is based on the positive impact of PBD on labor market tightness. Second, the calibration performed above suggests that PBD had a small impact on aggregate unemployment in the medium run.

\section{Conclusion}

This paper has used state-level variation in unemployment benefit duration during the Great Recession to investigate the general equilibrium impact of unemployment insurance. Using new data from the large job board CareerBuilder.com, I show that extensions in the duration of unemployment benefits do not have a robust impact on the number of vacancies, and therefore do not generate a labor demand externality. On the other hand, a one-week increase in the potential duration of unemployment benefits (PBD) leads to a $0.4 \%$ decline in applications, which corresponds to an elasticity of applications with respect to PBD of -0.1. The fact that extensions reduce the total number of job applications implies that extensions generate a search externality.

Unemployment insurance extensions increase labor market tightness. This positive effect of extensions on labor market tightness implies that the impact of unemployment insurance on aggregate unemployment is smaller than its impact on unemployment benefit recipients. Quantitatively, calibration indicates that a $10 \%$ increase in PBD increases aggregate unemployment by $0.6 \%$, an effect that is $40 \%$ smaller than the micro effect of PBD on benefit recipients. In other terms, the general equilibrium effect of unemployment insurance lowers its impact on aggregate unemployment by $40 \%$. Furthermore, to the extent that recessions are characterized by inefficiently low labor market tightness, increasing tightness through unemployment insurance extensions at the beginning of recessions is welfare improving. The evidence that unemployment insurance extensions increase labor market tightness thus contributes to vindicating the institution of extended unemployment benefits in the US. However, further empirical investigation is needed to quantify the longer run impacts of unemployment insurance extensions. 


\section{References}

Angrist, Joshua D., and Victor Lavy. 1999. "Using Maimonides' Rule to Estimate the Effect of Class Size on Scholastic Achievement." The Quarterly Journal of Economics 114 (2): 533-75.

Barnichon, Regis. 2010. "Building a Composite Help-Wanted Index." Economics Letters, Economics Letters, 109 (3): 175-78.

Card, David, Raj Chetty, and Andrea Weber. 2007. "Cash-on-Hand and Competing Models of Intertemporal Behavior: New Evidence from the Labor Market." The Quarterly Journal of Economics 122 (4): 1511-60. doi:10.1162/qjec.2007.122.4.1511.

Card, David, and Phillip B. Levine. 2000. "Extended Benefits and the Duration of UI Spells: Evidence from the New Jersey Extended Benefit Program." Journal of Public Economics 78 (1): 107-138.

Crépon, Bruno, Esther Duflo, Marc Gurgand, Roland Rathelot, and Philippe Zamora. 2013. "Do Labor Market Policies Have Displacement Effects? Evidence from a Clustered Randomized Experiment." The Quarterly Journal of Economics 128 (2): 531-80. doi:10.1093/qje/qjt001.

Davis, Steven J, R. Jason Faberman, and John C Haltiwanger. 2012. "Recruiting Intensity during and after the Great Recession: National and Industry Evidence." American Economic Review 102 (3): 58488. doi:10.1257/aer.102.3.584.

Dube, Arindrajit, T. William Lester, and Michael Reich. 2010. "Minimum Wage Effects Across State Borders: Estimates Using Contiguous Counties." Review of Economics and Statistics 92 (4): 94564. doi:10.1162/REST_a_00039.

Farber, Henry S., and Robert G. Valletta. 2013. "Do Extended Unemployment Benefits Lengthen Unemployment Spells? Evidence from Recent Cycles in the U.S. Labor Market." Working Paper 19048. National Bureau of Economic Research. http://www.nber.org/papers/w19048.

Green, A.E., M. de Hoyos, Y. Li, and D. Owen. 2011. "Job Search Study: Literature Review and Analysis of the Labour Force Survey." Department for Work and Pensions Research Report 726.

Hagedorn, Marcus, Fatih Karahan, lourii Manovskii, and Kurt Mitman. 2013. "Unemployment Benefits and Unemployment in the Great Recession: The Role of Macro Effects." Working Paper 19499. National Bureau of Economic Research. http://www.nber.org/papers/w19499.

Hagedorn, Marcus, lourii Manovskii, and Kurt Mitman. 2016. "Interpreting Recent Quasi-Experimental Evidence on the Effects of Unemployment Benefit Extensions." Working Paper 22280. National Bureau of Economic Research. http://www.nber.org/papers/w22280.

Katz, Lawrence F., and Bruce D. Meyer. 1990. "The Impact of the Potential Duration of Unemployment Benefits on the Duration of Unemployment." Journal of Public Economics, Journal of Public Economics, 41 (1): 45-72.

Kroft, Kory, Fabian Lange, and Matthew J. Notowidigdo. 2013. "Duration Dependence and Labor Market Conditions: Evidence from a Field Experiment*." The Quarterly Journal of Economics 128 (3): 1123-67. doi:10.1093/qje/qjt015.

Krueger, Alan B., and Andreas Mueller. 2010. "Job Search and Unemployment Insurance: New Evidence from Time Use Data." Journal of Public Economics, Journal of Public Economics, 94 (3-4): 298307.

- - . 2011. "Job Search and Job Finding in a Period of Mass Unemployment: Evidence from HighFrequency Longitudinal Data." Princeton University, Department of Economics, Industrial Relations Section. http://ideas.repec.org/p/pri/indrel/1283.html.

Kuhn, Peter J., and Hani Mansour. 2011. "Is Internet Job Search Still Ineffective?" IZA Discussion Paper 5955. Institute for the Study of Labor (IZA). http://ideas.repec.org/p/iza/izadps/dp5955.html.

Lalive, Rafael. 2007. "Unemployment Benefits, Unemployment Duration, and Post-Unemployment Jobs: A Regression Discontinuity Approach." The American Economic Review 97 (2): 108-12. 
Lalive, Rafael, Camille Landais, and Josef Zweimüller. 2013. "Market Externalities of Large Unemployment Insurance Extension Programs." IZA Discussion Paper. http://www.econstor.eu/handle/10419/90053.

Landais, Camille, Pascal Michaillat, and Emmanuel Saez. 2014. "Optimal Unemployment Insurance over the Business Cycle."

Marinescu, loana, and Roland Rathelot. 2014. "Mismatch Unemployment and the Geography of Job Search."

Meyer, Bruce D. 2002. “Unemployment and Workers' Compensation Programmes: Rationale, Design, Labour Supply and Income Support." Fiscal Studies 23 (1): 1-49.

Mitman, Kurt, and Stanislav Rabinovich. 2011. "Pro-Cyclical Unemployment Benefits? Optimal Policy in an Equilibrium Business Cycle Model." Penn Institute for Economic Research, Department of Economics, University of Pennsylvania Working Paper, 11-23.

Nekoei, Arash, and Andrea Weber. 2013. "Does Extending Unemployment Benefits Improve Job Quality?" mimeo, Harvard University, Cambridge, MA. http://www.econ.upf.edu/docs/seminars/nekoei.pdf.

Riddell, W. C, and X. Song. 2011. "The Impact of Education on Unemployment Incidence and ReEmployment Success: Evidence from the US Labour Market." Labour Economics.

Rothstein, Jesse. 2011. "Unemployment Insurance and Job Search in the Great Recession." Working Paper 17534. National Bureau of Economic Research. http://www.nber.org/papers/w17534.

Schmieder, Johannes F., Till von Wachter, and Stefan Bender. 2012. "The Effects of Extended Unemployment Insurance Over the Business Cycle: Evidence from Regression Discontinuity Estimates Over 20 Years." The Quarterly Journal of Economics 127 (2): 701-52. doi:10.1093/qje/qjs010.

Schmieder, Johannes, Till von Wachter, and Stefan Bender. 2012. "The Effect of Unemployment Insurance Extensions on Reemployment Wages." http://www.irs.princeton.edu/sites/irs/files/event/uploads/matchqual_wp_March2012.pdf.

van Ours, Jan C., and Milan Vodopivec. 2008. "Does Reducing Unemployment Insurance Generosity Reduce Job Match Quality?" Journal of Public Economics 92 (3-4): 684-95. doi:10.1016/j.jpubeco.2007.05.006. 
Figure 1: Simplified summary of the regulations governing the total duration of unemployed benefits in states with a TUR option for Extended Benefits (EB)

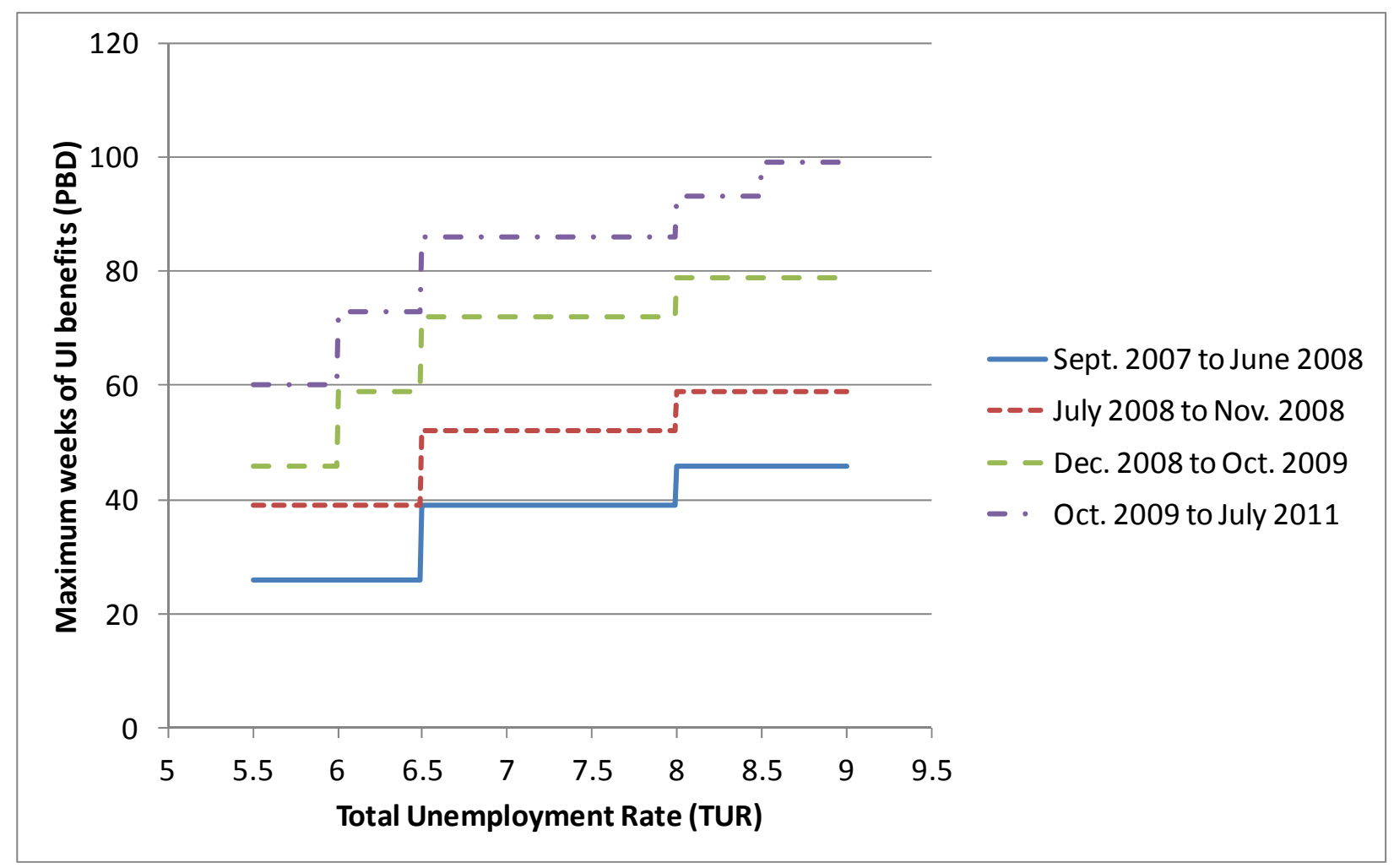

Note: Both EUC and EB are taken into account to calculate the maximum duration of UI benefits. The total unemployment rate (TUR) is, for each month and state, the average of the weekly three-months seasonally adjusted unemployment rate. This figure assumes that PBD only depends on the current level of TUR, while in fact PBD also depends on the past level of TUR and on the current and past levels of the insured unemployment rate (see text for more details). 
Table 1: Summary statistics

\begin{tabular}{lccccc}
\hline & $\mathrm{N}$ & mean & $\mathrm{sd}$ & $\mathrm{min}$ & $\mathrm{max}$ \\
\hline & & & & & \\
Applications & 2,397 & 431,725 & 584,975 & 2,424 & $3.179 \mathrm{e}+06$ \\
Vacancies & 2,397 & 13,357 & 15,455 & 438 & 123,090 \\
Job views (snippet) & 2,397 & $7.560 \mathrm{e}+07$ & $9.336 \mathrm{e}+07$ & $1.547 \mathrm{e}+06$ & $6.528 \mathrm{e}+08$ \\
Educ. required: high school & 2,397 & 0.137 & 0.032 & 0.047 & 0.358 \\
Educ. required: 2-year degree & 2,397 & 0.051 & 0.025 & 0.007 & 0.241 \\
Educ. required: 4-year degree & 2,397 & 0.160 & 0.049 & 0.043 & 0.463 \\
Educ. required: graduate degree & 2,397 & 0.020 & 0.017 & 0.001 & 0.593 \\
Educ. required: not specified & 2,397 & 0.633 & 0.061 & 0.267 & 0.857 \\
Share of wages over \$50000 (if posted) & 2,397 & 0.522 & 0.110 & 0.134 & 0.902 \\
Share of wages under \$30000 (if posted) & 2,397 & 0.254 & 0.096 & 0.022 & 0.808 \\
Share of wages over \$100000 (if posted) & 2,397 & 0.161 & 0.079 & 0.017 & 0.784 \\
Share of jobs with a posted wage & 2,397 & 0.216 & 0.062 & 0.049 & 0.433 \\
PBD in weeks & 2,397 & 61.90 & 26.12 & 26 & 99 \\
Total Unemployment Rate (TUR) (\%) & 2,397 & 7.138 & 2.557 & 2.325 & 15.20 \\
Insured unemployment rate (IUR) (\%) & 2,397 & 3.042 & 1.326 & 0.303 & 7.870 \\
\hline
\end{tabular}

Note: PBD is determined by weeks of UI available in the BLS trigger notices. The total unemployment rate is, for each month and state, the average of the weekly three-months seasonally adjusted unemployment rate. The insured unemployment rate is the 13-weeks insured unemployment rate.

Source: Department of Labor, and CareerBuilder.com for applications and vacancies. 
Figure 2: The evolution of the unemployment rate, job vacancies and potential unemployment benefit duration at the national level

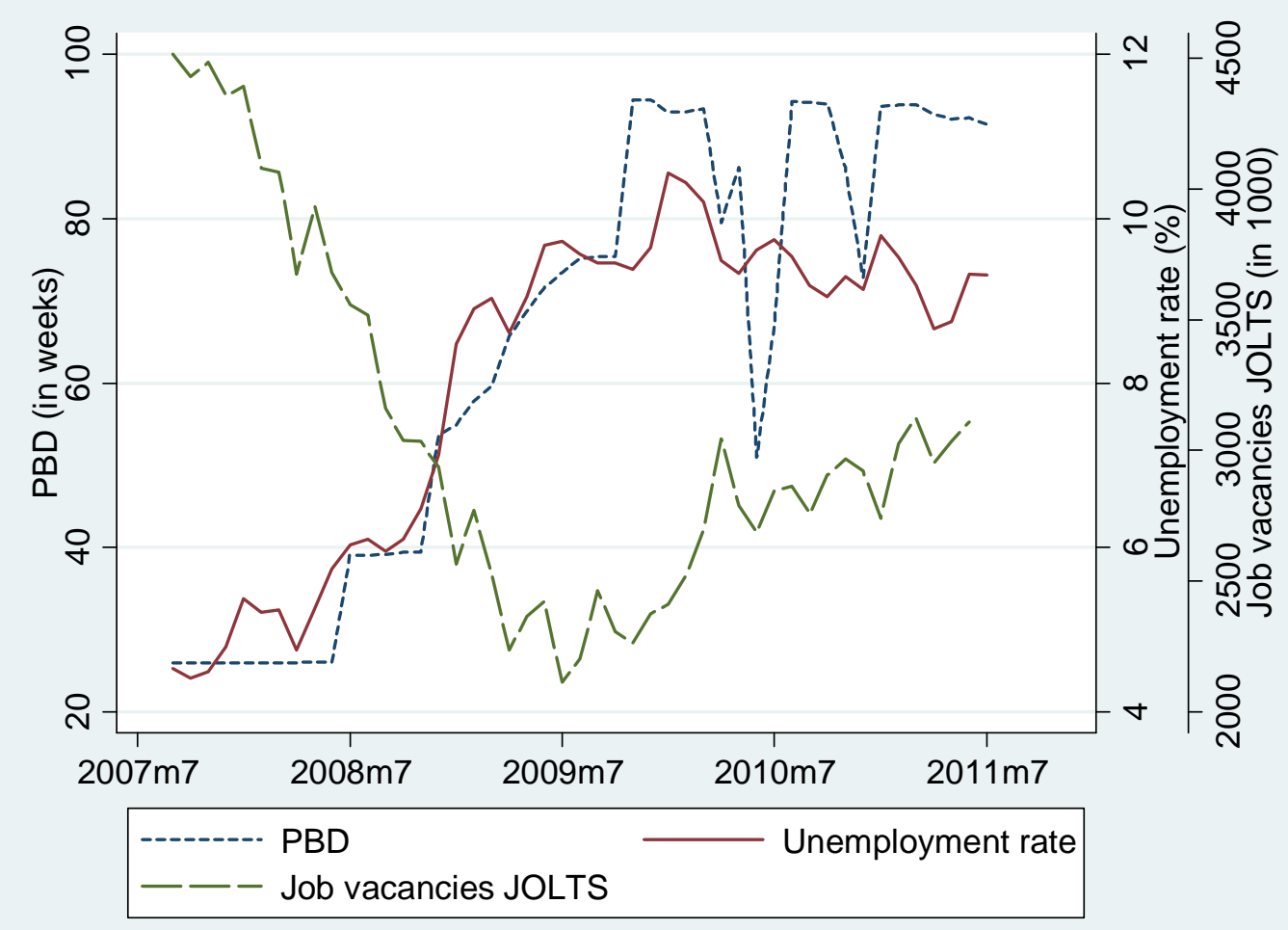

Note: Potential unemployment benefit duration (PBD) is calculated as an average over states, where each state is weighted accorded to the size of its labor force.

Source: Department of Labor. 

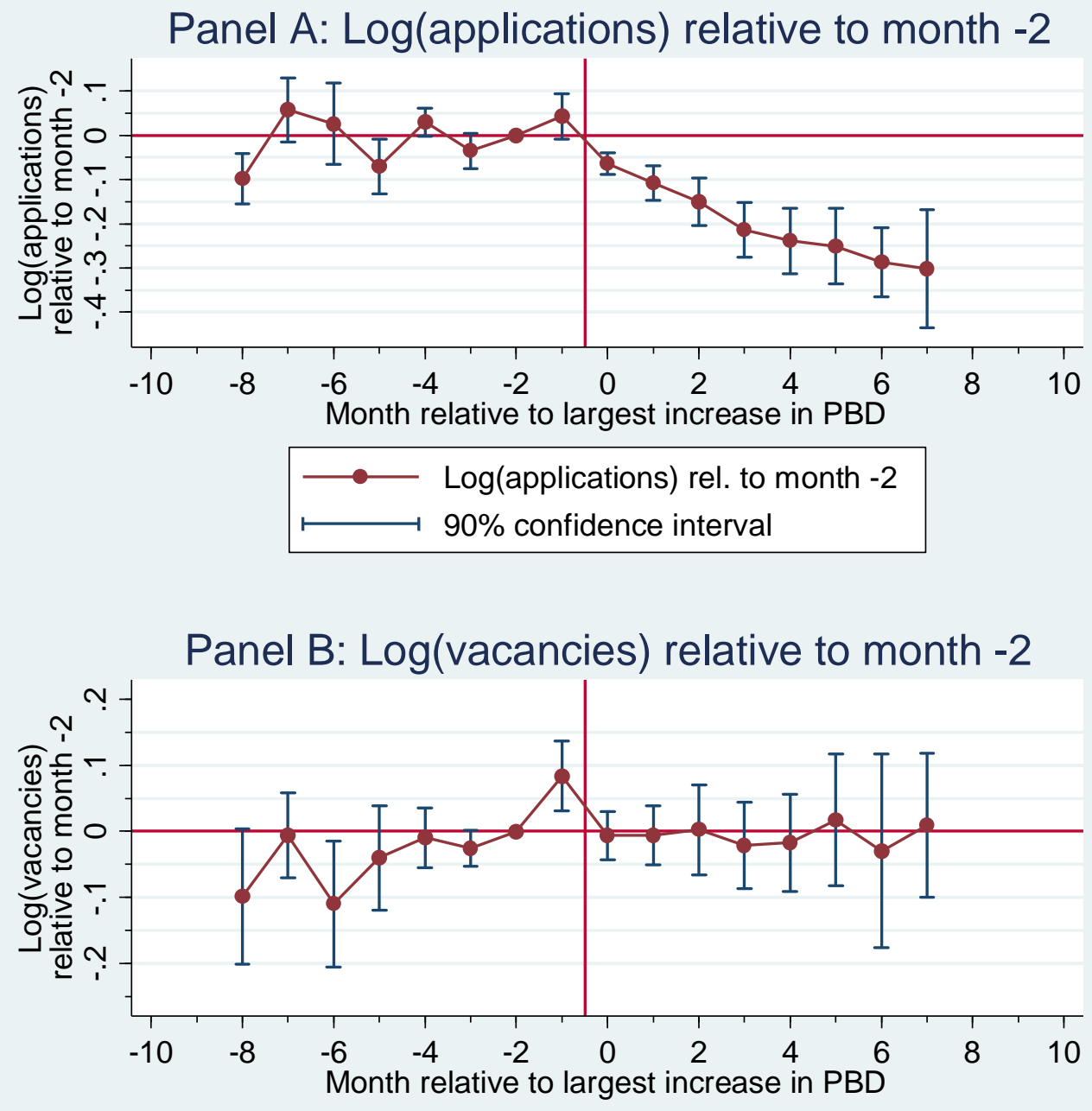

$\longmapsto 90 \%$ confidence interval

Note: The estimates are from a regression of log vacancies (Panel A) or log applications (Panel B) on relative month dummies, state, year and quarter of the year fixed effects. Standard errors are clustered by state. There are 318 observations. The largest increase in PBD is defined, for each state, as the largest increase that does not correspond to a change in the schedule, and is not due to a temporary interruption of EUC.

Source: Department of Labor, and CareerBuilder.com for applications and vacancies. 
Table 2: The impact of the largest increase in potential benefit duration (PBD) on log applications log vacancies, and labor market tightness, timing of events regressions

\begin{tabular}{|c|c|c|c|c|c|c|}
\hline & \multicolumn{2}{|c|}{ Log applications } & \multicolumn{2}{|c|}{ Log vacancies } & \multicolumn{2}{|c|}{ Log tightness } \\
\hline & $\begin{array}{l}\text { Diff } \\
(1)\end{array}$ & $\begin{array}{l}\text { DiD } \\
(2) \\
\end{array}$ & $\begin{array}{l}\text { Diff } \\
(3)\end{array}$ & $\begin{array}{l}\text { DiD } \\
(4)\end{array}$ & $\begin{array}{l}\text { Diff } \\
(5)\end{array}$ & $\begin{array}{l}\text { DiD } \\
(6)\end{array}$ \\
\hline Total PBD in weeks & $\begin{array}{c}-0.0035^{\star \star \star} \\
(0.0013)\end{array}$ & $\begin{array}{c}-0.0042^{\star \star \star} \\
(0.0010)\end{array}$ & $\begin{array}{l}-0.0012 \\
(0.0013)\end{array}$ & $\begin{array}{l}-0.0018 \\
(0.0011)\end{array}$ & $\begin{array}{c}0.0024^{*} \\
(0.0013)\end{array}$ & $\begin{array}{c}0.0024^{*} \\
(0.0013)\end{array}$ \\
\hline After & & $\begin{array}{l}-0.0214^{\star \star \star} \\
(0.0063)\end{array}$ & & $\begin{array}{l}-0.0200^{*} \\
(0.0104)\end{array}$ & & $\begin{array}{c}0.0014 \\
(0.0139)\end{array}$ \\
\hline Observations & 318 & 5,257 & 318 & 5,257 & 318 & 5,257 \\
\hline R-squared & 0.9970 & 0.9971 & 0.9926 & 0.9900 & 0.9832 & 0.9730 \\
\hline 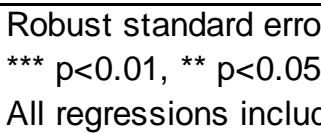 & $\begin{array}{l}\text { clustered b } \\
p<0.1 \\
\text { state, quar }\end{array}$ & $\begin{array}{l}\text { y state in } \\
\text { ter and ye }\end{array}$ & theses & & & \\
\hline
\end{tabular}

Note: The largest increase in potential benefit duration (PBD) is defined, for each state, as the largest increase that does not correspond to a change in the schedule, and is not due to a temporary interruption of EUC. Tightness is defined as vacancies/applications. In columns 2, 4 and 6, I include, for each state, all states that had constant PBD during the event window for the largest increase in PBD. In columns 2, 4 and 6, "After" is an interaction of the event window indicator and a dummy for the date being after the largest increase in PBD. In columns 2, 4 and 6, state by event window fixed effects are included (see text for more details).

Source: Department of Labor, and CareerBuilder.com for applications and vacancies. 
Figure 4: Potential benefit duration (PBD), log applications and log vacancies as a function of the total unemployment rate (Dec. 2008 onwards)
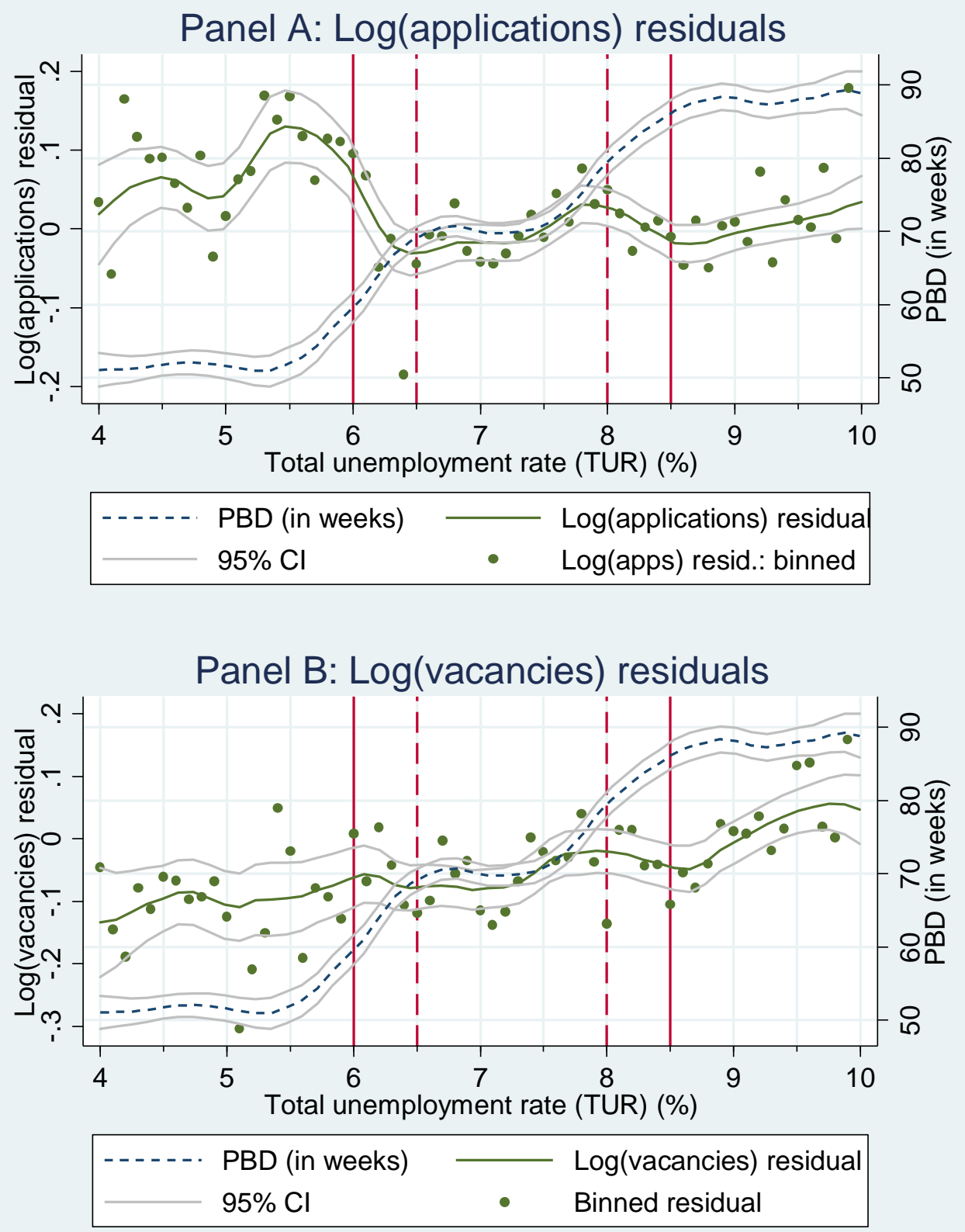

Note: Data is smoothed using kernel-weighted local polynomial smoothing with a 0.2 bandwidth. The applications residual is obtained after regressing log applications on state fixed effects. The total unemployment rate is, for each month and state, the average of the weekly three-months seasonally adjusted unemployment rate. The two solid vertical lines correspond to $6 \%$ TUR (threshold for EUC2 when it was conditional, and for EUC3), and 8.5\% TUR (threshold for EUC4). The two dashed vertical lines correspond to $6.5 \%$ TUR (threshold for 13 weeks extended benefits when the TUR option is active) and $8 \%$ TUR (threshold for 20 weeks extended benefits when the TUR option is active).

Source: Department of Labor, and CareerBuilder.com for applications and vacancies. 
Table 3: The impact of potential unemployment benefit duration on log applications: using the global parametric fuzzy RD design

\begin{tabular}{|c|c|c|c|c|}
\hline & \multicolumn{4}{|c|}{$4 \%<=$ TUR<=10\% } \\
\hline & $(1)$ & $(2)$ & (3) & (4) \\
\hline Total PBD in weeks & $\begin{array}{c}-0.0076^{\star \star \star} \\
(0.0016)\end{array}$ & $\begin{array}{l}-0.0028 \\
(0.0027)\end{array}$ & & \\
\hline EUC PBD in weeks & & & $\begin{array}{c}-0.0090^{\star \star \star} \\
(0.0012)\end{array}$ & $\begin{array}{l}-0.0072^{\star \star} \\
(0.0029)\end{array}$ \\
\hline EB PBD in weeks & & & $\begin{array}{l}-0.0004 \\
(0.0066)\end{array}$ & $\begin{array}{c}0.0032 \\
(0.0073)\end{array}$ \\
\hline $\begin{array}{l}\text { Total Unemployment Rate } \\
\text { (TUR) (\%) }\end{array}$ & $\begin{array}{l}0.0106 \\
(0.0675)\end{array}$ & $\begin{array}{c}0.0314 \\
(0.0613)\end{array}$ & $\begin{array}{l}0.0385 \\
(0.0534)\end{array}$ & $\begin{array}{c}0.0597 \\
(0.0558)\end{array}$ \\
\hline TUR^2 & $\begin{array}{c}0.0014 \\
(0.0039)\end{array}$ & $\begin{array}{l}-0.0006 \\
(0.0032)\end{array}$ & $\begin{array}{l}-0.0021 \\
(0.0031)\end{array}$ & $\begin{array}{l}-0.0032 \\
(0.0033)\end{array}$ \\
\hline $\begin{array}{l}\text { Insured Unemployment Rate } \\
\text { (IUR) (\%) }\end{array}$ & $\begin{array}{l}-0.0564 \\
(0.0415)\end{array}$ & $\begin{array}{l}-0.0113 \\
(0.0426)\end{array}$ & $\begin{array}{l}-0.0368 \\
(0.0416)\end{array}$ & $\begin{array}{c}0.0102 \\
(0.0490)\end{array}$ \\
\hline IUR^2 & $\begin{array}{c}0.0037 \\
(0.0058)\end{array}$ & $\begin{array}{l}-0.0031 \\
(0.0054)\end{array}$ & $\begin{array}{c}0.0004 \\
(0.0061)\end{array}$ & $\begin{array}{l}-0.0060 \\
(0.0064)\end{array}$ \\
\hline Month fixed effects & & $x$ & & $x$ \\
\hline Observations & 1,804 & 1,804 & 1,804 & 1,804 \\
\hline R-squared & 0.9925 & 0.9956 & 0.9929 & 0.9957 \\
\hline $\begin{array}{l}\text { Robust standard errors cluste } \\
\star \star * * \\
\text { All regressions include state, }\end{array}$ & $\begin{array}{l}\mathrm{d} \text { by state } \mathrm{i} \\
\text { ear and qua }\end{array}$ & $\begin{array}{l}\text { rentheses } \\
\text { ixed effect }\end{array}$ & & \\
\hline
\end{tabular}

Note: Instrumental variables regressions, where PBD is the endogenous variable. The instrument for Total PBD in weeks is PBD according to statutory rules, not taking into account temporary EUC expirations, and assuming that all states take up the TUR option. In col. 3-4, EB PBD is instrumented with EB PBD according to rules and assuming that all states have elected the TUR option, and EUC PBD is instrumented with the EUC PBD according to rules and ignoring temporary EUC lapses. The sample includes any observation for which TUR is between $4 \%$ and $10 \%$.

Source: Department of Labor, and CareerBuilder.com for vacancies. 
Table 4: The impact of potential unemployment benefit duration on log vacancies and log tightness: using the global parametric fuzzy RD design

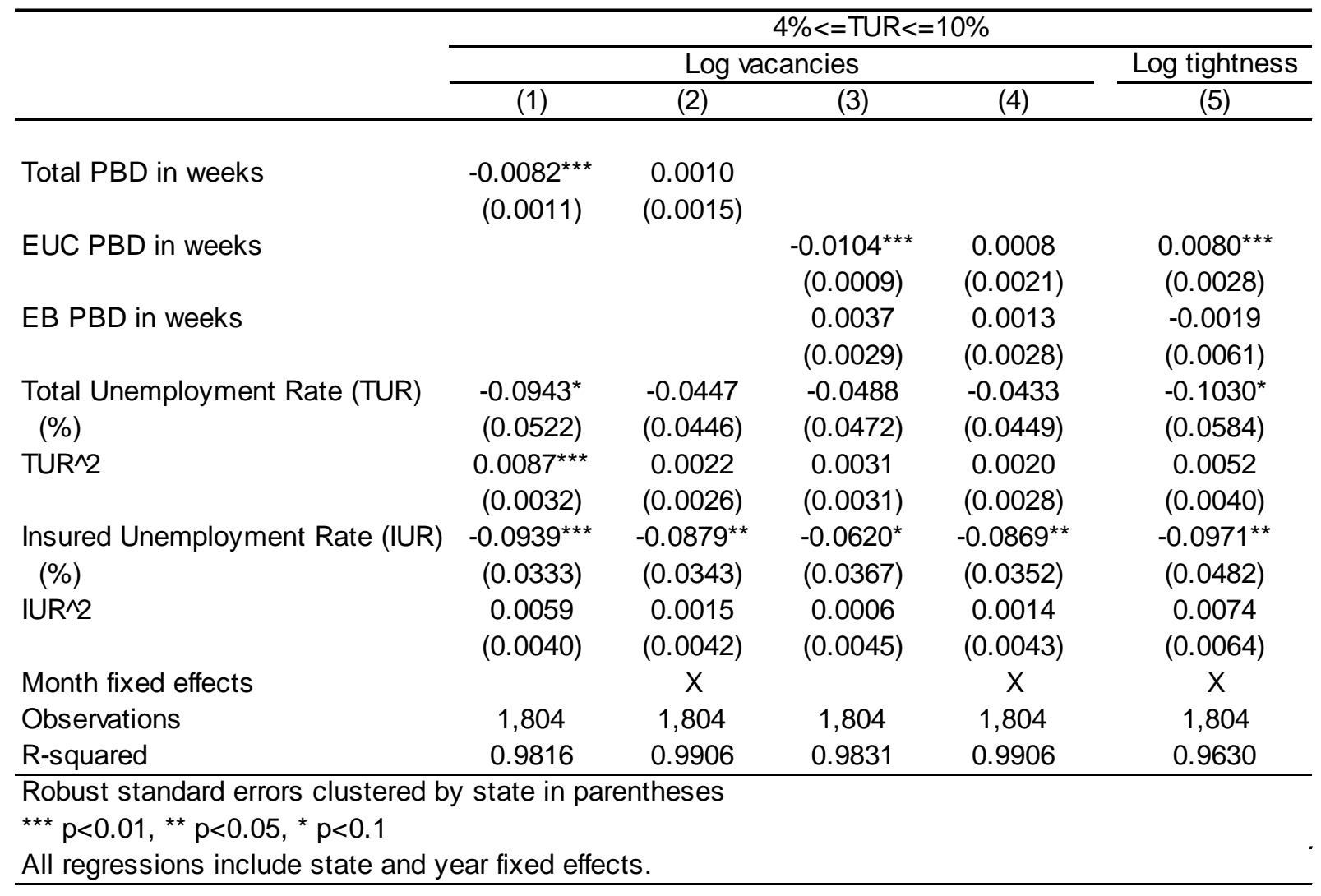

Note: Instrumental variables regressions, where PBD is the endogenous variable. The instrument for Total PBD in weeks is PBD according to statutory rules, not taking into account temporary EUC expirations, and assuming that all states take up the TUR option. In col. 3-5, EB PBD is instrumented with EB PBD according to rules and assuming that all states have elected the TUR option, and EUC PBD is instrumented with the EUC PBD according to rules and ignoring temporary EUC lapses. Tightness is defined as vacancies/applications. The sample includes any observation for which TUR is between $4 \%$ and $10 \%$.

Source: Department of Labor, and CareerBuilder.com for applications and vacancies. 
Table 5: The impact of potential unemployment benefit duration on log applications and log tightness using the global parametric fuzzy RD design: robustness

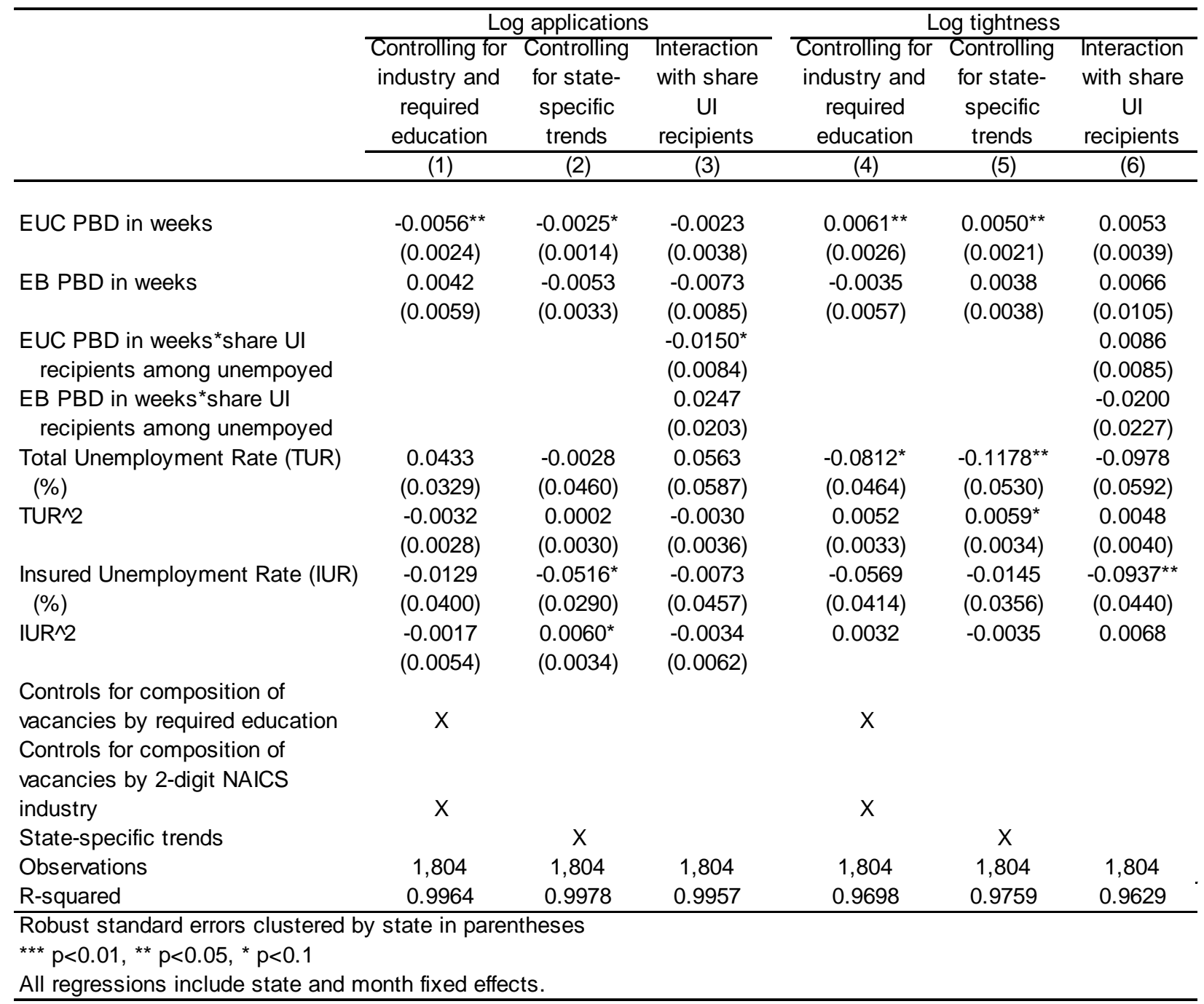

Note: Instrumental variables regressions, where PBD is the endogenous variable. EB PBD is instrumented with EB PBD according to rules and assuming that all states have elected the TUR option, and EUC PBD is instrumented with the EUC PBD according to rules and ignoring temporary EUC lapses. Tightness is defined as vacancies/applications. The sample includes any observation for which TUR is between $4 \%$ and $10 \%$. The specification is the same as in Table 3 , column 4 . In columns 1 and 4 , controls are included for the share of vacancies in each education category (see summary statistics Table 1), and for the share of vacancies in each 2-digit NAICS code. In columns 3 and 6, the share of UI recipients is, for each state, the average share of UI recipients among all unemployed between December 2008 and the end of the sample; the share of UI recipients (not interacted with PBD) is controlled for in the regression.

Source: Department of Labor, and CareerBuilder.com for applications and vacancies. 
Table 6: The impact of potential unemployment benefit duration on applications per view and on posted wages, using the global parametric fuzzy RD design

\begin{tabular}{|c|c|c|c|c|c|c|}
\hline & $\begin{array}{c}\text { Applications } \\
\text { per view } \\
(1) \\
\end{array}$ & $\begin{array}{c}\begin{array}{c}\text { Log real } \\
\text { posted wage }\end{array} \\
(2) \\
\end{array}$ & $\begin{array}{c}\text { Posted } \\
\text { wage }>=50000 \\
(3) \\
\end{array}$ & $\begin{array}{c}\text { Posted } \\
\text { wage }<=30000 \\
(4) \\
\end{array}$ & $\begin{array}{c}\text { Posted } \\
\text { wage }>=100000 \\
(5) \\
\end{array}$ & $\begin{array}{c}\begin{array}{c}\text { Share with } \\
\text { posted wage }\end{array} \\
(6) \\
\end{array}$ \\
\hline EUC PBD in weeks & $\begin{array}{l}-0.0013 \\
(0.0013)\end{array}$ & $\begin{array}{l}-0.0005 \\
(0.0030)\end{array}$ & $\begin{array}{l}-0.0010 \\
(0.0018)\end{array}$ & $\begin{array}{l}0.0010 \\
(0.0013)\end{array}$ & $\begin{array}{c}0.0007 \\
(0.0009)\end{array}$ & $\begin{array}{c}0.0008 \\
(0.0005)\end{array}$ \\
\hline EB PBD in weeks & $\begin{array}{c}0.0011 \\
(0.0026)\end{array}$ & $\begin{array}{l}0.0018 \\
(0.0025)\end{array}$ & $\begin{array}{c}0.0004 \\
(0.0017)\end{array}$ & $\begin{array}{l}-0.0011 \\
(0.0014)\end{array}$ & $\begin{array}{l}0.0004 \\
(0.0010)\end{array}$ & $\begin{array}{l}-0.0012^{*} \\
(0.0007)\end{array}$ \\
\hline $\begin{array}{l}\text { Total Unemployment Rate } \\
\text { (TUR) (\%) }\end{array}$ & $\begin{array}{c}0.0042 \\
(0.0292)\end{array}$ & $\begin{array}{l}-0.0078 \\
(0.0400)\end{array}$ & $\begin{array}{c}0.0128 \\
(0.0258)\end{array}$ & $\begin{array}{c}0.0070 \\
(0.0165)\end{array}$ & $\begin{array}{l}-0.0078 \\
(0.0143)\end{array}$ & $\begin{array}{l}-0.0002 \\
(0.0098)\end{array}$ \\
\hline TUR^2 & $\begin{array}{c}0.0008 \\
(0.0022)\end{array}$ & $\begin{array}{c}0.0004 \\
(0.0026)\end{array}$ & $\begin{array}{c}0.0000 \\
(0.0015)\end{array}$ & $\begin{array}{l}-0.0004 \\
(0.0010)\end{array}$ & $\begin{array}{c}0.0003 \\
(0.0010)\end{array}$ & $\begin{array}{c}0.0002 \\
(0.0007)\end{array}$ \\
\hline $\begin{array}{l}\text { Insured Unemployment Rate } \\
\text { (IUR) (\%) }\end{array}$ & $\begin{array}{l}0.0528 * \star \star \\
(0.0182)\end{array}$ & $\begin{array}{l}0.0840^{\star * *} \\
(0.0269)\end{array}$ & $\begin{array}{l}0.0504^{\star \star *} \\
(0.0172)\end{array}$ & $\begin{array}{l}-0.0491^{\star * \star} \\
(0.0145)\end{array}$ & $\begin{array}{c}0.0136 \\
(0.0099)\end{array}$ & $\begin{array}{l}-0.0152 \\
(0.0110)\end{array}$ \\
\hline IUR^2 & $\begin{array}{c}-0.0058^{\star * \star} \\
(0.0022)\end{array}$ & $\begin{array}{l}-0.0092^{\star \star \star} \\
(0.0031)\end{array}$ & $\begin{array}{c}-0.0064^{\star * *} \\
(0.0022)\end{array}$ & $\begin{array}{c}0.0053^{\star \star *} \\
(0.0017)\end{array}$ & $\begin{array}{l}-0.0022^{\star *} \\
(0.0011)\end{array}$ & $\begin{array}{c}0.0010 \\
(0.0013)\end{array}$ \\
\hline $\begin{array}{l}\text { Observations } \\
\text { R-squared }\end{array}$ & $\begin{array}{c}1,804 \\
0.9068\end{array}$ & $\begin{array}{c}1,804 \\
0.7859\end{array}$ & $\begin{array}{c}1,804 \\
0.7244\end{array}$ & $\begin{array}{c}1,804 \\
0.7634\end{array}$ & $\begin{array}{c}1,804 \\
0.7316\end{array}$ & $\begin{array}{c}1,804 \\
0.7954\end{array}$ \\
\hline $\begin{array}{l}\text { Robust standard errors clus } \\
\star \star \star \\
p<0.01,{ }^{* \star} p<0.05,{ }^{*} p<0 \\
\text { All regressions include stat }\end{array}$ & by state & $\begin{array}{l}\text { rentheses } \\
\text { fects. }\end{array}$ & & & & \\
\hline
\end{tabular}

Note: Instrumental variables regressions, where PBD is the endogenous variable. EB PBD is instrumented with EB PBD according to rules and assuming that all states have elected the TUR option, and EUC PBD is instrumented with the EUC PBD according to rules and ignoring temporary EUC lapses. The sample includes any observation for which TUR is between $4 \%$ and $10 \%$. In columns 3-5, the dependent variable is the share of vacancies that have a posted wage respectively above $\$ 50000$, below $\$ 30000$ and above $\$ 100000$; the denominator for the share is all vacancies with a posted wage.

Source: Department of Labor, and CareerBuilder.com for applications and vacancies. 
Table 7: The impact of PBD on log applications, log vacancies and log tightness: within county pair specification, and panel specification with spillover effects

\begin{tabular}{|c|c|c|c|c|c|c|}
\hline & \multicolumn{3}{|c|}{ Within county pair differences } & \multicolumn{3}{|c|}{ Smaller county panel } \\
\hline & d.Log apps & d.Log jobs & d.Log tight & Log apps & Log jobs & Log tight \\
\hline & (1) & (2) & (3) & (4) & (5) & (6) \\
\hline \multirow[t]{2}{*}{ d.EUC PBD in weeks } & 0.0001 & -0.0012 & -0.0016 & & & \\
\hline & $(0.0031)$ & $(0.0028)$ & $(0.0028)$ & & & \\
\hline \multirow[t]{2}{*}{ d.EB PBD in weeks } & 0.0016 & 0.0007 & -0.0008 & & & \\
\hline & $(0.0015)$ & $(0.0012)$ & $(0.0018)$ & & & \\
\hline \multirow[t]{2}{*}{ EUC PBD in weeks } & & & & 0.0004 & -0.0006 & -0.0010 \\
\hline & & & & $(0.0019)$ & $(0.0020)$ & $(0.0024)$ \\
\hline \multirow[t]{2}{*}{ EB PBD in weeks } & & & & -0.0007 & -0.0015 & -0.0007 \\
\hline & & & & $(0.0011)$ & $(0.0020)$ & $(0.0018)$ \\
\hline \multirow{2}{*}{$\begin{array}{l}\text { EUC PBD in weeks } \\
\text { in larger paired county }\end{array}$} & & & & $-0.0047^{\star *}$ & 0.0003 & $0.0053^{\star \star \star}$ \\
\hline & & & & $(0.0021)$ & $(0.0020)$ & $(0.0017)$ \\
\hline \multirow{2}{*}{$\begin{array}{l}\text { EB PBD in weeks } \\
\text { in larger paired county }\end{array}$} & & & & -0.0006 & -0.0010 & -0.0003 \\
\hline & & & & $(0.0015)$ & $(0.0016)$ & $(0.0014)$ \\
\hline Observations & 36,771 & 40,716 & 36,771 & 39,225 & 43,024 & 39,225 \\
\hline R-squared & 0.9516 & 0.9624 & 0.6342 & 0.9682 & 0.9776 & 0.7426 \\
\hline \multicolumn{7}{|c|}{ 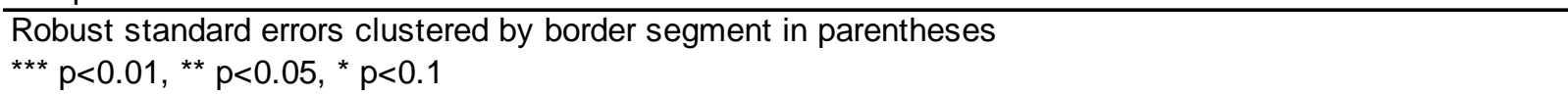 } \\
\hline All regressions include co & unty pair ar & onth fixe & & & & \\
\hline
\end{tabular}

Note: The sample is composed of county pairs straddling state borders. A border segment is the set of all counties along a given state border. Tight in columns 3 and 6 refers to tightness, which is defined as vacancies/applications. In columns 1-3, outcomes are defined as the difference within a given county pair for each month, and the explanatory variables are defined in the same way. In columns 4-6, only the smaller (in terms of population) county in each county pair in the sample is retained.

Observations are weighed by the total population in the two counties of the county pair (col. 1-3), or in the county (col. 4-6).

Source: Department of Labor, and CareerBuilder.com for applications and vacancies. 
ONLINE APPENDIX: not for publication

\section{APPENDIX 1: further results and robustness tests}

Table 8: Date of largest increase in PBD and amount of the increase for each state

\begin{tabular}{|c|c|c|c|c|c|}
\hline state & date & PBD increase & state & date & PBD increase \\
\hline AK & $2009 \mathrm{~m} 2$ & 13 & MT & $2009 \mathrm{~m} 3$ & 22.75 \\
\hline$A L$ & $2009 m 9$ & 20 & NC & $2011 \mathrm{~m} 7$ & 20 \\
\hline $\mathrm{AR}$ & $2009 \mathrm{~m} 5$ & 13 & ND & $2011 \mathrm{~m} 7$ & 0 \\
\hline$A Z$ & $2009 m 5$ & 13 & NE & $2011 \mathrm{~m} 7$ & 0 \\
\hline CA & $2009 m 5$ & 20 & $\mathrm{NH}$ & $2009 m 8$ & 13 \\
\hline $\mathrm{CO}$ & $2009 m 6$ & 15.6 & $\mathrm{NJ}$ & $2009 m 4$ & 14.4 \\
\hline CT & $2009 \mathrm{~m} 3$ & 13 & NM & $2009 \mathrm{~m} 10$ & 13 \\
\hline DC & $2009 m 5$ & 20 & NV & $2009 \mathrm{~m} 3$ & 13 \\
\hline $\mathrm{DE}$ & $2009 m 8$ & 16.75 & NY & $2009 m 6$ & 13 \\
\hline $\mathrm{FL}$ & $2009 \mathrm{~m} 7$ & 20 & $\mathrm{OH}$ & $2009 \mathrm{~m} 5$ & 20 \\
\hline GA & $2009 m 6$ & 20 & OK & $2009 m 8$ & 13 \\
\hline $\mathrm{HI}$ & $2009 m 5$ & 13 & OR & $2009 \mathrm{~m} 3$ & 7 \\
\hline IA & $2009 \mathrm{~m} 10$ & 13 & PA & $2009 \mathrm{~m} 2$ & 22.75 \\
\hline ID & $2009 \mathrm{~m} 2$ & 26 & $\mathrm{RI}$ & $2008 m 11$ & 7 \\
\hline IL & $2009 m 5$ & 13 & $\mathrm{SC}$ & $2009 m 4$ & 13 \\
\hline IN & $2009 m 4$ & 13 & SD & $2011 \mathrm{~m} 7$ & 0 \\
\hline KS & $2009 \mathrm{~m} 7$ & 26 & $\mathrm{TN}$ & $2011 \mathrm{~m} 7$ & 20 \\
\hline $\mathrm{KY}$ & $2009 \mathrm{~m} 5$ & 20 & $\mathrm{TX}$ & $2009 m 8$ & 13 \\
\hline LA & $2009 m 8$ & 13 & UT & $2011 \mathrm{~m} 7$ & 0 \\
\hline MA & $2009 m 3$ & 19.5 & VA & $2009 m 5$ & 26 \\
\hline $\mathrm{MD}$ & $2009 m 5$ & 13 & VT & $2009 \mathrm{~m} 3$ & 19.5 \\
\hline ME & $2009 m 5$ & 13 & WA & $2009 \mathrm{~m} 3$ & 13 \\
\hline Ml & $2009 m 2$ & 13 & WI & $2009 \mathrm{~m} 3$ & 20.8 \\
\hline $\mathrm{MN}$ & $2009 \mathrm{~m} 4$ & 13 & WV & $2009 \mathrm{~m} 9$ & 20 \\
\hline $\mathrm{MO}$ & $2010 \mathrm{~m} 3$ & 20 & WY & $2010 \mathrm{~m} 2$ & 13 \\
\hline MS & $2011 \mathrm{~m} 7$ & 0 & & & \\
\hline
\end{tabular}

Note: The largest increase in PBD is defined, for each state, as the largest increase that does not correspond to a change in the schedule, and is not due to a temporary interruption of EUC.

Source: Department of Labor 
Figure 5: The evolution of applications and vacancies around lapses in EUC
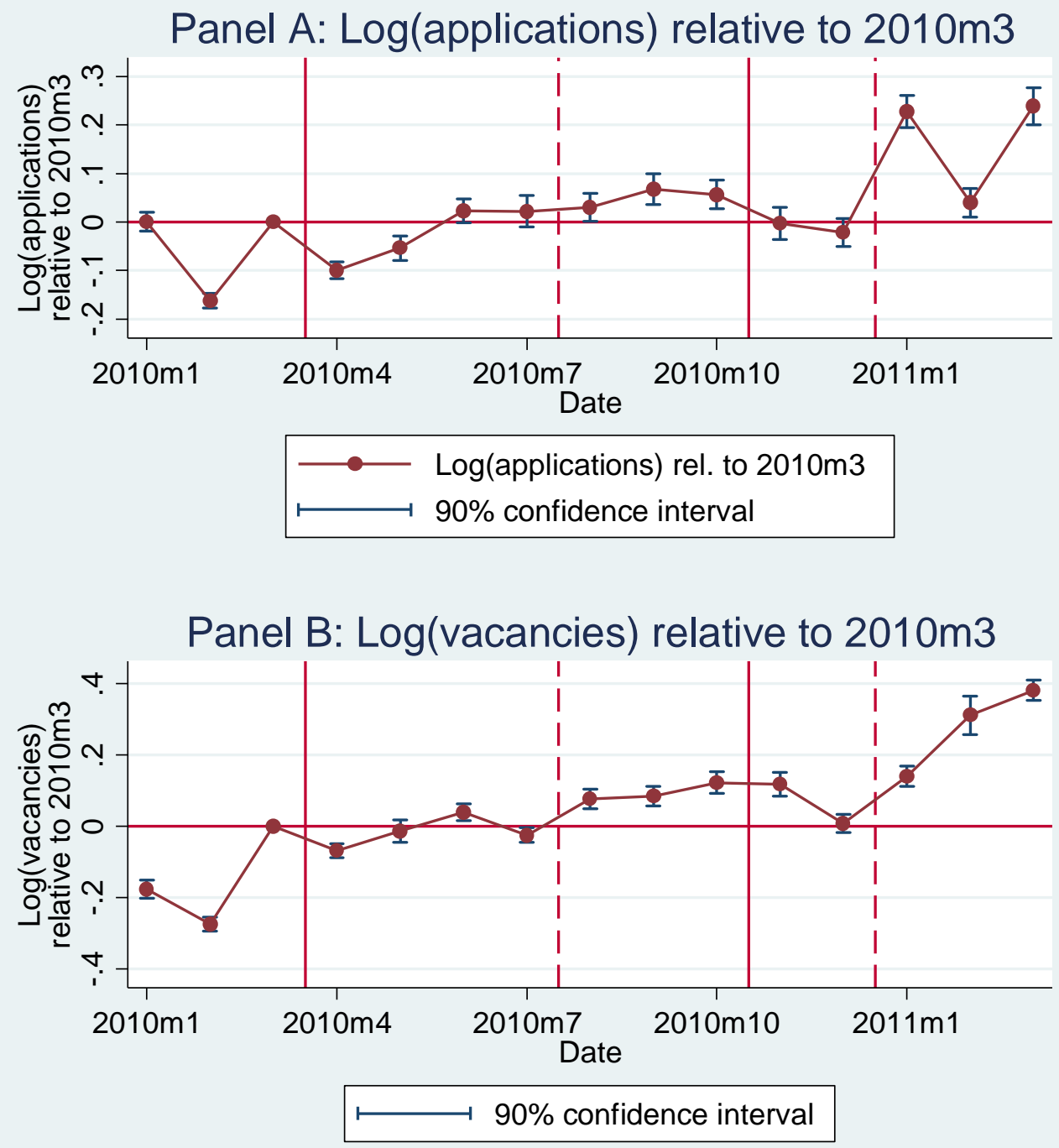

Note: The estimates for applications and vacancies are from a regression of the outcome on month dummies, and state fixed effects. Standard errors are clustered by state. A month is counted as having a EUC lapse if the lapse is ongoing for any week of the month. The plain vertical lines mark the beginning of a lapse in EUC, while the dashed vertical lines mark the end of the lapse in EUC.

Source: Department of Labor, and CareerBuilder.com for applications and vacancies. 
Figure 6: Timing of events: number of states used for estimation and PBD around the largest increase in PBD for each state

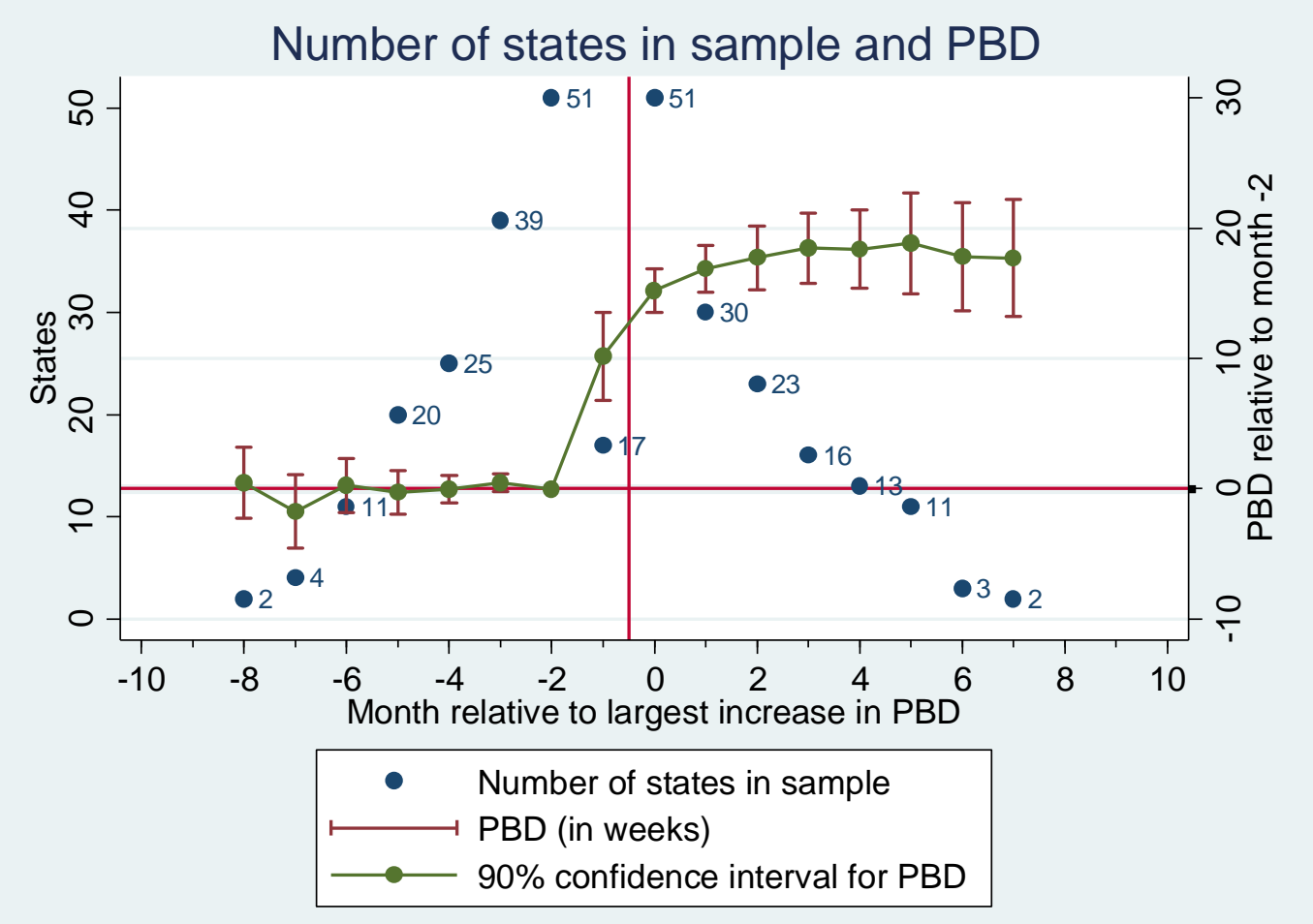

Note: The estimates for PBD are from a regression of PBD on relative month dummies, state, year and quarter of the year fixed effects. Standard errors are clustered by state. The largest increase in PBD is defined, for each state, as the largest increase that does not correspond to a change in the schedule, and is not due to a temporary interruption of EUC.

Source: Department of Labor, and CareerBuilder.com for applications and vacancies. 
Figure 7: The impact of potential unemployment benefit duration on log applications and log vacancies, timing of events, balanced panel
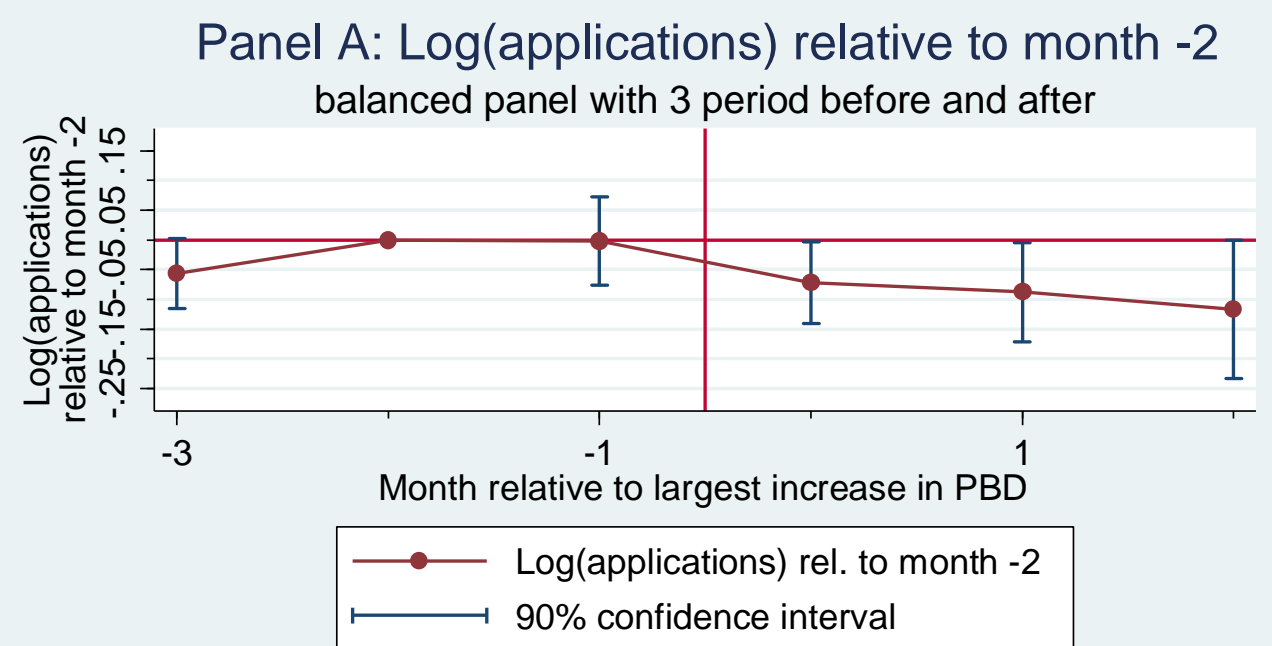

\section{Panel B: Log(vacancies) relative to month -2} balanced panel with 3 period before and after

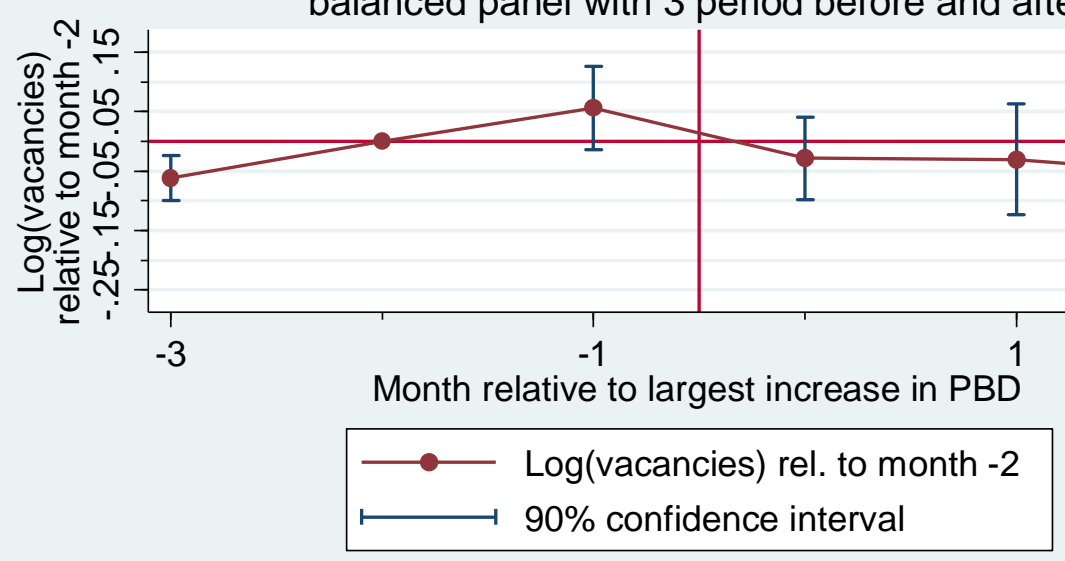

Note: The estimates are from a regression of log vacancies (Panel A) or log applications (Panel B) on relative month dummies, state, year and quarter of the year fixed effects. Standard errors are clustered by state. The sample consists of 18 states that have a constant PBD 3 months before and after the largest increase in PBD. The largest increase in PBD is defined, for each state, as the largest increase that does not correspond to a change in the schedule, and is not due to a temporary interruption of EUC.

Source: Department of Labor, and CareerBuilder.com for applications and vacancies. 
Figure 8: The impact of potential unemployment benefit duration on log applications and log vacancies, timing of events, treated vs. control group
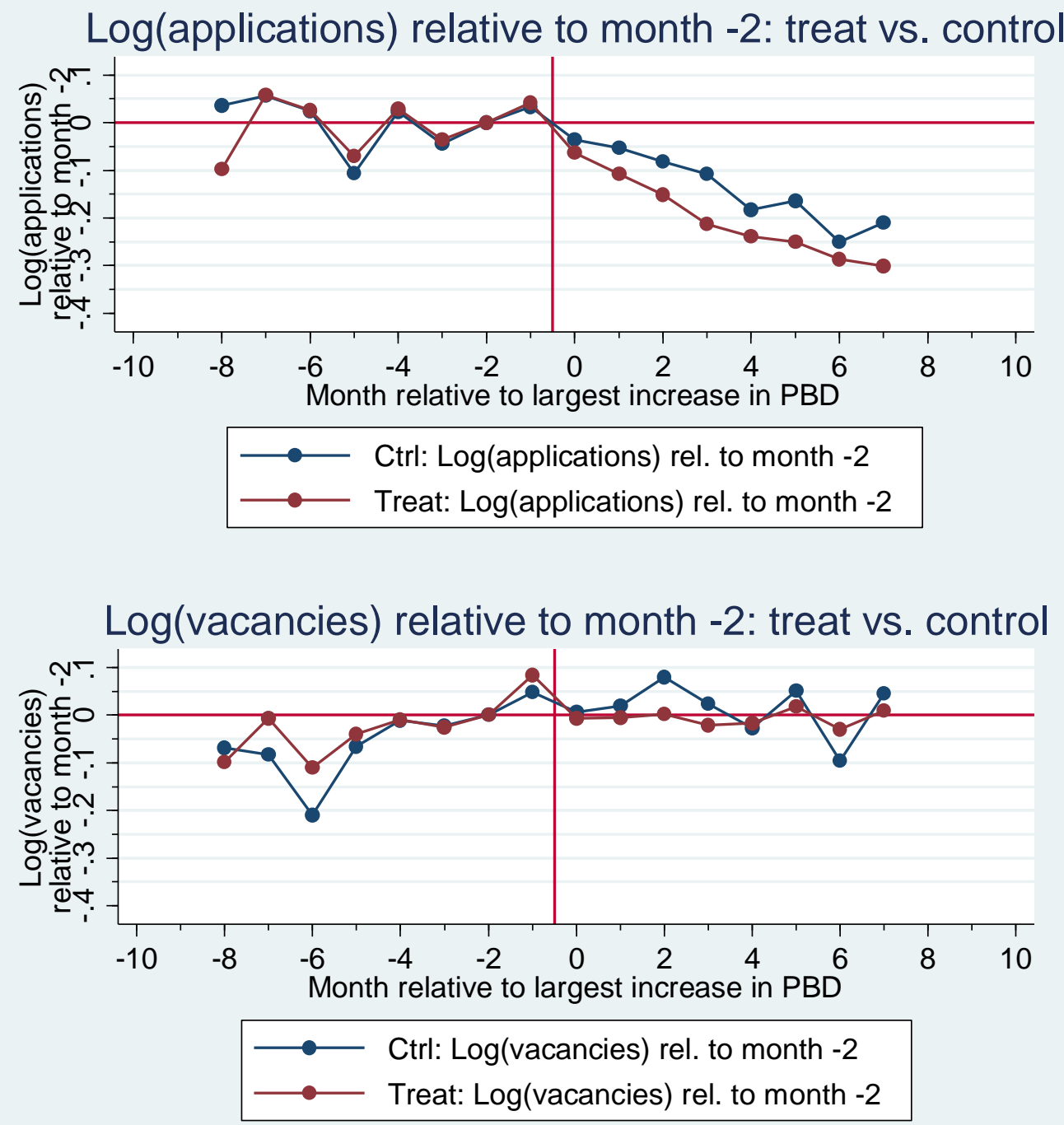

Note: The estimates are from a regression of log vacancies (Panel A) or log applications (Panel B) on relative month dummies, state, year and quarter of the year fixed effects. Standard errors are clustered by state. There are 318 observations. The largest increase in PBD is defined, for each state, as the largest increase that does not correspond to a change in the schedule, and is not due to a temporary interruption of EUC.

Source: Department of Labor, and CareerBuilder.com for applications and vacancies. 
Figure 9: The impact of potential unemployment benefit duration on log tightness, timing of events

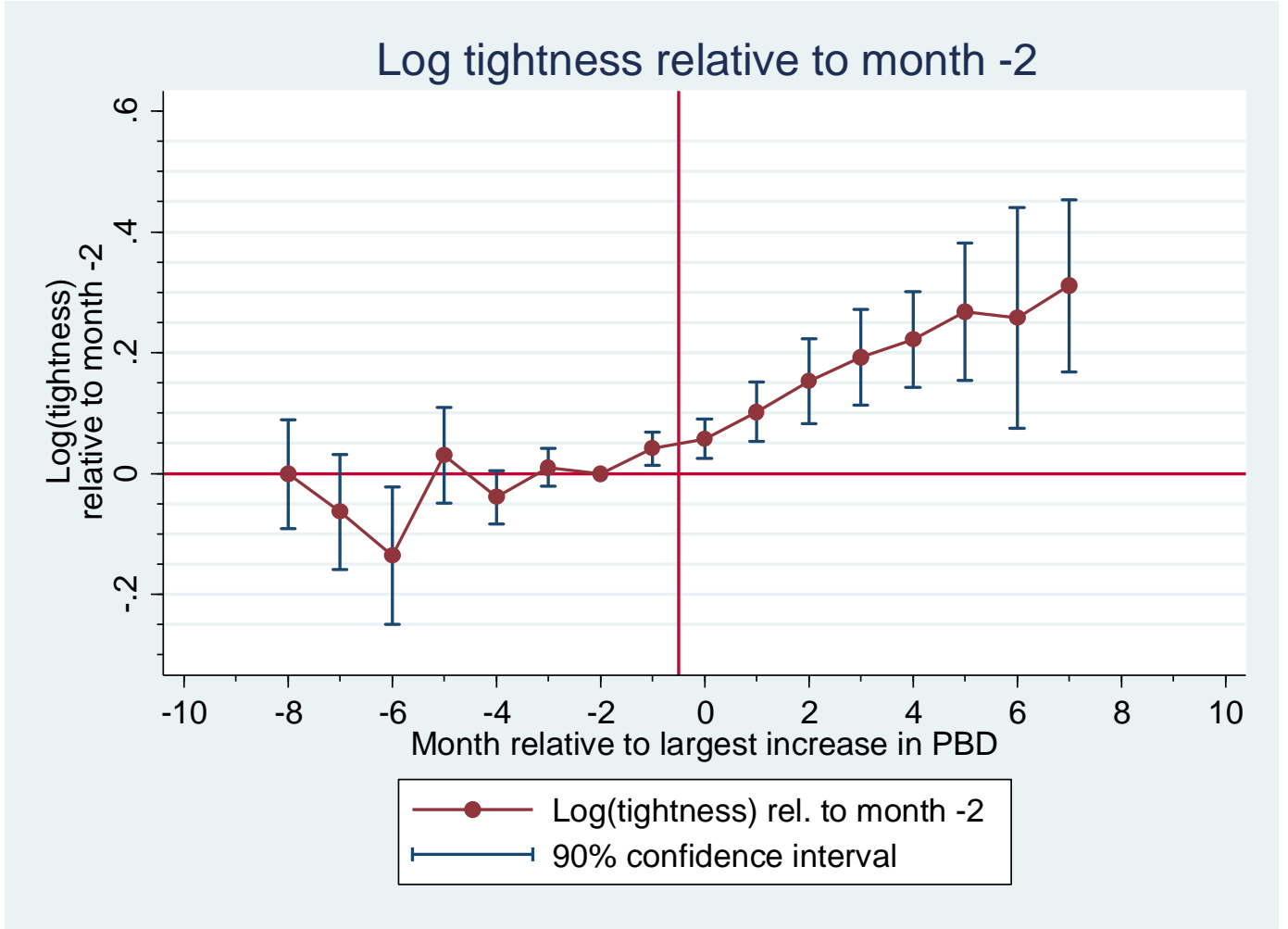

Note: The estimates are from a regression of log tightness (i.e. log vacancies-log applications) on relative month dummies, state, year and quarter of the year fixed effects. Standard errors are clustered by state. There are 318 observations. The largest increase in PBD is defined, for each state, as the largest increase that does not correspond to a change in the schedule, and is not due to a temporary interruption of EUC.

Source: Department of Labor, and CareerBuilder.com for applications and vacancies. 
Table 9: The impact of the largest increase in potential benefit duration (PBD) on log applications log vacancies, and labor market tightness, timing of events regressions, robustness to month fixed effects

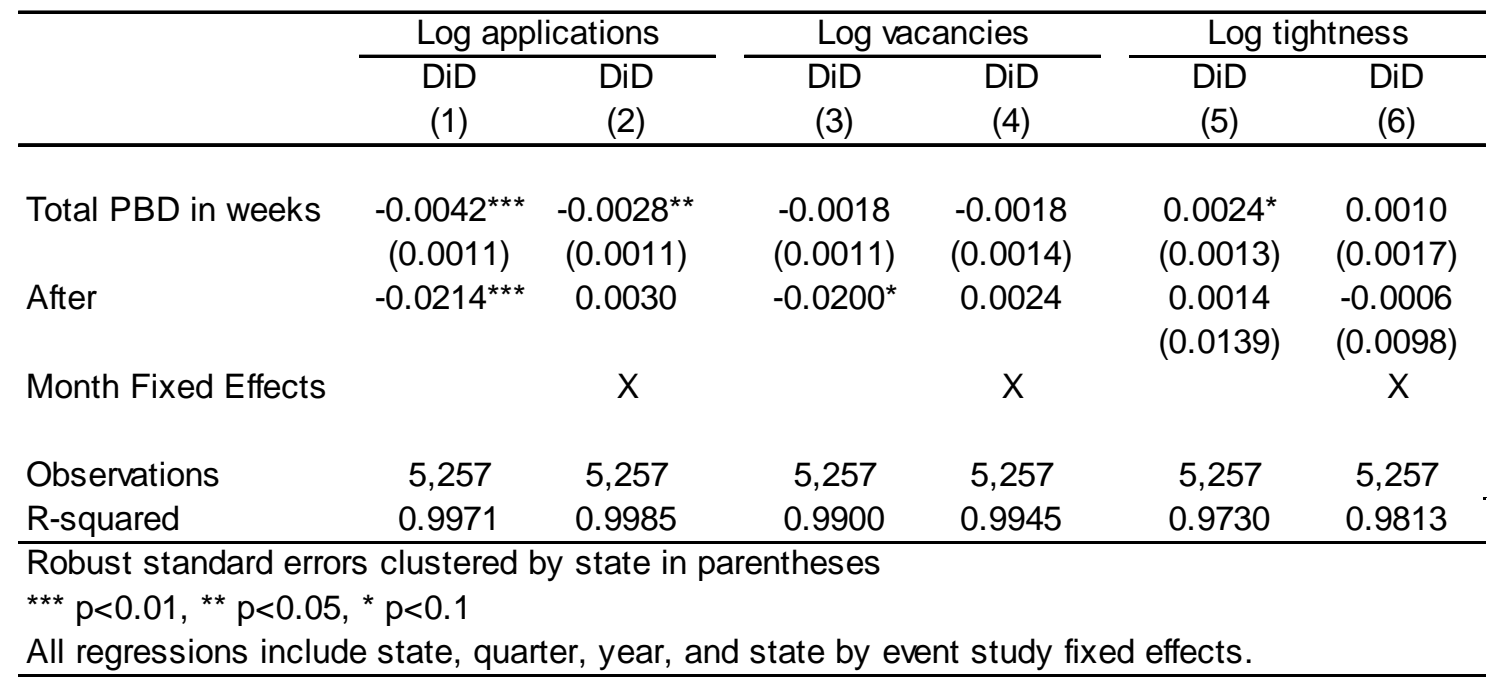

Note: The largest increase in potential benefit duration (PBD) is defined, for each state, as the largest increase that does not correspond to a change in the schedule, and is not due to a temporary interruption of EUC. I include, for each state, all states that had constant PBD during the event window for the largest increase in PBD. "After" is an interaction of the event window indicator and a dummy for the date being after the largest increase in PBD. See text for more details. Tightness is defined as vacancies/applications.

Source: Department of Labor, and CareerBuilder.com for applications and vacancies. 


\section{APPENDIX 1}

Table 10: : The impact increases in potential benefit duration (PBD) on log applications, log vacancies, and labor market tightness, timing of events regressions, robustness to alternative definitions of the event

\begin{tabular}{|c|c|c|c|c|c|c|}
\hline & \multicolumn{3}{|c|}{ More than 10 weeks PBD increase } & \multicolumn{3}{|c|}{ Less than 10 weeks PBD increase } \\
\hline & Log applications & Log vacancies & Log tightness & Log applications & Log vacancies & Log tightness \\
\hline & $(1)$ & $(2)$ & (3) & (4) & $(5)$ & (6) \\
\hline \multirow[t]{2}{*}{ Total PBD in weeks } & $-0.0030^{\star \star}$ & -0.0016 & 0.0014 & -0.0051 & -0.0012 & 0.0040 \\
\hline & $(0.0012)$ & $(0.0014)$ & $(0.0014)$ & $(0.0035)$ & $(0.0045)$ & (0.0033) \\
\hline \multirow[t]{2}{*}{ After } & -0.0007 & $0.0228^{\star \star}$ & $0.0235^{\star \star}$ & $-0.0389^{\star \star \star \star}$ & $-0.0434^{\star \star \star}$ & -0.0045 \\
\hline & $(0.0053)$ & $(0.0094)$ & $(0.0109)$ & $(0.0070)$ & $(0.0097)$ & $(0.0070)$ \\
\hline Observations & 4,116 & 4,116 & 4,116 & 4,704 & 4,704 & 4,704 \\
\hline R-squared & 0.9976 & 0.9901 & 0.9786 & 0.9974 & 0.9908 & 0.9765 \\
\hline \multicolumn{7}{|c|}{ 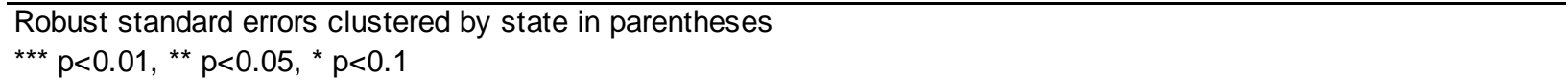 } \\
\hline All regressions inclu & de state, quarter & and year fix & ects. & & & \\
\hline
\end{tabular}

Note: Difference-in-differences specifications. In col. 1-3, the event is, for each state, the last increase in potential benefit duration (PBD) of 10 weeks or more that does not correspond to a change in the schedule, and is not due to a temporary interruption of EUC. In col. 4-6, the event is, for each state, the last increase in potential benefit duration (PBD) of less than 10 weeks that does not correspond to a change in the schedule, and is not due to a temporary interruption of EUC. I include, for each state, all states that had constant PBD during the event window. "After" is an interaction of the event window indicator and a dummy for the date being after the largest increase in PBD. Tightness is defined as vacancies/applications. See text for more details.

Source: Department of Labor, and CareerBuilder.com for applications and vacancies. 
Figure 10: Potential unemployment benefit duration and applications residuals as a function of the total unemployment rate (before Dec. 2008)

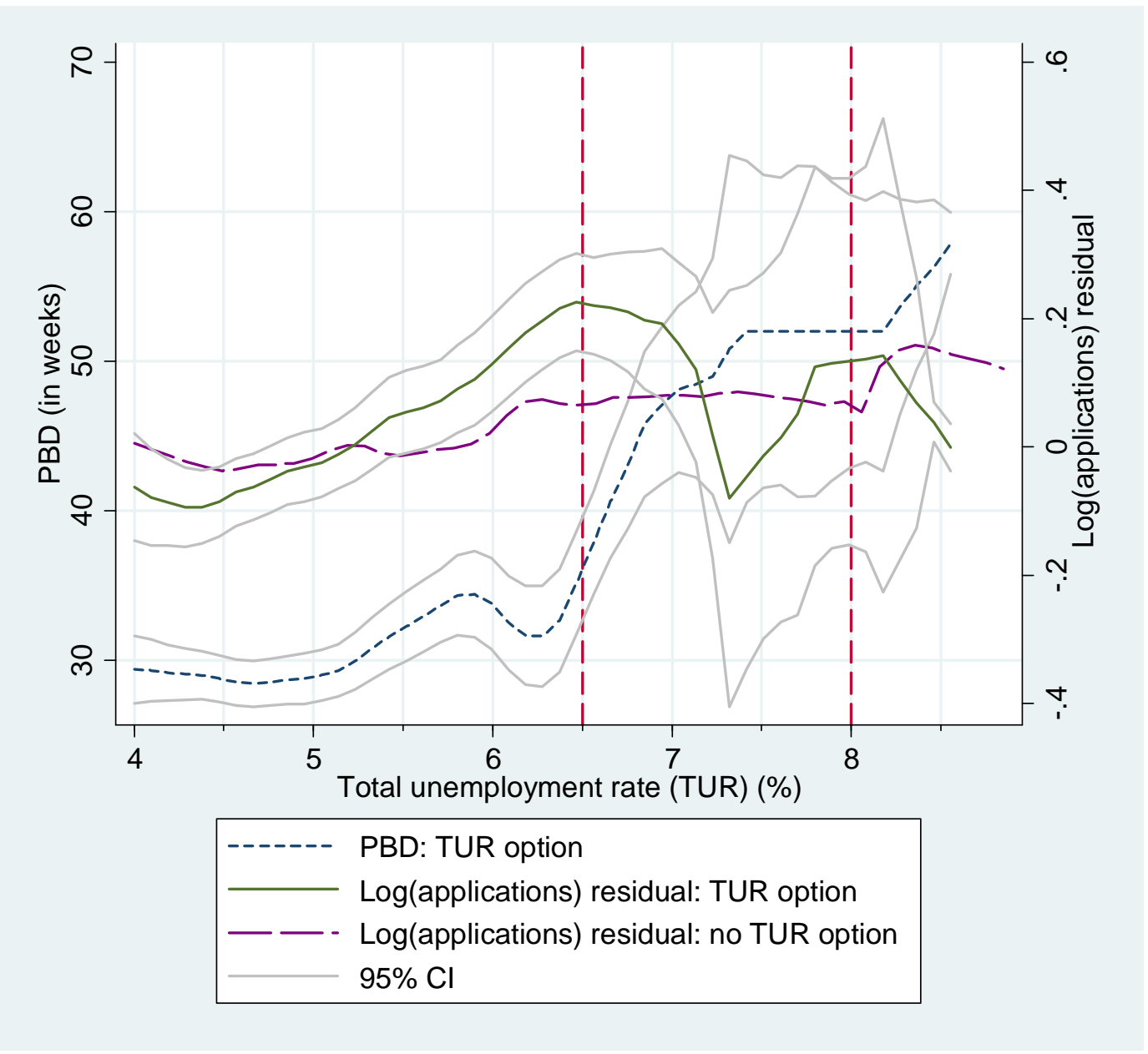

Note: Data is smoothed using kernel-weighted local polynomial smoothing with a 0.2 bandwidth. States that had a TUR option before Dec. 2008 are the following: Alaska, Connecticut, Kansas, New Hampshire, New Jersey, New Mexico, North Carolina, Oregon, Rhode Island, Vermont, Washington. The applications residual is obtained after regressing log applications on state fixed effects. The total unemployment rate is, for each month and state, the average of the weekly three-months seasonally adjusted unemployment rate. The two dashed vertical lines correspond to 6.5\% TUR (threshold for 13 weeks extended benefits when the TUR option is active) and $8 \%$ TUR (threshold for 20 weeks extended benefits when the TUR option is active).

Source: Department of Labor, and CareerBuilder.com for applications. 
Figure 11: Potential unemployment benefit duration and applications residuals as a function of the insured unemployment rate (Dec. 2008 onwards)
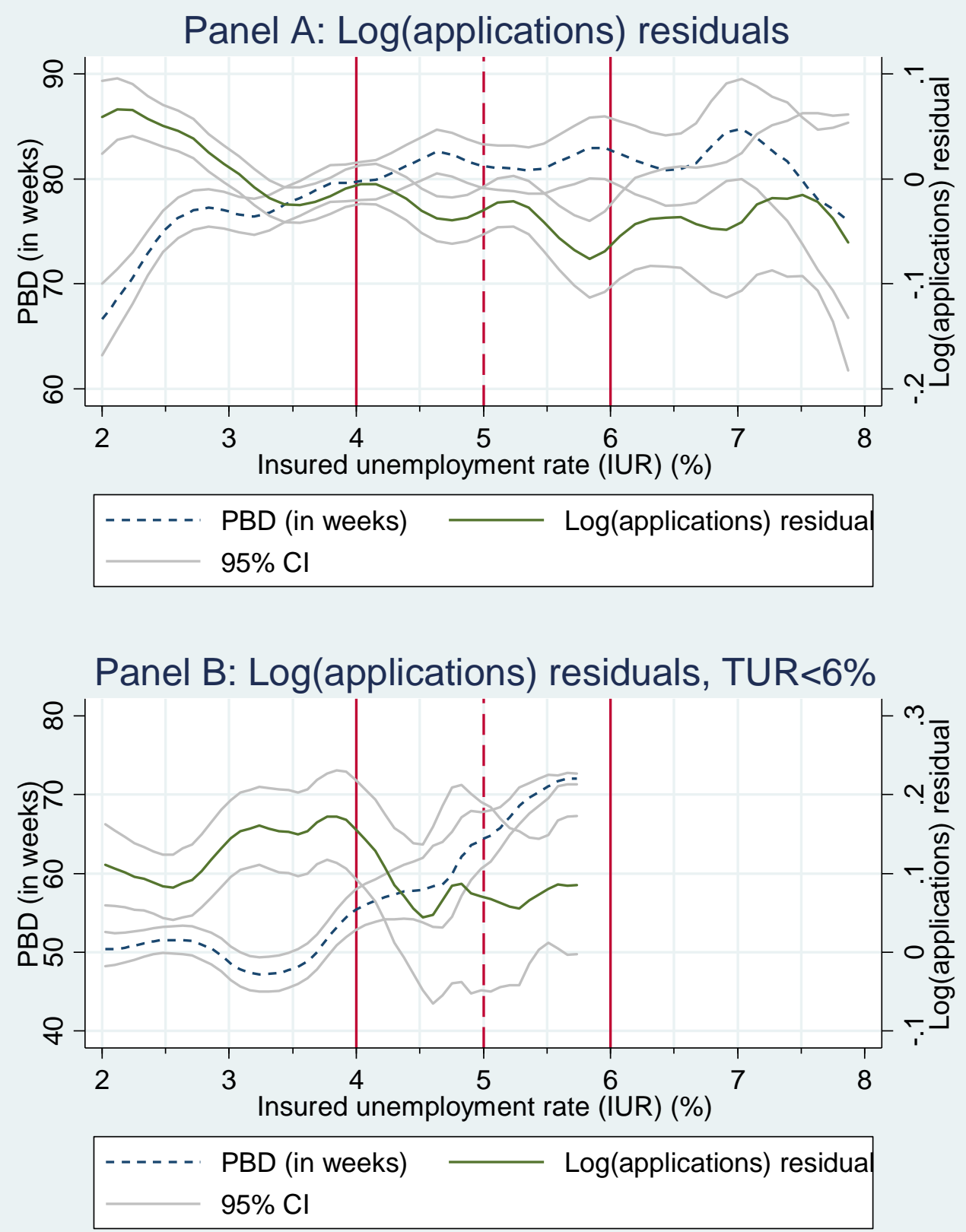

Note: Data is smoothed using kernel-weighted local polynomial smoothing with a 0.2 bandwidth. The applications residual is obtained after regressing log applications on state fixed effects. The two solid vertical lines correspond to $4 \%$ IUR (threshold for EUC), and 6\% IUR (threshold for EUC). The dashed vertical line corresponds to 5\% IUR (threshold for EB). In Panel B, the data is restricted to monthly TUR<6\% so that TUR conditions are unlikely to trigger higher PBD.

Source: Department of Labor, and CareerBuilder.com for applications and vacancies. 
Figure 12: Potential benefit duration (PBD) and applications per CPS unemployed as a function of the total unemployment rate (Dec. 2008 onwards)

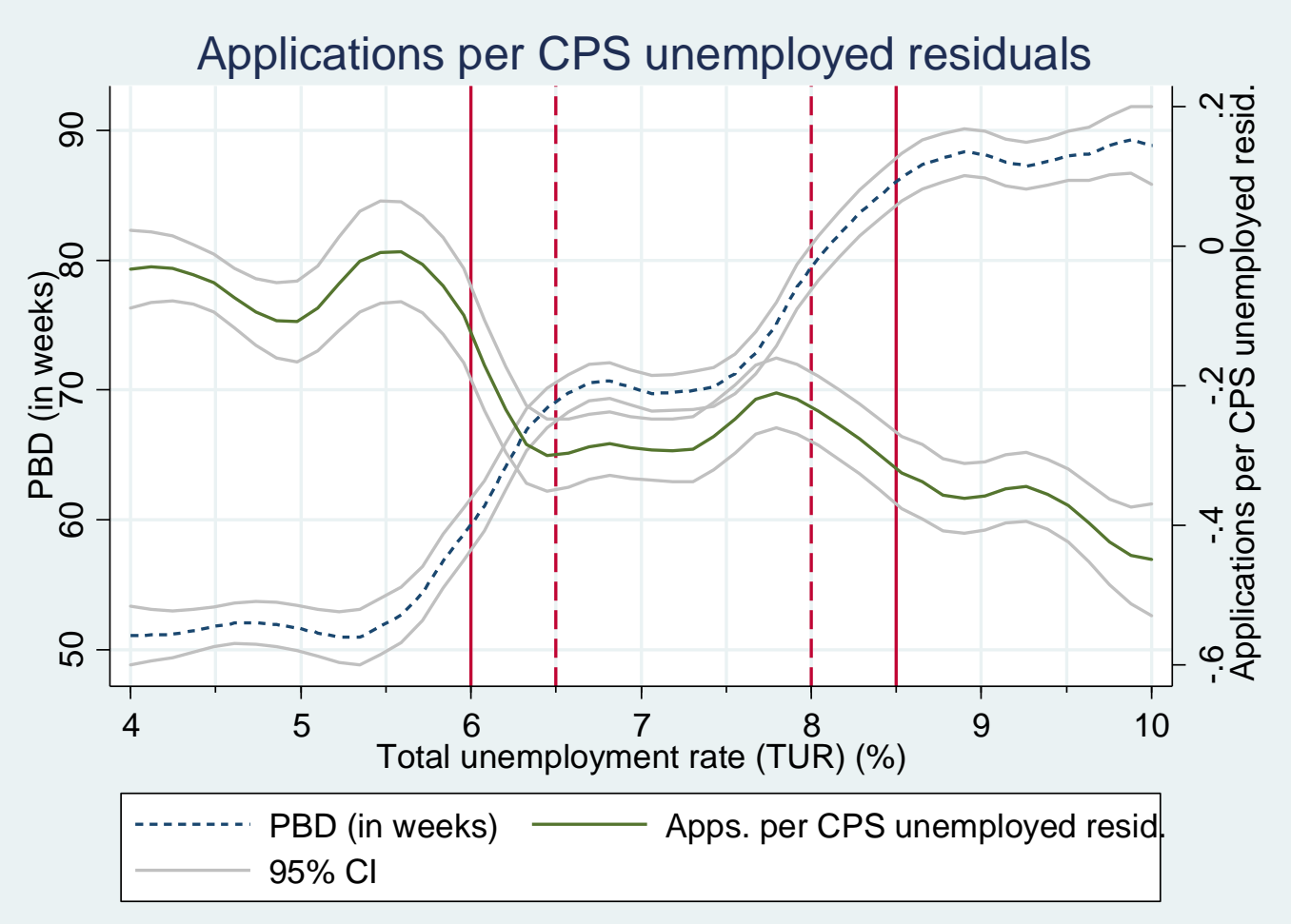

Note: Data is smoothed using kernel-weighted local polynomial smoothing with a 0.2 bandwidth. The applications per CPS unemployed residual is obtained after regressing applications per CPS unemployed on state fixed effects. The total unemployment rate is, for each month and state, the average of the weekly three-months seasonally adjusted unemployment rate. The two solid vertical lines correspond to 6\% TUR (threshold for EUC2 when it was conditional, and for EUC3), and 8.5\% TUR (threshold for EUC4). The two dashed vertical lines correspond to 6.5\% TUR (threshold for 13 weeks extended benefits when the TUR option is active) and 8\% TUR (threshold for 20 weeks extended benefits when the TUR option is active).

Source: Department of Labor, and CareerBuilder.com for applications. 
Table 11: The impact of potential unemployment benefit duration on log tightness, complete results using the global parametric fuzzy RD design

\begin{tabular}{|c|c|c|c|c|}
\hline & \multicolumn{4}{|c|}{$4 \%<=$ TUR<=10\% } \\
\hline & $(1)$ & $(2)$ & (3) & $(4)$ \\
\hline Total PBD in weeks & $\begin{array}{l}-0.0005 \\
(0.0017)\end{array}$ & $\begin{array}{c}0.0039 \\
(0.0026)\end{array}$ & & \\
\hline EUC PBD in weeks & & & $\begin{array}{l}-0.0014 \\
(0.0013)\end{array}$ & $\begin{array}{r}0.0080^{* \star \star} \\
(0.0028)\end{array}$ \\
\hline EB PBD in weeks & & & $\begin{array}{c}0.0040 \\
(0.0062)\end{array}$ & $\begin{array}{l}-0.0019 \\
(0.0061)\end{array}$ \\
\hline $\begin{array}{l}\text { Total Unemployment Rate (TUR) } \\
(\%)\end{array}$ & $\begin{array}{l}-0.1049 \\
(0.0706)\end{array}$ & $\begin{array}{l}-0.0761 \\
(0.0645)\end{array}$ & $\begin{array}{l}-0.0873 \\
(0.0682)\end{array}$ & $\begin{array}{l}-0.1030^{\star} \\
(0.0584)\end{array}$ \\
\hline TUR^2 & $\begin{array}{l}0.0073^{\star} \\
(0.0044)\end{array}$ & $\begin{array}{c}0.0027 \\
(0.0040)\end{array}$ & $\begin{array}{c}0.0052 \\
(0.0044)\end{array}$ & $\begin{array}{c}0.0052 \\
(0.0040)\end{array}$ \\
\hline $\begin{array}{l}\text { Insured Unemployment Rate (IUR) } \\
(\%)\end{array}$ & $\begin{array}{l}-0.0375 \\
(0.0439)\end{array}$ & $\begin{array}{l}-0.0766 \\
(0.0476)\end{array}$ & $\begin{array}{l}-0.0251 \\
(0.0494)\end{array}$ & $\begin{array}{r}-0.0971^{\star \star} \\
(0.0482)\end{array}$ \\
\hline IUR^2 & $\begin{array}{c}0.0022 \\
(0.0060)\end{array}$ & $\begin{array}{c}0.0046 \\
(0.0062)\end{array}$ & $\begin{array}{c}0.0002 \\
(0.0070)\end{array}$ & $\begin{array}{l}0.0074 \\
(0.0064)\end{array}$ \\
\hline Month fixed effects & & $x$ & & $x$ \\
\hline Observations & 1,804 & 1,804 & 1,804 & 1,804 \\
\hline R-squared & 0.9412 & 0.9617 & 0.9415 & 0.9630 \\
\hline $\begin{array}{l}\text { Robust standard errors clustered } \\
\star \star \star \\
\text { All } p<0.01,{ }^{* \star} p<0.05,{ }^{*} p<0.1 \\
\text { All regressions include state and }\end{array}$ & $\begin{array}{l}\text { state in } p \\
\text { ar fixed ef }\end{array}$ & ntheses & & \\
\hline
\end{tabular}

Note: Tightness is defined as vacancies/applications. Instrumental variables regressions, where PBD is the endogenous variable. The instrument for Total PBD in weeks is PBD according to statutory rules, not taking into account temporary EUC expirations, and assuming that all states take up the TUR option. In col. 3-4, EB PBD is instrumented with EB PBD according to rules and assuming that all states have elected the TUR option, and EUC PBD is instrumented with the EUC PBD according to rules and ignoring temporary EUC lapses. The sample includes any observation for which TUR is between $4 \%$ and $10 \%$.

Source: Department of Labor, and CareerBuilder.com for applications and vacancies. 
Table 12: The impact of PBD on applications, vacancies and tightness using the global parametric fuzzy RD design, sensitivity to higher-order polynomials in the assignment variables

\begin{tabular}{|c|c|c|c|c|c|c|}
\hline & \multicolumn{2}{|c|}{ Log applications } & \multicolumn{2}{|c|}{ Log vacancies } & \multicolumn{2}{|c|}{ Log tightness } \\
\hline & $(1)$ & $(2)$ & (3) & $(4)$ & $(5)$ & $(6)$ \\
\hline EUC PBD in weeks & $\begin{array}{l}-0.0070^{\star \star} \\
(0.0029)\end{array}$ & $\begin{array}{l}-0.0078^{\star \star} \\
(0.0036)\end{array}$ & $\begin{array}{c}0.0009 \\
(0.0021)\end{array}$ & $\begin{array}{c}0.0013 \\
(0.0022)\end{array}$ & $\begin{array}{l}0.0079 \star \star \star \\
(0.0029)\end{array}$ & $\begin{array}{l}0.0091^{\star \star \star} \\
(0.0033)\end{array}$ \\
\hline EB PBD in weeks & $\begin{array}{l}0.0044 \\
(0.0068)\end{array}$ & $\begin{array}{c}0.0040 \\
(0.0069)\end{array}$ & $\begin{array}{c}0.0019 \\
(0.0037)\end{array}$ & $\begin{array}{c}0.0017 \\
(0.0038)\end{array}$ & $\begin{array}{l}-0.0024 \\
(0.0068)\end{array}$ & $\begin{array}{l}-0.0023 \\
(0.0068)\end{array}$ \\
\hline $\begin{array}{l}\text { Total Unemployment } \\
\text { Rate (TUR) (\%) }\end{array}$ & $\begin{array}{c}0.1780 \\
(0.2287)\end{array}$ & $\begin{array}{l}-1.5724 \\
(1.5643)\end{array}$ & $\begin{array}{l}0.0163 \\
(0.3171)\end{array}$ & $\begin{array}{c}0.3979 \\
(1.1469)\end{array}$ & $\begin{array}{l}-0.1617 \\
(0.3715)\end{array}$ & $\begin{array}{c}1.9703 \\
(1.4626)\end{array}$ \\
\hline TUR² & $\begin{array}{l}-0.0210 \\
(0.0318)\end{array}$ & $\begin{array}{c}0.3756 \\
(0.3644)\end{array}$ & $\begin{array}{l}-0.0070 \\
(0.0454)\end{array}$ & $\begin{array}{l}-0.0957 \\
(0.2589)\end{array}$ & $\begin{array}{c}0.0140 \\
(0.0541)\end{array}$ & $\begin{array}{l}-0.4713 \\
(0.3324)\end{array}$ \\
\hline TUR^3 & $\begin{array}{l}0.0008 \\
(0.0015)\end{array}$ & $\begin{array}{l}-0.0379 \\
(0.0363)\end{array}$ & $\begin{array}{c}0.0004 \\
(0.0021)\end{array}$ & $\begin{array}{c}0.0093 \\
(0.0254)\end{array}$ & $\begin{array}{l}-0.0004 \\
(0.0025)\end{array}$ & $\begin{array}{c}0.0472 \\
(0.0328)\end{array}$ \\
\hline TUR4 & & $\begin{array}{l}0.0014 \\
(0.0013)\end{array}$ & & $\begin{array}{l}-0.0003 \\
(0.0009)\end{array}$ & & $\begin{array}{l}-0.0017 \\
(0.0012)\end{array}$ \\
\hline $\begin{array}{l}\text { Insured Unemploymen } \\
\text { Rate (IUR) (\%) }\end{array}$ & $\begin{array}{c}0.0770 \\
(0.0973)\end{array}$ & $\begin{array}{c}0.2073 \\
(0.2338)\end{array}$ & $\begin{array}{l}-0.0375 \\
(0.0906)\end{array}$ & $\begin{array}{c}0.1253 \\
(0.2179)\end{array}$ & $\begin{array}{l}-0.1145 \\
(0.1074)\end{array}$ & $\begin{array}{l}-0.0820 \\
(0.2467)\end{array}$ \\
\hline IUR^2 & $\begin{array}{l}-0.0260 \\
(0.0229)\end{array}$ & $\begin{array}{l}-0.0880 \\
(0.1150)\end{array}$ & $\begin{array}{l}-0.0135 \\
(0.0229)\end{array}$ & $\begin{array}{l}-0.0919 \\
(0.0971)\end{array}$ & $\begin{array}{c}0.0125 \\
(0.0270)\end{array}$ & $\begin{array}{l}-0.0039 \\
(0.1199)\end{array}$ \\
\hline IUR^3 & $\begin{array}{c}0.0018 \\
(0.0017)\end{array}$ & $\begin{array}{c}0.0136 \\
(0.0226)\end{array}$ & $\begin{array}{c}0.0013 \\
(0.0019)\end{array}$ & $\begin{array}{l}0.0165 \\
(0.0179)\end{array}$ & $\begin{array}{l}-0.0005 \\
(0.0021)\end{array}$ & $\begin{array}{c}0.0029 \\
(0.0232)\end{array}$ \\
\hline IUR^4 & & $\begin{array}{l}-0.0008 \\
(0.0015)\end{array}$ & & -0.0010 & & $\begin{array}{l}-0.0002 \\
(0.0015)\end{array}$ \\
\hline Observations & 1,804 & 1,804 & 1,804 & 1,804 & 1,804 & 1,804 \\
\hline R-squared & 0.9957 & 0.9957 & 0.9906 & 0.9907 & 0.9630 & 0.9631 \\
\hline $\begin{array}{l}\text { Robust standard error } \\
* * * p<0.01,{ }^{* *} p<0.05 \text {, } \\
\text { All regressions includ }\end{array}$ & $\begin{array}{l}\text { clustere } \\
p<0.1 \\
\text { month at }\end{array}$ & state ir & theses & & & \\
\hline
\end{tabular}

Note: Instrumental variables regressions, where PBD is the endogenous variable. EB PBD is instrumented with EB PBD according to rules and assuming that all states have elected the TUR option, and EUC PBD is instrumented with the EUC PBD according to rules and ignoring temporary EUC lapses. The sample includes any observation for which TUR is between $4 \%$ and $10 \%$. Tightness is defined as vacancies/applications.

Source: Department of Labor, and CareerBuilder.com for applications and vacancies. 
Figure 13: The impact of EUC PBD on applications, using the global parametric fuzzy RD design, and running separate regressions for different posted wage ranges

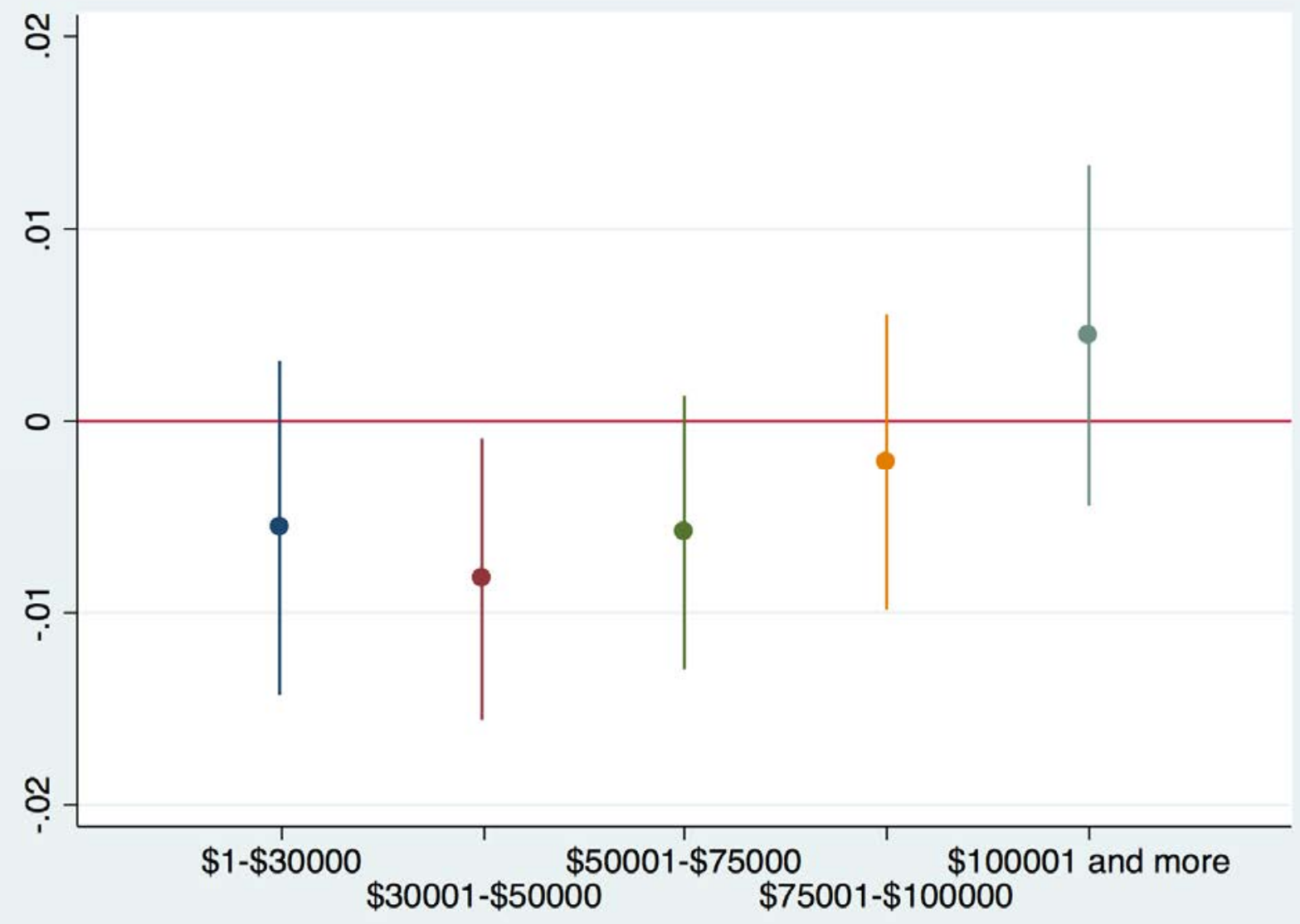

Note: The figure plots coefficients on EUC PBD in weeks from running the specification from Table 3, col. 4, and using samples with different ranges of posted wages. $90 \%$ confidence intervals are represented in the figure.

Source: Department of Labor, and CareerBuilder.com for applications and vacancies. 
Table 13: The impact of potential unemployment benefit duration on log vacancies using the global parametric fuzzy RD design: robustness

\begin{tabular}{|c|c|c|c|c|c|}
\hline & $\begin{array}{c}\begin{array}{c}\text { Baseline } \\
\text { specification }\end{array} \\
(1)\end{array}$ & $\begin{array}{c}\text { Controlling for } \\
\text { industry and } \\
\text { required } \\
\text { education }\end{array}$ & $\begin{array}{c}\begin{array}{c}\text { Controlling for } \\
\text { state-specific } \\
\text { trends }\end{array} \\
(3)\end{array}$ & $\begin{array}{c}\text { Interaction } \\
\text { with share UI } \\
\text { recipients } \\
\text { (4) }\end{array}$ & $\begin{array}{c}\text { Baseline } \\
\text { specification } \\
\text { with HWOL } \\
\text { data } \\
\text { (5) }\end{array}$ \\
\hline EUC PBD in weeks & $\begin{array}{c}0.0008 \\
(0.0021)\end{array}$ & $\begin{array}{c}0.0003 \\
(0.0015)\end{array}$ & $\begin{array}{c}0.0025 \\
(0.0019)\end{array}$ & $\begin{array}{c}0.0030 \\
(0.0031)\end{array}$ & $\begin{array}{c}0.0026 \\
(0.0029)\end{array}$ \\
\hline EB PBD in weeks & $\begin{array}{c}0.0013 \\
(0.0028)\end{array}$ & $\begin{array}{c}0.0011 \\
(0.0020)\end{array}$ & $\begin{array}{l}-0.0015 \\
(0.0023)\end{array}$ & $\begin{array}{l}-0.0007 \\
(0.0083)\end{array}$ & $\begin{array}{l}-0.0013 \\
(0.0019)\end{array}$ \\
\hline $\begin{array}{l}\text { EUC PBD in weeks*share UI } \\
\text { recipients among unempoyed }\end{array}$ & & & & $\begin{array}{l}-0.0064 \\
(0.0080)\end{array}$ & \\
\hline $\begin{array}{l}\text { EB PBD in weeks*share UI } \\
\text { recipients among unempoyed }\end{array}$ & & & & $\begin{array}{c}0.0048 \\
(0.0169)\end{array}$ & \\
\hline $\begin{array}{l}\text { Total Unemployment Rate (TUR) } \\
(\%)\end{array}$ & $\begin{array}{l}-0.0433 \\
(0.0449)\end{array}$ & $\begin{array}{l}-0.0404 \\
(0.0394)\end{array}$ & $\begin{array}{l}-0.1206^{\star *} \\
(0.0580)\end{array}$ & $\begin{array}{l}-0.0414 \\
(0.0446)\end{array}$ & $\begin{array}{c}-0.1679 * \star * \\
(0.0593)\end{array}$ \\
\hline TUR^2 & $\begin{array}{c}0.0020 \\
(0.0028)\end{array}$ & $\begin{array}{c}0.0021 \\
(0.0023)\end{array}$ & $\begin{array}{l}0.0061^{*} \\
(0.0034)\end{array}$ & $\begin{array}{c}0.0017 \\
(0.0028)\end{array}$ & $\begin{array}{l}0.0102^{\star * *} \\
(0.0035)\end{array}$ \\
\hline $\begin{array}{l}\text { Insured Unemployment Rate } \\
\text { (IUR) (\%) }\end{array}$ & $\begin{array}{l}-0.0869 * * \\
(0.0352)\end{array}$ & $\begin{array}{l}-0.0645^{\star *} \\
(0.0287)\end{array}$ & $\begin{array}{l}-0.0662^{\star *} \\
(0.0306)\end{array}$ & $\begin{array}{l}-0.1010^{\star \star \star} \\
(0.0369)\end{array}$ & $\begin{array}{l}-0.0177 \\
(0.0418)\end{array}$ \\
\hline IUR² & $\begin{array}{l}0.0014 \\
(0.0043)\end{array}$ & $\begin{array}{l}0.0008 \\
(0.0037)\end{array}$ & $\begin{array}{l}0.0025 \\
(0.0039)\end{array}$ & $\begin{array}{l}0.0034 \\
(0.0048)\end{array}$ & $\begin{array}{l}-0.0021 \\
(0.0042)\end{array}$ \\
\hline $\begin{array}{l}\text { Controls for composition of } \\
\text { vacancies by required education } \\
\text { Controls for composition of } \\
\text { vacancies by 2-digit NAICS }\end{array}$ & & $x$ & & & \\
\hline $\begin{array}{l}\text { industry } \\
\text { State-specific trends }\end{array}$ & & $x$ & X & & \\
\hline Observations & 1,804 & 1,804 & 1,804 & 1,804 & 1,210 \\
\hline R-squared & 0.9906 & 0.9931 & 0.9937 & 0.9907 & 0.9934 \\
\hline
\end{tabular}

Note: Instrumental variables regressions, where PBD is the endogenous variable. EB PBD is instrumented with EB PBD according to rules and assuming that all states have elected the TUR option, and EUC PBD is instrumented with the EUC PBD according to rules and ignoring temporary EUC lapses. The sample includes any observation for which TUR is between $4 \%$ and $10 \%$. Column 1 is taken from Table 4, column 4. In column 2, controls are included for the share of vacancies in each education category (see summary statistics Table 1), and for the share of vacancies in each 2-digit NAICS code. In column 4, the share of UI recipients is, for each state, the average share of UI recipients among all unemployed between December 2008 and the end of the sample; the share of UI recipients (not interacted with PBD) is controlled for in the regression. In column 5, the sample is restricted to vacancies with posted wages of $\$ 100000$ or less per year. In column 6 , the sample is restricted to vacancies that pay more than $\$ 100000$ per year.

Source: Department of Labor, and CareerBuilder.com for applications and vacancies. 
Table 14: The impact of PBD on log applications using the global parametric fuzzy RD design: first difference, and lags and leads of PBD

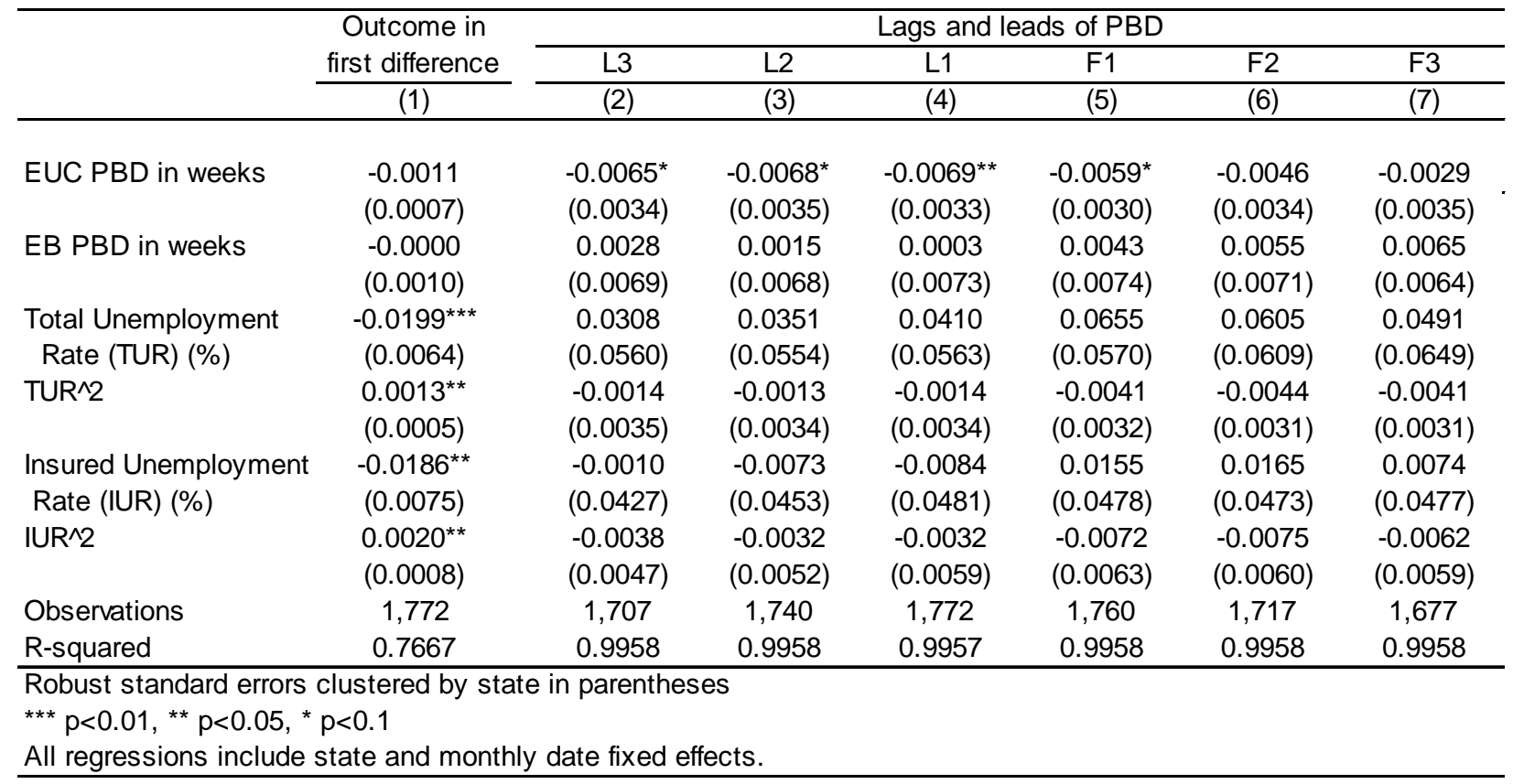

Note: Instrumental variables regressions, where PBD is the endogenous variable. EB PBD is instrumented with EB PBD according to rules and assuming that all states have elected the TUR option, and EUC PBD is instrumented with the EUC PBD according to rules and ignoring temporary EUC lapses. The sample includes any observation for which TUR is between $4 \%$ and $10 \%$. In column 1, the outcome variable is the first difference in log applications. In columns 2-7, EUC PBD and EB PBD are used in lags or leads as described by the column heading.

Source: Department of Labor, and CareerBuilder.com for applications and vacancies. 
Table 15: The impact of PBD on log jobs using the global parametric fuzzy RD design: first difference, and lags and leads of PBD

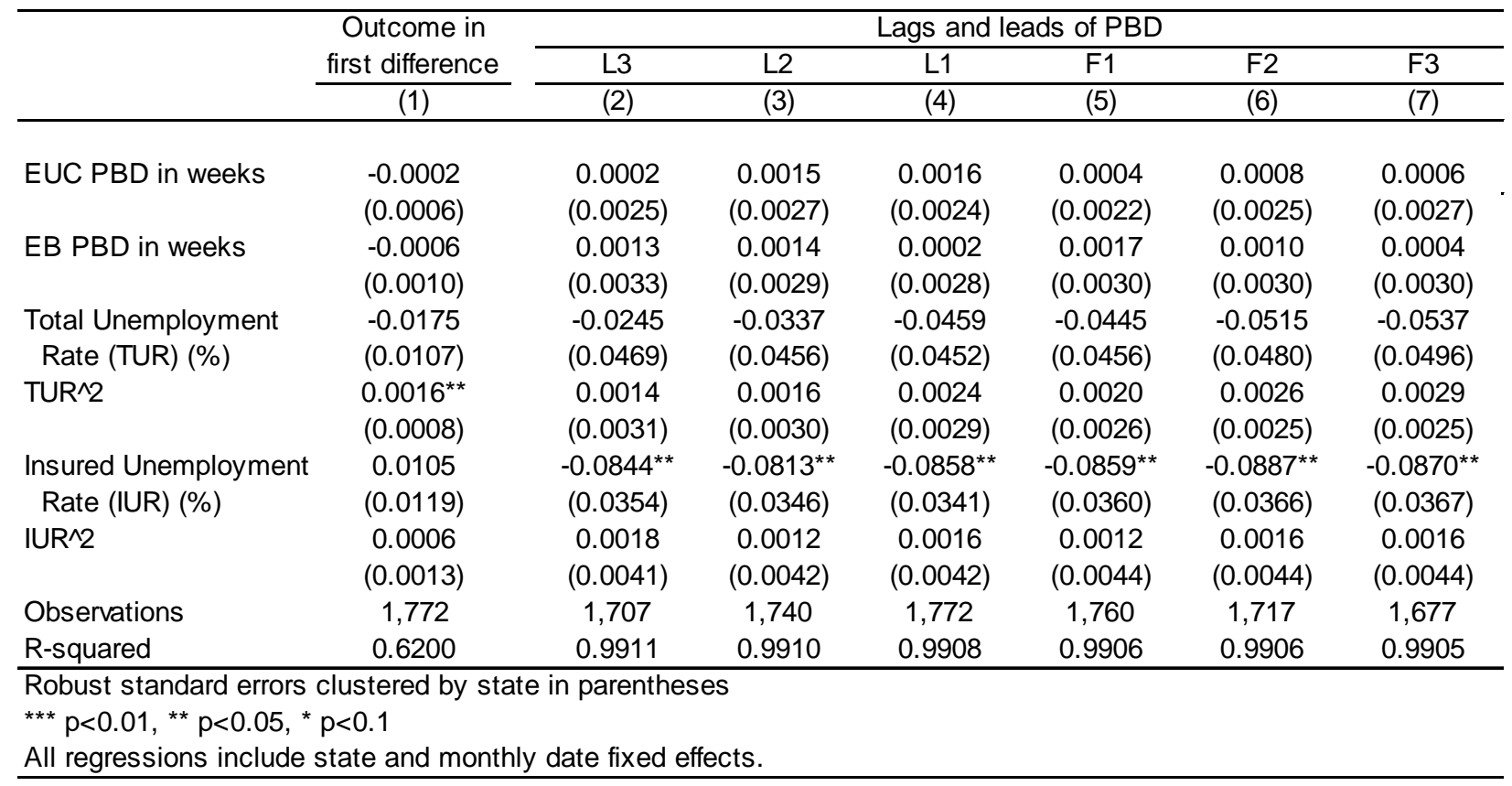

Note: Instrumental variables regressions, where PBD is the endogenous variable. EB PBD is instrumented with EB PBD according to rules and assuming that all states have elected the TUR option, and EUC PBD is instrumented with the EUC PBD according to rules and ignoring temporary EUC lapses. The sample includes any observation for which TUR is between $4 \%$ and $10 \%$. In column 1, the outcome variable is the first difference in log jobs. In columns 2-7, EUC PBD and EB PBD are used in lags or leads as described by the column heading.

Source: Department of Labor, and CareerBuilder.com for applications and vacancies. 


\section{APPENDIX 2: local parametric fuzzy regression discontinuity design}

Crossing a threshold in the total unemployment rate (TUR) is much more likely to lead to an actual increase in PBD than crossing a threshold in the insured unemployment rate (IUR) (see p. 8). I therefore focus on TUR thresholds. Among all the TUR thresholds, the one at 6\% TUR for EUC is the best candidate for a regression discontinuity design because it applies to all states. Moreover, around 6\% TUR, states would typically not have extended benefits (EB). Indeed, TUR must be above $6.5 \%$ in the states with a TUR option for EB to be turned on. By contrast, the next EUC TUR threshold is met at 8.5\%, which would trigger EB in states that have an 8\% TUR threshold for EB. The potential triggering of EB would introduce additional interpretation issues, thus the EUC discontinuity around $6 \%$ is a better option.

Increases in PBD occur at specific TUR thresholds (Figure 14). The data in the figure is at the week by state level for December 2008 to October 2009, a period during which the PBD schedule as a function of TUR was constant. Two main reasons justify the limitation of observations to December 2008 to October 2009. First, prior to December 2008, EUC did not depend on TUR, and after October 2009, PBD increased at more TUR thresholds. Second, after October 2009, there were few states with TUR just below 6\%, making that latter period unsuitable for a regression discontinuity design around 6\% TUR.

If we focus on 1 percentage point around 6\% TUR (i.e. 5.5\% TUR to 6.4\% TUR) then no clear discontinuity in PBD is observed (Appendix 2, Figure 14, blue hollow circles). This is because some states are eligible for EB or EUC under IUR conditions, which means that PBD can be at a higher level even when TUR is below $6 \%$. Additionally, even when TUR is above $6 \%$, some states have the lower PBD level because there is usually a delay between when a state crosses the threshold and when benefits become available. To focus on a situation where PBD only depends on TUR (and not IUR), and to apply a standard fuzzy regression discontinuity design, I exclude some of the observations. First, state-week observations are dropped where any EB is available due to IUR conditions. Second, I also drop stateweek observations where TUR is below $6 \%$ and the IUR condition for EUC is satisfied. Substantively, what these exclusions do is drop the $15 \%$ of state-week observations ${ }^{42}$ in the $5.5 \%$ to $6.4 \%$ TUR range where IUR is unusually high compared to TUR. This procedure leaves only observations where TUR is between 5.5\% to 6.4\% and PBD is either 46 or 59 weeks (red diamonds in Appendix 2, Figure 14).

\footnotetext{
${ }^{42}$ If we don't exclude these observations, the point estimates for the impact of PBD in Appendix 2, Table 16 are essentially unchanged.
} 
Some states may value higher PBD and might want to manipulate their unemployment rate towards that objective ${ }^{43}$, which would result in bunching of observations at the threshold, potentially compromising the assumptions behind the fuzzy regression discontinuity design. However, no evidence for bunching at the 6\% TUR threshold was found (Appendix 2, Figure 15).

The data from CareerBuilder is only available at the monthly level, even though PBD varies at the weekly level. I therefore use the monthly average of PBD, and only include months where TUR lies between $5.5 \%$ and $6.4 \%$ in each and every week. With monthly data on the outcomes of interest, the fuzzy regression discontinuity framework is embodied in the following instrumental variables regression:

$$
y_{s t}=\beta b_{s t}+\alpha^{\prime} X_{s t}+\delta_{t}+\gamma_{s}+\epsilon_{s t}
$$

where $y_{s t}$ is log applications, log vacancies or log tightness (i.e. log vacancies-log applications) in state $s$ and month $t, b_{s t}$ is the PBD in weeks, $X_{s t}$ is a vector of controls which can include a quadratic in TUR and IUR, $\delta_{t}$ is a year fixed effect, $\gamma_{s}$ is a state fixed effect, and $\epsilon_{s t}$ is the error term. Standard errors are clustered at the state level. Given that this is a fuzzy regression discontinuity design, $b_{s t}$ is instrumented with the PBD that should be in place given program rules. The instrument is therefore PBD such that extra weeks of benefit are made available by states without delay.

This application of a fuzzy regression discontinuity design is similar to the work by Angrist and Lavy (1999). While it is typical to include the forcing variable (here TUR) as a control in a regression discontinuity design, I report results both with and without this control. Indeed, the TUR is endogenous in a regression with applications on the left-hand side: if jobseekers send in fewer applications, then, all other things equal, unemployment will increase.

As previously stated, using the EUC 6\% TUR threshold is the best one can do with a single threshold in this sample, but it leaves only 44 state-month observations ${ }^{44}$. A larger sample would be desirable, though it will not be possible to use the regression discontinuity framework strictly speaking. Figure 14 illustrates why this is the case: while the crossing of TUR thresholds plays an important role in the determination of PBD, the relationship between PBD and TUR does not present very sharp discontinuities.

\footnotetext{
${ }^{43}$ Such manipulation would however be exceedingly difficult in practice since states do not control the data collection and calculation of the TUR by the Bureau of Labor statistics.

${ }^{44}$ There are 21 states in the sample.
} 
The impact of PBD on applications is negative and significant (Appendix 1, Table 16, col. 1). A 1-week increase in PBD decreases applications by $1.36 \%$. If we compare this estimate to the results from the timing of events approach, a $1.36 \%$ decrease in applications corresponds to the impact of PBD on applications 4 months after the largest PBD increase ${ }^{45}$. Therefore, while the impact estimated by the fuzzy regression discontinuity design is large, it is within the range of what was found for the timing of events approach.

Given that unemployment is also a potential determinant of applications, it is important to see how results change when we control for this variables. When controlling for a quadratic in TUR, which is the forcing variable, the quadratic in TUR itself does not have a significant impact on applications. The impact of PBD on log applications stays negative but becomes statistically insignificant (Appendix 1, Table 16, col. 2). While this specification lacks power (see also the graphical analysis in Appendix 1, Figure 16, which is supportive of the results but noisy), it suggests that PBD increases led to decreases in applications.

By contrast, the impact of PBD on vacancies is positive and insignificant both without and with controls (Appendix 1, Table 16, cols. 3 and 4). Therefore, the decline in applications around the 6\% TUR discontinuity was not accompanied by a decline in the number of vacancies.

Finally the impact of PBD on tightness is positive and significant in a regression without controls for the unemployment rate (Appendix 1, Table 16, col. 5), and becomes insignificant when controls for the unemployment rate are added (Appendix 1, Table 16, col. 6).

Overall, the results from the fuzzy regression discontinuity approach are consistent with the results from the timing of events approach. Indeed, there is no significant impact of PBD on vacancies and a negative impact of PBD on applications. The results from the fuzzy regression discontinuity design therefore agree with the timing of events approach to show that longer PBD increases labor market tightness.

\footnotetext{
${ }^{45}$ Indeed, in the timing of events approach, the estimated impact in month 3 (see Figure 3 ) is -0.21 , which is for a 15 weeks increase in PBD: this implies that a one week increase in PBD decreases applications by $1.4 \%$.
} 
Figure 14: Potential unemployment benefit duration as a function of TUR, weekly level data, December 2008 to October 2009

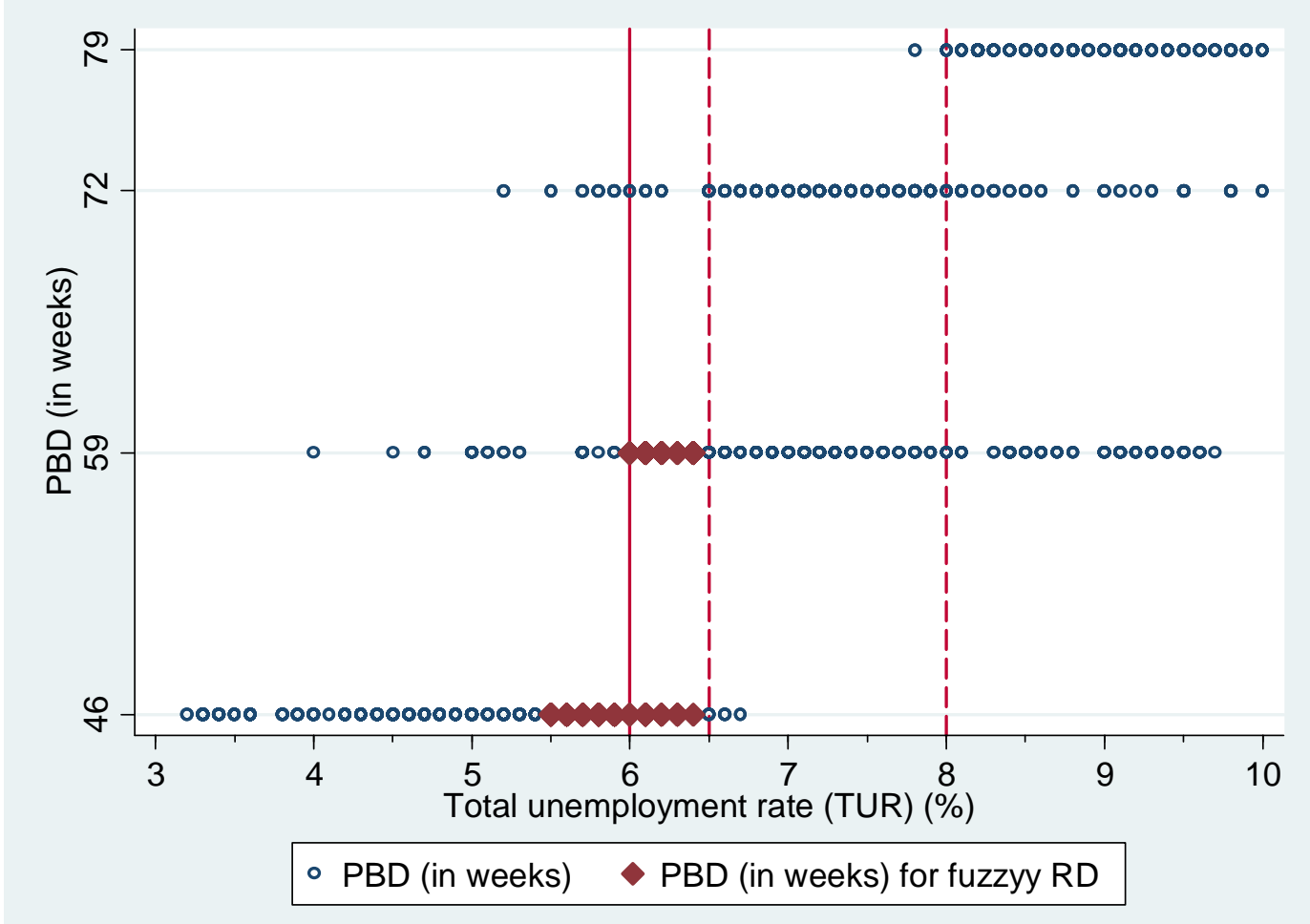

Note: Each circle corresponds to a state and week. The total unemployment rate is the weekly three-months seasonally adjusted unemployment rate. The diamonds correspond to the states and weeks that are retained for the fuzzy regression discontinuity graphs and regressions. The solid vertical line corresponds to the $6 \%$ TUR threshold for EUC. The dashed vertical lines correspond to the $6.5 \%$ and $8 \%$ thresholds for EB.

Source: Department of Labor. 
APPENDIX 2

Figure 15: The distribution of the total unemployment rate (TUR) in the fuzzy RD sample, weekly level data

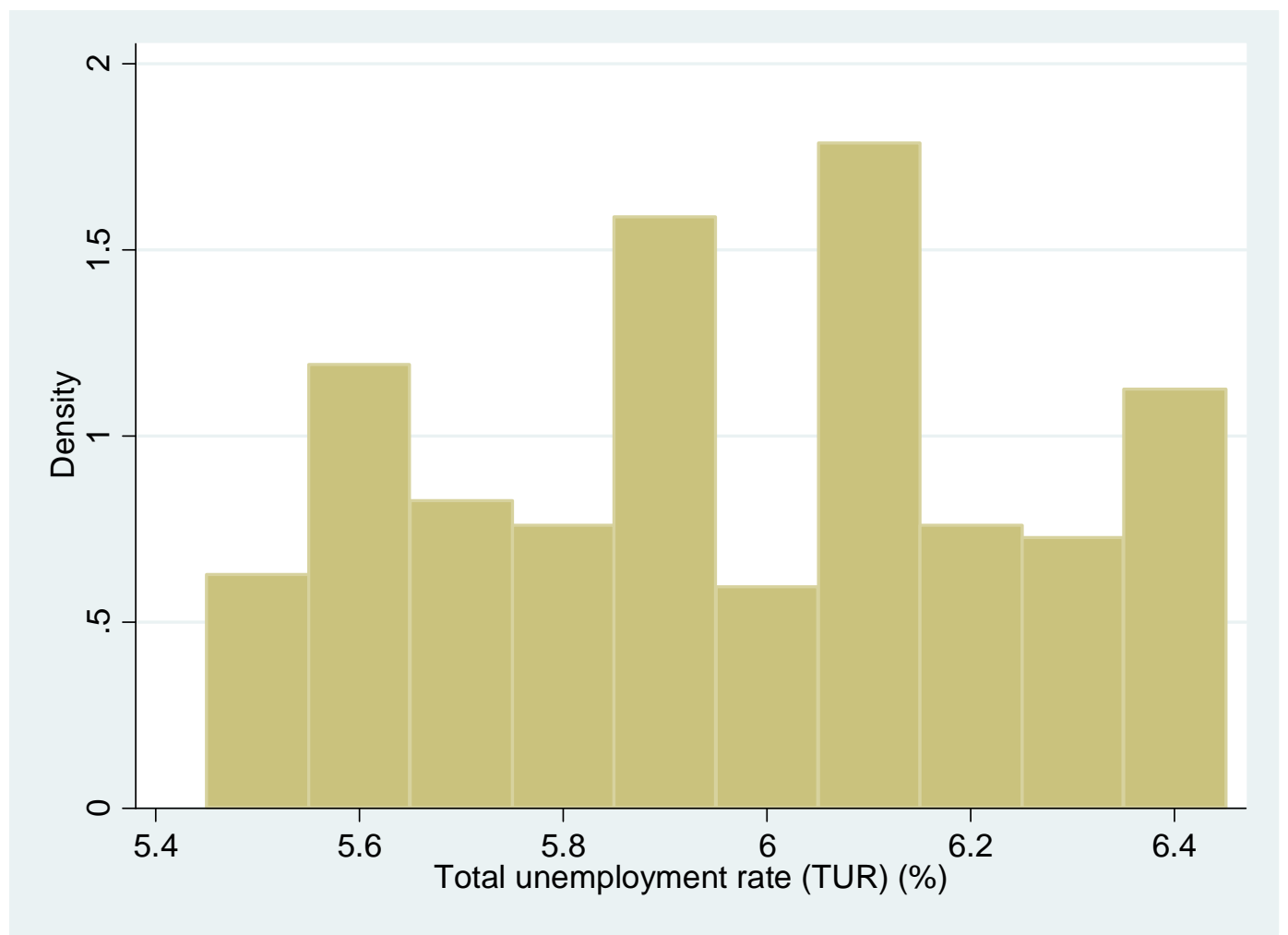

Note: The total unemployment rate is the weekly three-months seasonally adjusted unemployment rate.

Source: Department of Labor. 
Figure 16: RD graph for the impact of EUC on log vacancies and log applications around 6\% unemployment rate (TUR), December 2008 to October 2009, monthly data
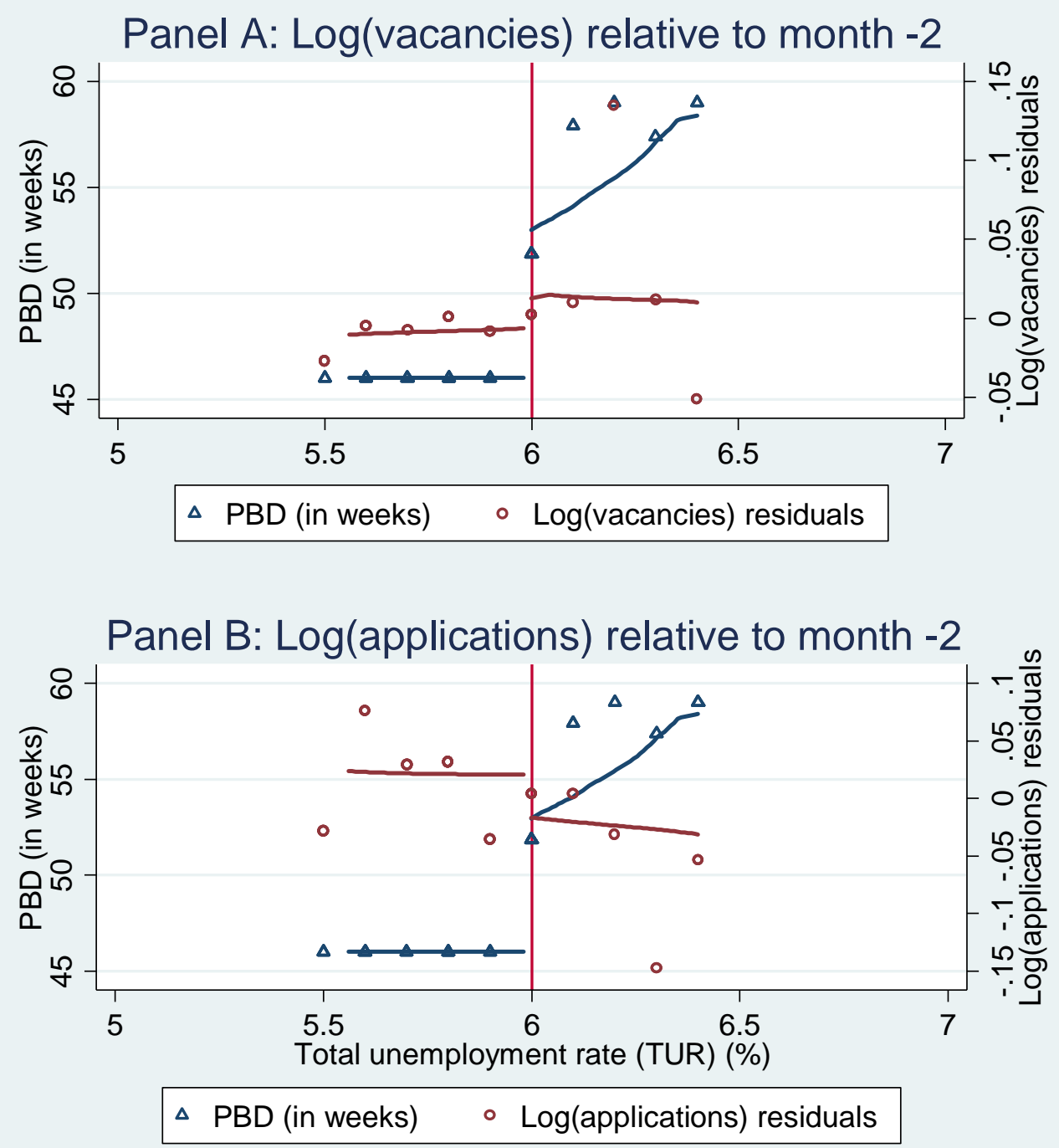

Note: The vacancies (Panel A) and applications (Panel B) residuals are obtained after regressing respectively log vacancies and log applications on state and year fixed effects. The sample is restricted to points that are valid to estimate the impact of the discontinuous change in PBD at 6\% TUR due to EUC regulations between December 2008 and October 2009 (see text for more details). The total unemployment rate is, for each month and state, the average of the weekly three-months seasonally adjusted unemployment rate. The applications residuals and the PBD are averaged over 0.1 percentage point TUR bins.

Source: Department of Labor, and CareerBuilder.com for applications. 
APPENDIX 2

Table 16: The impact of potential benefit duration on applications, vacancies and tightness: fuzzy regression discontinuity

\begin{tabular}{|c|c|c|c|c|c|c|}
\hline & \multicolumn{2}{|c|}{ Log applications } & \multicolumn{2}{|c|}{ Log vacancies } & \multicolumn{2}{|c|}{ Log tightness } \\
\hline & $(1)$ & $(2)$ & (3) & $(4)$ & $(5)$ & $(6)$ \\
\hline Total PBD in weeks & $\begin{array}{l}-0.0136^{\star} \\
(0.0076)\end{array}$ & $\begin{array}{l}-0.0032 \\
(0.0156)\end{array}$ & $\begin{array}{c}0.0064 \\
(0.0094)\end{array}$ & $\begin{array}{c}0.0102 \\
(0.0123)\end{array}$ & $\begin{array}{l}0.0200^{\star \star \star} \\
(0.0051)\end{array}$ & $\begin{array}{c}0.0134 \\
(0.0100)\end{array}$ \\
\hline $\begin{array}{l}\text { Total Unemployment Rate } \\
\text { (TUR) (\%) }\end{array}$ & & $\begin{array}{l}6.3144^{\star} \\
(3.6059)\end{array}$ & & $\begin{array}{c}4.2366 \\
(4.0899)\end{array}$ & & $\begin{array}{l}-2.0778 \\
(3.1294)\end{array}$ \\
\hline TUR^2 & & $\begin{array}{l}-0.5486^{\star} \\
(0.2938)\end{array}$ & & $\begin{array}{l}-0.3625 \\
(0.3506)\end{array}$ & & $\begin{array}{c}0.1861 \\
(0.2563)\end{array}$ \\
\hline $\begin{array}{l}\text { Insured Unemployment Rat } \\
\text { (IUR) (\%) } \\
\text { IUR^2 }\end{array}$ & & & & & & \\
\hline Observations & 44 & 44 & 44 & 44 & 44 & 44 \\
\hline R-squared & 0.9972 & 0.9976 & 0.9962 & 0.9964 & 0.9903 & 0.9916 \\
\hline $\begin{array}{l}\text { Robust standard errors clus } \\
\star \star \star \\
p<0.01,{ }^{* *} p<0.05,{ }^{*} p<0 \\
\text { All regressions include stat }\end{array}$ & red by sta & in parenth & & & & \\
\hline
\end{tabular}

Note: Instrumental variables regressions. Total PBD in weeks is instrumented by PBD according to statutory rules, not taking into account temporary EUC expirations, and assuming that all states take up the TUR option. The sample is restricted to points that are valid to estimate the impact of the discontinuous change in PBD at 6\% TUR due to EUC regulations between December 2008 and October 2009. Tightness is defined as vacancies/applications. See text for more details.

Source: Department of Labor, and CareerBuilder.com for applications and vacancies. 


\section{APPENDIX 3: additional specifications for the county pair difference identification strategy}

This appendix presents additional specifications for the county pair difference identification strategy. Specifically, I present regressions a la Hagedorn et al. (2013) and a la Dube, Lester, and Reich (2010).

For the regressions a la Hagedorn et al. (2013), I adopt the following specification:

$$
\Delta_{\mathrm{t}+1, \mathrm{c}} y_{c s t}=\beta_{1} \Delta_{\mathrm{c}} E U C_{c s t}+\beta_{2} \Delta_{\mathrm{c}} E B_{c s t}+\delta_{t}+\epsilon_{c s t}
$$

where $y_{c s t}$ is the outcome $y$ in county $c$ in state $s$ at date $t . E U C_{c s t}$ is the number of weeks of EUC available, $E B_{\text {cst }}$ is the number of weeks of EB available. $\Delta_{\mathrm{t}+1, \mathrm{c}}$ stands for a double difference: for county $c$ in state $s$ and its paired county $c^{\prime}$ in state $s^{\prime}$, we have $\Delta_{t+1, c} y_{c s t}=\left(y_{c s, t+1}-y_{c s t}\right)-\left(y_{c \prime s^{\prime}, t+1}-\right.$ $y c^{\prime} s^{\prime} t$. $\Delta c$ stands for the difference across counties in a pair at a given date $t . \delta t$ is a date fixed effect (monthly). $\epsilon_{c s t}$ is the error term.

The specification above was chosen to be as transparent as possible while still being very close to the one used by Hagedorn et al. (2013). There are two minor differences between this specification and the one used in Hagedorn et al. (2013).

- I take the undiscounted lead of the first difference ${ }^{46}$ of the outcomes over time.

- I do not estimate factor loadings for common time effects but simply use a set of time (monthly) dummies. Not using any time effects makes no difference to the qualitative results.

For the regressions a la Dube, Lester, and Reich (2010), I use the following specification:

$$
\tilde{y}_{c s t}=\beta_{1} \widetilde{E U C}_{c s t}+\beta_{2} \widetilde{E B}_{c s t}+\gamma_{p t}+\epsilon_{c s t}
$$

where $\tilde{y}_{c s t}$ is the residual of outcome $y$ in county $c$ in state $s$ at date $t$, after a regression of $y_{c s t}$ on county fixed effects. Similarly, $\widetilde{E U C}_{c s t}$ is the residual of the number of weeks of EUC available after county fixed effects, and $\widetilde{E B}_{c s t}$ is the residual of the number of weeks of EB available after county fixed effects. $\gamma_{p t}$ is a county pair by monthly date fixed effect. $\epsilon_{c s t}$ is the error term, and standard errors are clustered by border segment, i.e. the set of all counties along a given state border.

\footnotetext{
${ }^{46}$ For comparison, I have also run as specification from this paper that relies on the global parametric fuzzy regression discontinuity (i.e. in Table 3 and Table 4), but using the first difference of the outcome. PBD (EUC and EB) has no significant impact on the first-difference of applications (Appendix 1 Table 14, col. 1) or vacancies (Appendix 1, Table 15, col. 1), though EUC PBD still has a negative (insignificant) impact on applications.
} 
The only difference between this specification and the one used in Dube, Lester, and Reich (2010) is the clustering of standard errors: for simplicity, I use border segment clustering, rather than separately clustering on state and border segment.

Both the regressions a la Hagedorn et al. (2013) (Appendix 3, Table 17, col. 1-3) and a la Dube, Lester, and Reich (2010) (Appendix 3, Table 17, col. 4-6) yield an insignificant effect of EUC PBD and EB PBD on applications, vacancies and labor market tightness. 
APPENDIX 3

Table 17: Regressions a la Hagedorn et al. (2013) and Dube et al. (2010)

\begin{tabular}{|c|c|c|c|c|c|c|}
\hline & \multicolumn{3}{|c|}{ A la Hagedorn et al. (2013) } & \multicolumn{3}{|c|}{ A la Dube et al. (2010) } \\
\hline & $\frac{\text { dd.Log apps }}{(1)}$ & $\frac{\text { dd.Log jobs }}{(2)}$ & $\frac{\text { dd.Log tight }}{(3)}$ & $\begin{array}{c}\text { Log apps } \\
\text { resid. } \\
\text { (4) }\end{array}$ & $\begin{array}{l}\text { Log jobs } \\
\text { resid. } \\
\text { (5) }\end{array}$ & $\begin{array}{l}\text { Log tight } \\
\text { resid. } \\
(6)\end{array}$ \\
\hline d.EUC PBD in weeks & $\begin{array}{c}0.0008 \\
(0.0020)\end{array}$ & $\begin{array}{c}0.0012 \\
(0.0009)\end{array}$ & $\begin{array}{c}0.0003 \\
(0.0018)\end{array}$ & & & \\
\hline d.EB PBD in weeks & $\begin{array}{l}-0.0008 \\
(0.0010)\end{array}$ & $\begin{array}{l}-0.0002 \\
(0.0004)\end{array}$ & $\begin{array}{c}0.0005 \\
(0.0009)\end{array}$ & & & \\
\hline EUC PBD in weeks resid. & & & & $\begin{array}{c}0.0043 \\
(0.0062)\end{array}$ & $\begin{array}{c}0.0036 \\
(0.0038)\end{array}$ & $\begin{array}{l}-0.0018 \\
(0.0052)\end{array}$ \\
\hline EB PBD in weeks resid. & & & & $\begin{array}{l}-0.0009 \\
(0.0025)\end{array}$ & $\begin{array}{l}-0.0004 \\
(0.0028)\end{array}$ & $\begin{array}{c}0.0002 \\
(0.0029)\end{array}$ \\
\hline Time fixed effects & $\mathrm{x}$ & $x$ & $\mathrm{x}$ & & & \\
\hline $\begin{array}{l}\text { County pair by time } \\
\text { fixed effects }\end{array}$ & & & & $x$ & $x$ & $x$ \\
\hline Observations & 32,889 & 37,409 & 32,889 & 87,990 & 93,689 & 87,990 \\
\hline R-squared & 0.0027 & 0.0036 & 0.0023 & 0.6212 & 0.6339 & 0.6431 \\
\hline
\end{tabular}

Note: The sample is composed of county pairs straddling state borders. In columns 1-3, outcomes are defined in double differences: for outcome $y$ in county $\mathrm{c}$ in state $\mathrm{s}$ and paired county $\mathrm{c}^{\prime}$ in state $\mathrm{s}^{\prime}$, we have $\Delta_{\mathrm{t}+1, \mathrm{c}} y_{c s t}=\left(y_{c s, t+1}-y_{c s t}\right)-$ $\left(y_{c^{\prime} s^{\prime}, t+1}-y_{c^{\prime} s^{\prime} t}\right)$. In columns 4-6, residuals are from a regression of the variable on county fixed effects. In columns 4-6, standard errors are clustered by border segment, where a border segment is the set of all counties along a given state border. Tight in col. 3 and 6 stands for tightness, which is defined as vacancies/applications. See text above for more details.

Source: Department of Labor, and CareerBuilder.com for applications and vacancies. 